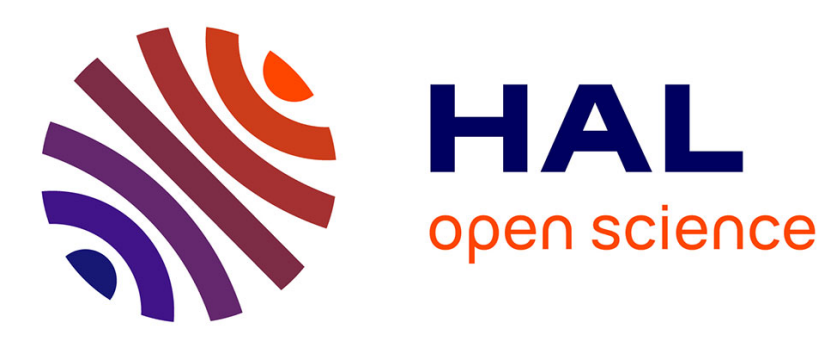

\title{
The hidden and external costs of pesticide use
}

Denis Bourguet, Thomas Guillemaud

\section{To cite this version:}

Denis Bourguet, Thomas Guillemaud. The hidden and external costs of pesticide use. Sustainable Agriculture Reviews, 19, Springer International Publishing, pp.35-120, 2016, Sustainable Agriculture Reviews, 978-3-319-26776-0. 10.1007/978-3-319-26777-7_2 . hal-01303109

\section{HAL Id: hal-01303109 \\ https://hal.science/hal-01303109}

Submitted on 22 Jul 2020

HAL is a multi-disciplinary open access archive for the deposit and dissemination of scientific research documents, whether they are published or not. The documents may come from teaching and research institutions in France or abroad, or from public or private research centers.
L'archive ouverte pluridisciplinaire HAL, est destinée au dépôt et à la diffusion de documents scientifiques de niveau recherche, publiés ou non, émanant des établissements d'enseignement et de recherche français ou étrangers, des laboratoires publics ou privés. 


\title{
Chapter 2 \\ The Hidden and External Costs of Pesticide Use
}

\author{
Denis Bourguet and Thomas Guillemaud
}

\begin{abstract}
A fair evaluation of the net benefits provided by pesticides is essential to feed the current debate on their benefits and adverse consequences. Pesticides provide many benefits by killing agricultural and human pests. However, they also entail several types of costs, including internal costs due to the purchase and application of pesticides, and various other costs due to the impact of treatments on human health and the environment. Here, we provide a comprehensive review of these costs and their evaluation. We define four categories of costs: regulatory costs, human health costs, environmental costs and defensive expenditures. Those costs are either internal to the market, but hidden to the users, or external to the market and most often paid by a third party. We analysed 61 papers published between 1980 and 2014, and 30 independent dataset. Regulatory costs reached very large values, e.g. US\$4 billion yearly in the United States in the 2000s. However, if all regulations were respected, these costs would have jumped to US\$22 billion in this country. Health costs studies generally did not take into account fatal cases due to chronic exposure such as fatal outcomes of cancers. Doing so would have increased estimates of health costs by up to tenfold, e.g. from US $\$ 1.5$ billion to US\$15 billion in the United States in 2005.

Most environmental impacts have never been quantified in the literature. Environmental costs were nevertheless estimated to up to US\$8 billion in the United States in 1992. Although defensive expenditures have rarely been considered in the literature, they include at least the extra cost of the part of organic food consumption due to aversive behavior linked to pesticide use. This cost reached more than US\$6.4 billion worldwide in 2012. Our review thus revealed that the economic costs of pesticide use have been seldom considered in the literature and have undoubtedly
\end{abstract}

\footnotetext{
D. Bourguet $(\bowtie)$

INRA, UMR 1062 Centre de Biologie pour la Gestion des Populations (CBGP)

INRA-IRD-CIRAD-Montpellier SupAgro, 755 avenue du Campus

Agropolis, CS 30016, 34988 Montferrier/Lez cedex, France

e-mail: bourguet@supagro.inra.fr

T. Guillemaud

INRA, Université Nice Sophia Antipolis, CNRS, UMR 1355-7254 Institut Sophia

Agrobiotech, 06903 Sophia Antipolis, France
} 
been strongly underestimated in the past. Despite this underestimation, we found that overall hidden and external costs ranged from US\$5.4 million in Niger in 1996 to US\$13.6 billion in the United States in 1992. We perform an updated and more complete retrospective evaluation of these costs in the United States and show that they probably reached the value of US $\$ 39.5$ billion per year at the end of the 1980s-start of the 1990s. We also re-evaluate past benefit-cost ratio of pesticide use in various countries and reveal that the cost of pesticide use might have outreached its benefits, e.g. in the United States at the start of the 1990s. We finally advocate that the key impact to be evaluated is the cost of illnesses and deaths triggered and favored by chronic exposure to pesticides. The benefit-cost ratio of pesticide use may have easily fallen below 1 if this cost had been taken into account. The quantification of this key cost is therefore urgently required for a more accurate evaluation of pesticide use and for regulatory purposes.

Keywords Insecticides $\bullet$ Fungicides $\bullet$ Herbicides $\bullet$ Environmental impact $\bullet$ Costof-illness $\bullet$ Defensive expenditures $\bullet$ External costs $\bullet$ Benefit-cost ratio analysis

\subsection{Introduction}

High levels of agricultural productivity will be required to sustain the world population, given current population growth rates. Between 1960 and 2000, the Green Revolution increased global food production by a factor of two to three (Evenson and Gollin 2003). However, the approaches used to increase production damaged many ecosystems, rendering them more vulnerable to pests. The control of these pests is essential if we are to maintain the high levels of productivity required to meet demand. The growth of the world population has also been accompanied by a desire to improve the length and quality of human life. With people living longer and in better health, food demands have increased, also necessitating the effective control of pests.

Organisms harmful to humans, their environment and production can be controlled in many different ways. Pesticides are one of the most widely used and effective tools for this purpose. Almost two billion people work in agriculture, and most use pesticides to protect their crops or livestock. Pesticides are also widely used in gardens and around the home, in the framework of public health programs. Pesticide sales increased by a factor of 20-30 between the 1960s and 1990s (Oerke 2006). Pesticide use has continued to increase over the last two decades in most developing countries, e.g. Thailand during the 1990s and 2000s (Praneetvatakul et al. 2013) and Pakistan during the 1990s (Khan et al. 2002). Moreover, contrary to what is commonly believed, pesticide use has remained stable in several developed countries, e.g. the United States (Osteen and Fernandez-Cornejo 2013), mostly due to an increase in herbicide use (Schreinemachers and Tipraqsa 2012). Overall pesticide 
consumption is currently close to two to three million tons per year (United States Environment Protection Agency 2011), $45 \%$ of all pesticides being used in Europe, $25 \%$ in the United States, $4 \%$ in India and $26 \%$ in the rest of the world (De et al. 2014). Total expenditure on pesticides is about US\$40 billion per year (Popp et al. 2013).

Despite the high cost of their purchase, the widespread application of pesticides has been favored by the benefits they provide. In particular, they have increased crop and livestock yields and, in some circumstances, have improved human health, e.g. by killing vectors of human pathogens, and quality of life, e.g. by killing troublesome organisms (Cooper and Dobson 2007).

However, the purchase costs are only one of the types of cost associated with pesticide use. Indeed, the spraying of these chemicals has an impact on the environment and health, with potentially serious financial consequences (Fig. 2.1). For instance, in a report published in 1990, the World Health Organization (WHO)

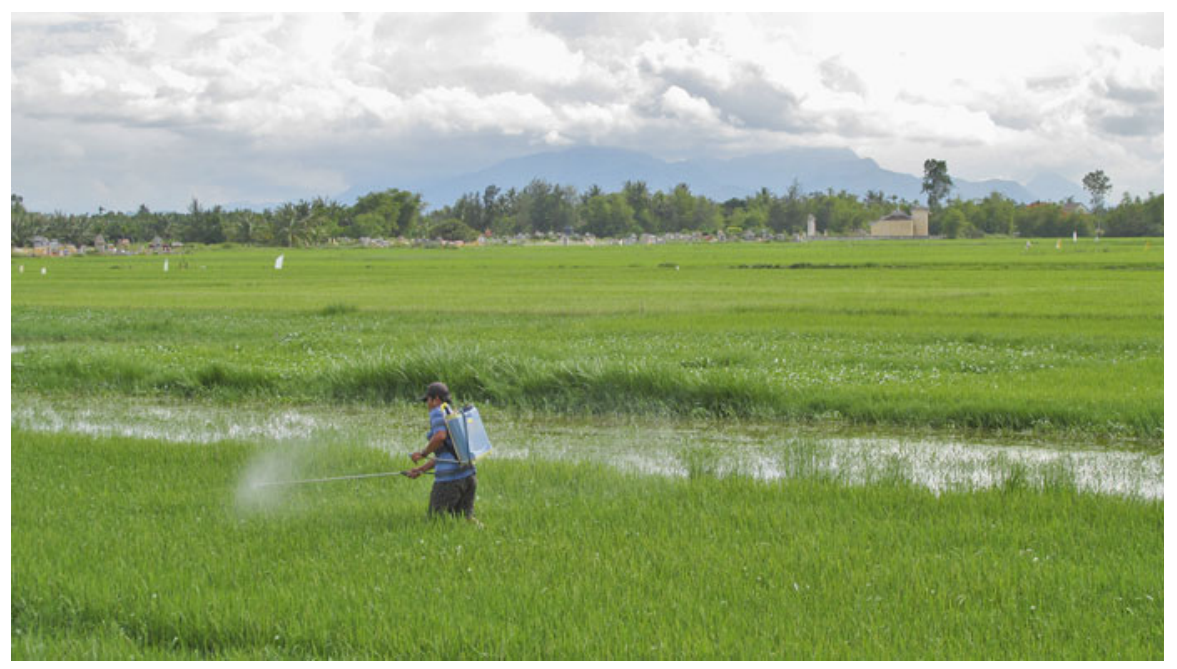

Fig. 2.1 Vietnamese farmer spraying pesticide on rice without protections in Hội An, Quảng Nam, Vietnam. A fair evaluation of the net benefits provided by pesticides requires a thorough estimation of their costs, including those associated with their impact on health and the environment. The purchase costs are only one of the types of cost associated with pesticide use. Indeed, the spraying of these chemicals has an impact on the environment and health, with potentially serious financial consequences. For instance, farmers take safety measures when handling and applying pesticides to their crops, to decrease or prevent direct exposure to these chemicals. The defensive expenditures taken into account include costs associated with precautions taken to reduce direct exposure to pesticides, such as masks, caps, shoes/boots, handkerchiefs, long-sleeved shirts/pants. Spraying is sometimes carried out without protection and even those farmers who do try to protect themselves generally limit this protection to the wearing of long-sleeved shirts and long pants. Low levels of income, awareness and education, the hot and humid climate, cultural taboos, fashion and discomfort are significant factors accounting for the lack of personal protection (Unmodified photography by Garycycles, under Creative Common License CC BY (https://creativecommons.org/ licenses/by/2.0/)) 
indicated that there may be as many as one million unintentional severe acute poisoning incidents annually, resulting in 20,000 deaths (WHO 1990). These serious cases of poisoning account for a minute fraction of the overall impact of pesticides on health. On the basis of a survey of self-reported minor poisoning events in Asia, Jeyaratnam (1990) estimated that as many as 25 million agricultural workers in the developing world annually may suffer a poisoning incident.

A fair evaluation of the net benefits provided by pesticides requires a thorough estimation of their costs, including those associated with their impact on health and the environment. Donald J Epp and coworkers (1977) were probably the first to espouse this idea, with the description of a complete taxonomy of the negative impacts of pesticide use to be taken into account. However, they concluded that the state-of-the-art at the time at which they wrote their report was insufficiently advanced for a monetary evaluation of environmental impacts. David Pimentel performed such an evaluation few years later, providing the first overall estimate of the externalities induced by pesticide use. The articles he published from the late 1970s (Pimentel et al. 1979) onwards (most recently, Pimentel and Burgess 2014) focused on the United States. They inspired a few studies in other countries, but there has never been a synthetic analysis of these studies, their shortcomings, limitations and conclusions. Such a synthesis is essential for the current debate on the benefits and consequences of the use of these chemicals.

This review aims to (i) identify and categorize the various costs triggered by the use of chemical pesticides, (ii) provide a comprehensive overview of the articles estimating - in economic terms - these costs, whether at local, regional or national scale, for a single pesticide or for total pesticide use, (iii) report the costs estimated in these articles. These costs, in US\$, have been updated to 2013 values, using annual inflation factors and the 2013 purchasing power parity (PPP) conversion factors obtained from the development indicators of the World Bank (http://data.worldbank.org/indicator/PA.NUS.PPP), (iv) identify the consequences for benefit-cost ratio analyses on pesticide use and (v) provide perspectives concerning the evaluation of these costs.

\subsection{Types of Costs Generated by the Deleterious Consequences of Pesticide Use}

Pesticides are designed to kill, repel, attract, regulate or stop the growth of living organisms considered to be pests (United States Environmental Protection Agency 2007). A pest is any type of living organism, e.g. mammals, birds, reptiles, fish, amphibians, mollusks, insects, nematodes, weeds and microbes (bacteria and viruses), that competes with our food crops or space, spreads disease or acts as a vector for disease and/or causes us discomfort.

Pesticides include chemicals, biopesticides and biological agents (United States Environmental Protection Agency 2007). We have decided to focus this review on 
chemical pesticides, for several reasons. First, chemical pesticides account for the vast majority of pesticides used worldwide, e.g. more than $80 \%$ in the United States (United States Environmental Protection Agency 2008). Second, chemical pesticides are probably the most harmful pesticides for the environment and human health. For instance, according to the Stockholm Convention on Persistent Organic Pollutants, nine of the 12 most dangerous and persistent organic pollutants are chemical pesticides (United Nations Environment Programme 2001).

We will also focus mostly on chemicals protecting plants from the damage caused by weeds, plant diseases or animals, notably insects. In fact, the term 'pesticide' is often exclusively used to refer to plant protection products, although pesticides are also used for non-agricultural purposes. Chemical pesticides are of three main types - herbicides, insecticides and fungicides - but several other types of biocides, such as nematicides and rodenticides, are also used.

Pesticide use has been shown to have a marked positive effect on agriculture (Cooper and Dobson 2007; Gianessi 2009; Gianessi and Reigner 2005, 2007) and human health (Cooper and Dobson 2007). However, pesticides may also have deleterious effects on the environment and human health, generating several types of costs.

For the purposes of this review, we have defined four broad categories of costs (Table 2.1): regulatory costs, human health costs, environmental costs and defensive expenditures. Regulatory costs are all the costs entailed as part of private or public mandatory measures to remove pesticides, to protect the environment or human health from the potential damage caused by pesticides and/or to repair damage already inflicted. For instance, the monitoring and decontamination of tap water can be considered a regulatory cost. Human health costs, often referred to as cost-ofillness, are the expenses associated with acute or chronic pesticide poisoning. These costs are mostly incurred by the farmers applying pesticides, although all citizens can be exposed to pesticides and may, therefore, suffer chronic health effects, in particular. Environmental costs are the costs of both pesticide damage to animals, plants, algae and microorganisms and pest resistance to pesticides. These costs may be incurred by farmers or by society as a whole. Finally, defensive expenditures cover all expenses by farmers and society to prevent pesticide exposure, such as the purchase of organic food or bottled water consumption. These four broad categories of costs include both internal and external costs (Table 2.1).

The internal costs of pesticide use are the costs, to the farmer, of pesticide use within the agricultural production process. These costs are described as "internal" because they determine the price of the final product, i.e. they are internal to the market. We do not review here the "usual" internal costs of pesticide use such as market prices of pesticides, taxes on these products, costs of the application, transport and storage of pesticides, accounting costs, etc., but these costs are taken into account in the re-evaluation of overall costs and of the benefit-cost ratio of pesticide use (see Sect. 2.9). We were particularly interested in the "hidden" costs associated with the impact of pesticides on the environment and human health, regulatory measures and defensive behavior. These additional costs are "hidden" in the sense that farmers are not necessarily aware of them. This is the case for environmental 
Table 2.1 Types and categories of costs generated by environmental and health impacts, regulatory actions and defensive behavior

\begin{tabular}{|c|c|c|c|c|c|c|}
\hline \multirow[b]{2}{*}{$\begin{array}{l}\text { Category of } \\
\text { cost }\end{array}$} & \multirow[b]{2}{*}{ Pesticide impact } & \multicolumn{3}{|c|}{ Hidden costs } & \multicolumn{2}{|c|}{ External costs } \\
\hline & & $\begin{array}{l}\text { Decrease } \\
\text { in benefits }^{\mathrm{a}}\end{array}$ & $\begin{array}{l}\text { Increase } \\
\text { in "usual" } \\
\text { internal } \\
\text { costs }^{\mathrm{b}}\end{array}$ & $\begin{array}{l}\text { Generation } \\
\text { of other } \\
\text { internal } \\
\text { costs }\end{array}$ & $\begin{array}{l}\text { Private } \\
\text { external } \\
\text { costs }\end{array}$ & $\begin{array}{l}\text { External } \\
\text { costs } \\
\text { sensu } \\
\text { stricto }\end{array}$ \\
\hline \multirow[t]{3}{*}{$\begin{array}{l}\text { Regulatory } \\
\text { costs }\end{array}$} & $\begin{array}{l}\text { Public research, } \\
\text { communication, } \\
\text { expertise on } \\
\text { pesticides }\end{array}$ & & & & & $\mathrm{X}$ \\
\hline & $\begin{array}{l}\text { Regulations, decrees } \\
\text { and laws }\end{array}$ & & & & & $\mathrm{X}$ \\
\hline & $\begin{array}{l}\text { Mandatory pesticide } \\
\text { handling and } \\
\text { disposal }\end{array}$ & & & $X$ & & \\
\hline \multirow[t]{3}{*}{$\begin{array}{l}\text { Human health } \\
\text { costs }\end{array}$} & $\begin{array}{l}\text { Preventive medicine, } \\
\text { annual check-ups }\end{array}$ & & & $X$ & $X$ & \\
\hline & $\begin{array}{l}\text { Health issues for } \\
\text { farmers }\end{array}$ & $\mathrm{X}$ & & $X$ & $\mathrm{X}$ & \\
\hline & $\begin{array}{l}\text { Health issues for the } \\
\text { public }\end{array}$ & & & & & $\mathrm{X}$ \\
\hline \multirow{10}{*}{$\begin{array}{l}\text { Environmental } \\
\text { costs }\end{array}$} & Pesticide resistance & $X$ & $X$ & & & $\mathrm{X}$ \\
\hline & Soil degradation & $\mathrm{X}$ & & & & $\mathrm{X}$ \\
\hline & Pollination decrease & $X$ & & & & $X$ \\
\hline & $\begin{array}{l}\text { Decrease in natural } \\
\text { enemies }\end{array}$ & $\mathrm{X}$ & $\mathrm{X}$ & & & $\mathrm{X}$ \\
\hline & $\begin{array}{l}\text { Lower plant } \\
\text { production due to } \\
\text { herbicide } \\
\text { application }\end{array}$ & $X$ & & & & \\
\hline & Bee renting & & & $X$ & & \\
\hline & $\begin{array}{l}\text { Degradation of the } \\
\text { farm environment }\end{array}$ & & & & $X$ & \\
\hline & $\begin{array}{l}\text { Livestock health } \\
\text { issues }\end{array}$ & & & & $\mathrm{X}$ & \\
\hline & $\begin{array}{l}\text { Degradation of the } \\
\text { environment }\end{array}$ & & & & & $\mathrm{X}$ \\
\hline & $\begin{array}{l}\text { Domestic animal } \\
\text { health issues }\end{array}$ & & & & & $\mathrm{X}$ \\
\hline \multirow[t]{2}{*}{$\begin{array}{l}\text { Defensive } \\
\text { expenditure }\end{array}$} & $\begin{array}{l}\text { Purchase of } \\
\text { protective clothing, } \\
\text { glasses and masks }\end{array}$ & & & $X$ & & \\
\hline & $\begin{array}{l}\text { Purchase of organic } \\
\text { food and bottled } \\
\text { water }\end{array}$ & & & & & X \\
\hline
\end{tabular}

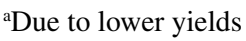

${ }^{b}$ Due to an increase in the amount of pesticide applied 
impacts increasing pesticide requirements for the production process. These hidden costs increase the "usual" internal costs (Table 2.1). The environmental impact of pesticide use may also decrease production levels. Such "hidden" costs are paid through the achievement of a smaller benefit than would have been achieved by farmers in the absence of a deleterious impact of pesticide use (Table 2.1). Finally, pesticide use generates other internal costs, concerning the purchase of protective equipment, e.g. gloves and masks, the renting of bees for pollination, specific mandatory requirements for pesticide handling and disposal, preventive medicine and annual check-ups for farmers. In addition to the usual internal costs, farmers incur this third class of hidden costs directly (Table 2.1).

Environmental and human health impacts, regulatory actions and defensive behavior triggered by pesticide use also generate external costs (Table 2.1). These costs are described as "external" because they are not included in the farmers" production costs, i.e. they are external to the market. They are mostly paid by a third party, but some, such as those concerning the health of the farmer or degradation of the farm environment, may have a direct impact on farmers. Hence, external costs may be incurred by the farmers themselves ("external private costs", Table 2.1) or by other parties, e.g. consumers, public authorities, people living close to the farm ("external costs sensu stricto", Table 2.1).

Health issues for farmers generate both hidden internal costs and external private costs. The impairment of the farmer's health due to the use of pesticides for a specific type of production, such as crop production, may increase crop production costs, e.g. loss of working hours devoted to crop production, lower yields or the need to pay workers for a larger number of hours of work. Some of the costs of pesticide use relating to health are therefore internal. However, the impairment of farmers' health due to pesticide use may also have economic consequences relating to other types of production, such as livestock production, or lower levels of nonmarket goods, such as childcare or leisure time. Thus, some pesticide costs relating to health issues are external (Table 2.1). However, it is difficult to determine the proportions of health costs that should be considered internal and external. We will therefore consider all these costs as externalities in this review.

Here, we defined four categories of costs - regulatory costs, human health costs, environmental costs and defensive expenditures - that are commonly not included in the economic evaluation of pesticide use. These costs are either internal to the market, but hidden to the users, or external to the market and most often paid by a third party.

\subsection{Literature Surveyed}

We carried out a literature review as comprehensive as possible, using Google Scholar and the Web of Science, and screening the references cited by the articles identified relating to this topic. We excluded papers based on contingent valuation methods (see below), resulting in the identification of 61 relevant articles in total 
(Table 2.2). These articles were published in peer-reviewed scientific journals (23), scientific journals without peer review (11), books (1), book chapters (10), conference proceedings (2), $\mathrm{PhD}$ theses (2) and reports (12) (Table 2.2). These 61 papers are based on only 30 independent datasets, because several papers were based on the same dataset (Table 2.2). These publications have differed in terms of their scientific impact. The 12 articles written by Pimentel and coworkers obtained more than 1500 citations in Google Scholar, the other 49 papers having about 2500 citations between them (Table 2.2). The costs estimated for the United States by David Pimentel et al. are the most widely known, and the corresponding dataset is often considered to be the key dataset when referring to the overall cost of pesticide use. Two other datasets have been widely cited: one relating to the externalities of pesticide use in the United Kingdom (Pretty et al. 2000, 2001, cited about 750 times in total) and the other concerning these externalities in the Philippines (Pingali et al. 1994, 1995; Rola and Pingali 1993, cited about 500 times in total).

The studies identified used different methodologies to estimate costs and these methodological differences partly reflect the heterogeneity of the types of cost considered. Some of the impacts of pesticide use have a value that can be directly estimated from market prices. For instance, mandatory governmental regulations concerning pesticide use may require particular activities, e.g. water monitoring (Pretty et al. 2000, 2001; Waibel et al. 1999), and equipment, e.g. water filters (Pimentel et al. 1992, 1993a, b; Pimentel and Greiner 1997; Pimentel and Hart 2001). Their costs can be determined from market values. Other effects, such as food contamination (e.g. Jungbluth 1996) or the loss of working days if the farmer is ill, have costs based on market price (e.g. Pimentel et al. 1980a, b) that can be evaluated by productivity function methods (Bowles and Webster 1995). The same is true for losses of agricultural production (see the series of papers by Pimentel et al.) due to lower pollination rates, livestock health issues, soil degradation or increases in pesticide use due to the selection of pesticide resistance (e.g. Tegtmeier and Duffy 2004). However, some of the goods affected by pesticide use are nonmarket goods. For instance, the increase in health risk associated with pesticide use has no directly observable price. In such cases, economists must use non-market evaluation techniques to monetize individual preferences. The monetary values obtained with these techniques reflect the individuals' willingness to pay for a reduction of the risk (Travisi et al. 2006). Revealed willingness to pay is an approach in which the monetary value of a change in risk is derived from individuals' purchasing decisions in existing markets. This approach is often used to estimate the costs of aversive behavior, e.g. wearing protection clothes, drinking bottled or purified water, eating organic food, designed to decrease the risk of human health impairment. Revealed willingness to pay can also be used to estimate the cost of wildlife loss. For instance, the cost linked to human activities, such as bird watching, can be used to estimate bird losses due to pesticides (Pimentel 2005). The contingent valuation method - also referred to as stated willingness to pay - is also often used for the market valuation of non-market goods (Venkatachalam 2004). This method is based on stated preferences in hypothetical market settings. We decided not to use estimates based on stated willingness to pay because the answers 


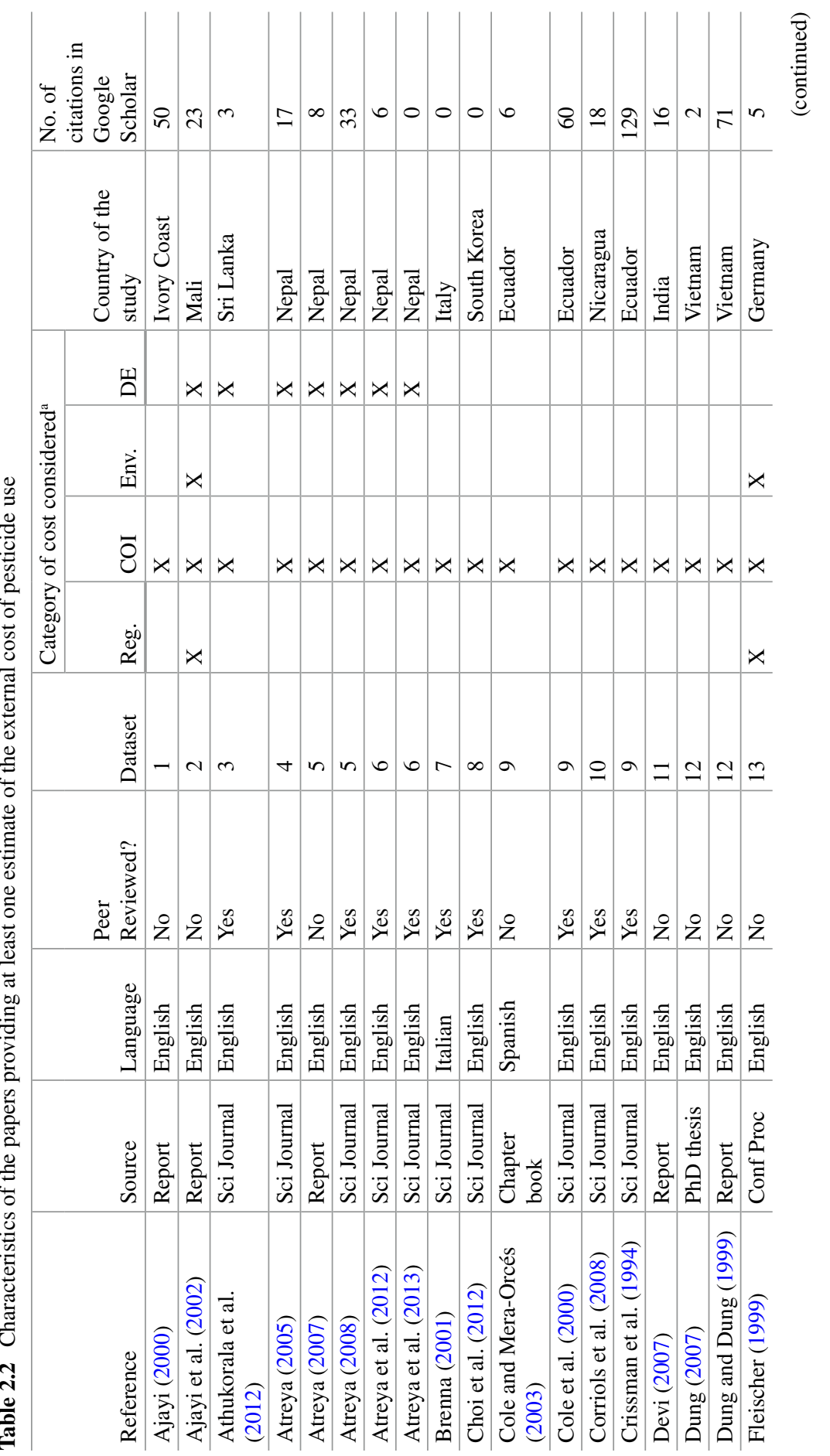




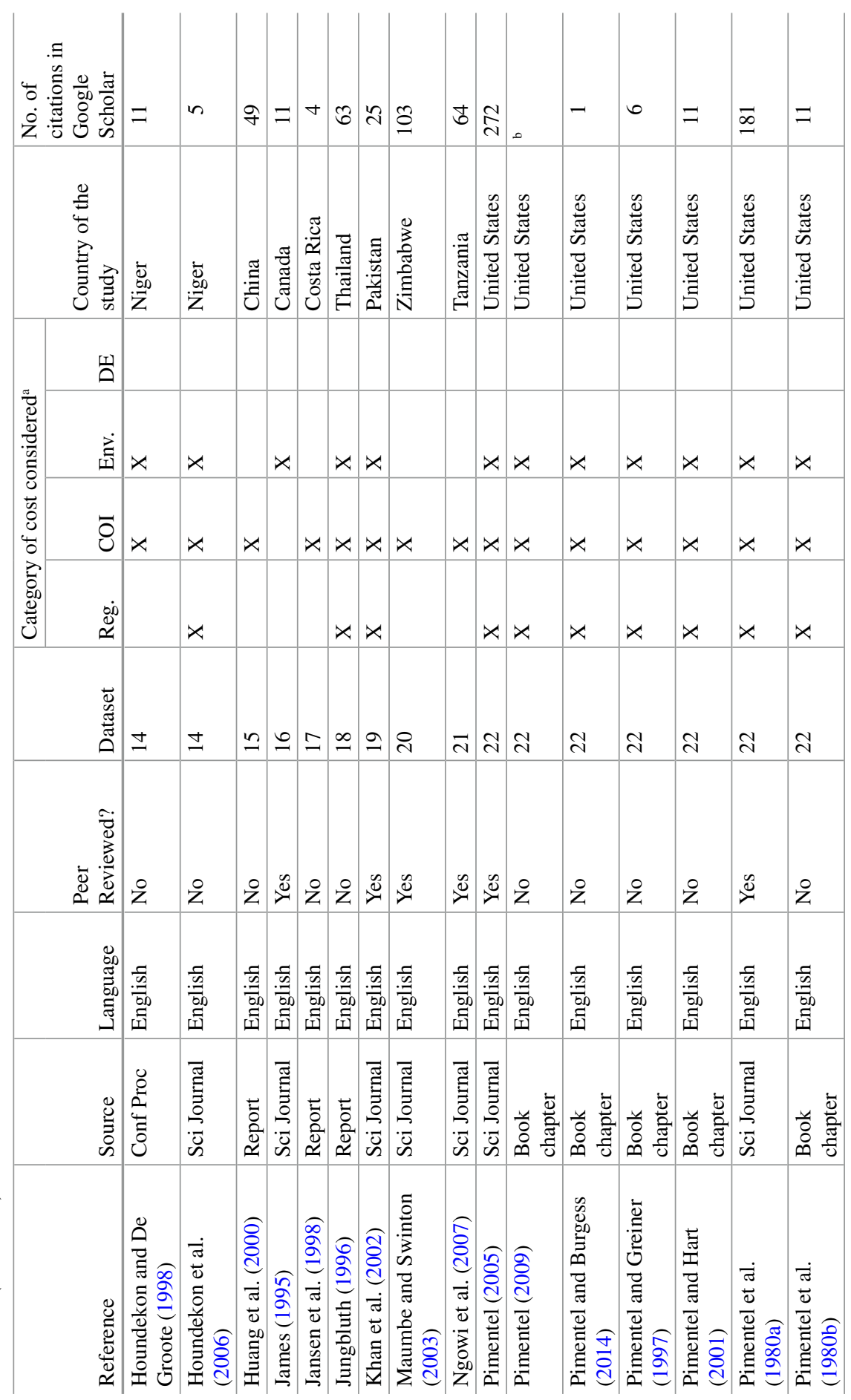




\begin{tabular}{|c|c|c|c|c|c|c|c|c|c|c|c|c|c|c|c|}
\hline A & 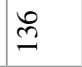 & तె & $\stackrel{m}{2}$ & ๙ & 点 & $\bar{m}$ & $r$ & $\hat{n}$ & $\stackrel{\sim}{\sim}$ & तె & ల & $m$ & \pm & $\stackrel{f}{f}$ & 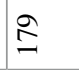 \\
\hline 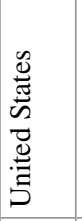 & 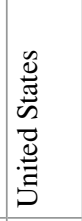 & 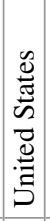 & 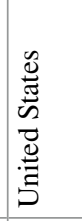 & 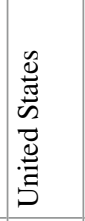 & 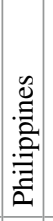 & 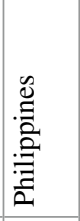 & 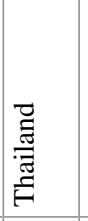 & 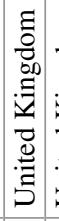 & 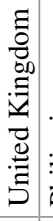 & 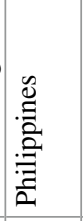 & 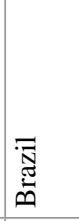 & $\begin{array}{l}\overline{\mathcal{N}} \\
\stackrel{\overparen{\Xi}}{\mathscr{ص}}\end{array}$ & 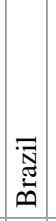 & 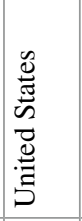 & 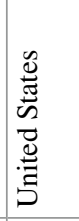 \\
\hline$x$ & $x$ & $x$ & $x$ & $x$ & & & $x$ & $x$ & $x$ & & & & & $x$ & $x$ \\
\hline$x$ & $x$ & $x$ & $x$ & $x$ & $x$ & $x$ & $x$ & $x$ & $x$ & $x$ & $x$ & $x$ & $x$ & $x$ & $x$ \\
\hline$x$ & $x$ & $x$ & $x$ & $x$ & & & $x$ & $x$ & $x$ & & & & & $x$ & $x$ \\
\hline ป & กิ & ปี & ป & สิ & $\hat{\imath}$ & $\hat{\imath}$ & $\stackrel{\mathbb{N}}{\text { D }}$ & $\approx$ & ¿ิ & $\ddot{\lambda}$ & స్ర & i & $\hat{\imath}$ & $\stackrel{\infty}{\sim}$ & ৯े \\
\hline$\stackrel{0}{Z}$ & 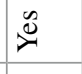 & 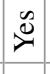 & z & $\lesssim$ & $\stackrel{0}{2}$ & $\stackrel{0}{z}$ & 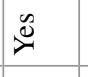 & $\underset{\sim}{\infty}$, & $\overbrace{}^{\infty}$ & Z & $\approx$ & $\stackrel{0}{0}$ & $\stackrel{0}{2}$ & $\ddot{z}$ & $\lesssim$ \\
\hline 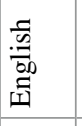 & 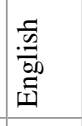 & $\begin{array}{l}\frac{5}{5} \\
: 0 \\
00 \\
\text { Iิ }\end{array}$ & 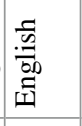 & 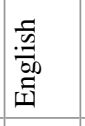 & 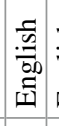 & $\begin{array}{l}\overline{5} \\
: \overline{0} \\
\dot{\omega} \\
\underline{\omega}\end{array}$ & 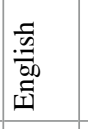 & 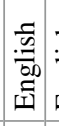 & 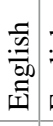 & 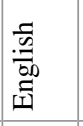 & 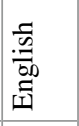 & $\begin{array}{l}\overline{5} \\
: \underline{0} \\
00 \\
\text { 鳬 }\end{array}$ & 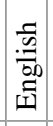 & 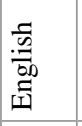 & 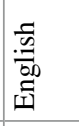 \\
\hline 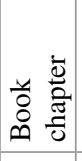 & 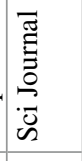 & 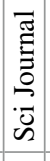 & 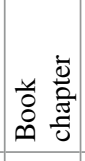 & 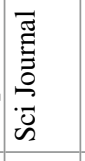 & 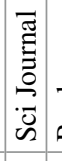 & 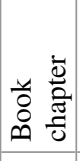 & 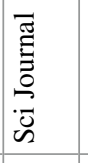 & 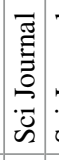 & 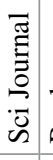 & $\begin{array}{l} \\
4 \\
0 \\
0 \\
0\end{array}$ & 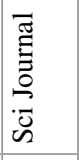 & 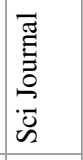 & 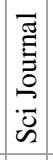 & 苛 & 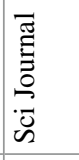 \\
\hline 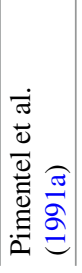 & 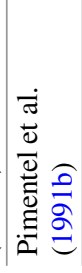 & 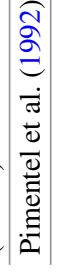 & 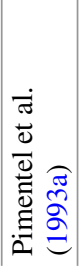 & 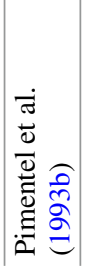 & 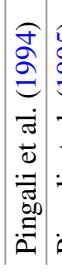 & 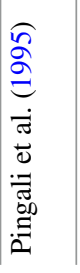 & 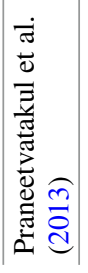 & 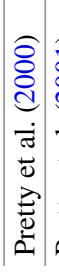 & 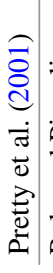 & 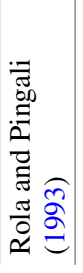 & 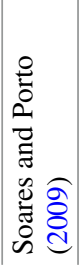 & 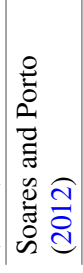 & 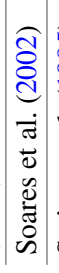 & 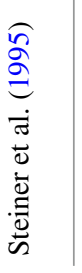 & 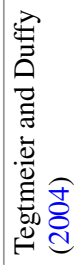 \\
\hline
\end{tabular}




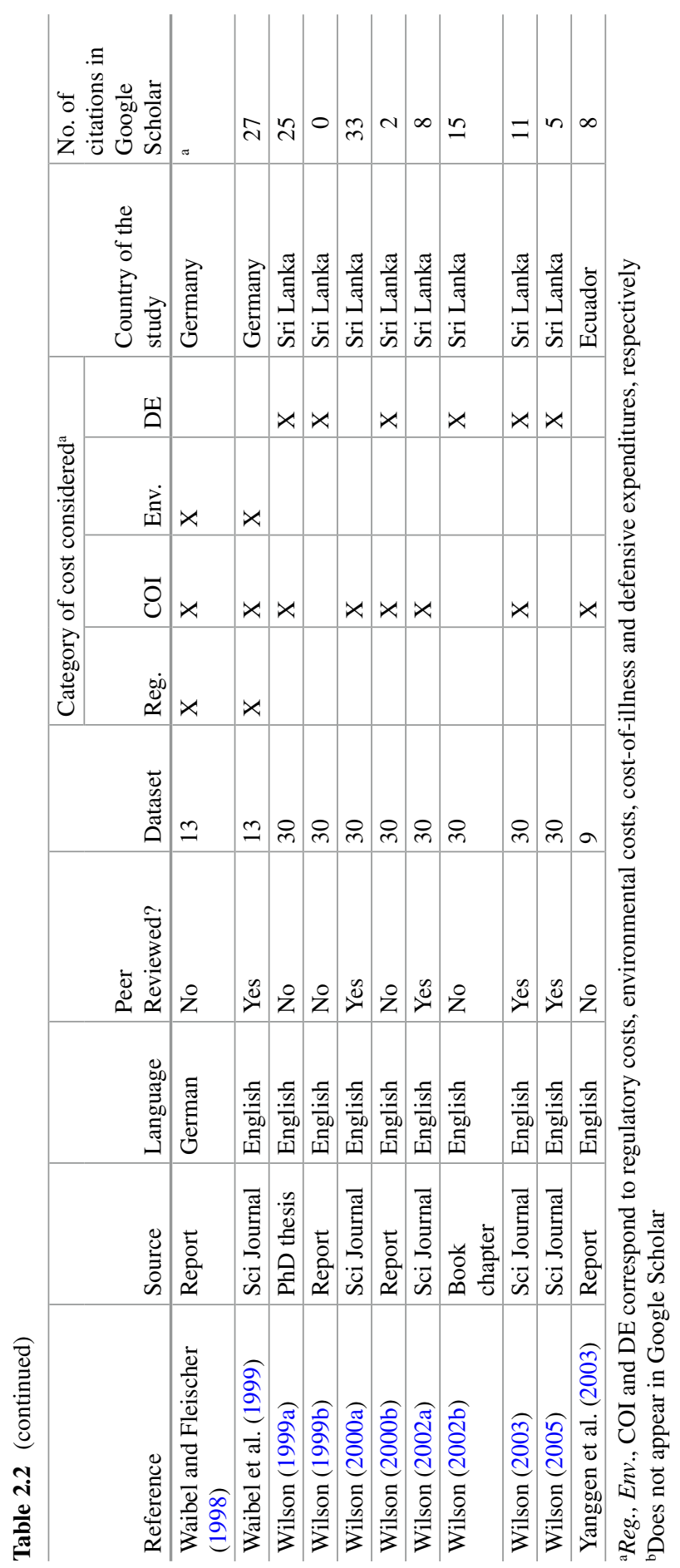


given by respondents may be highly dependent on the way in which contextual information is presented (see Florax et al. 2005).

The literature on hidden internal and external costs of pesticide use thus consists of 61 papers published between 1980 and 2014, these papers being based on 30 independent datasets. The costs were evaluated using both market and non-market methods. Among these latter we chose to exclude studies based on stated willingness to pay.

\subsection{Regulatory Costs}

Regulations concerning pesticide use are laid down by government bodies and concern (i) mandatory actions that must be undertaken by users and consumers, (ii) governmental actions to organize and check compliance with mandatory actions, and (iii) the activity of governmental agencies associated with pesticide use, such as research agencies. These regulations entail monetary costs. In general, these costs are not included in the market price of the pesticides. They must therefore be paid subsequently, as externalities, by public authorities (hence by consumers and citizens), producers or users.

\subsubsection{A Small Number of Studies}

Regulatory costs were taken into account in 24 articles (Table 2.2): eight book chapters ( 7 written by Pimentel and coworkers), four reports ( 2 from the Hannover Pesticide Policy project), one non-reviewed journal article and 11 articles published in peer-review scientific journals. However, the estimates given in several articles were partly or fully based on the same dataset. This was the case of all papers written by Pimentel and coworkers. It was also the case for Praneetvatakul et al. (2013), who actualized some of the costs originally estimated by Jungbluth (1996). We identified 15 different estimates, but only nine fully independent datasets (Table 2.3).

\subsubsection{A High Diversity of Costs}

Both external and internal costs are associated with the testing and registration, production, distribution - including importation, transport and sales - use and disposal of pesticides. The external costs are the economic burden to the public authorities responsible for organizing controls and checks on the compliance of stakeholders, e.g. public authorities, consumers, sellers and producers, with the regulations. The internal costs are the monetary subsidiaries paid by pesticide 
Table 2.3 Economic costs due to regulations governing pesticide use

\begin{tabular}{l|l|l|l|c}
\hline & & & $\begin{array}{l}\text { Fully } \\
\text { independent }_{\text {dataset }^{\mathrm{a}}}\end{array}$ & $\begin{array}{l}\text { Overall costs } \\
\text { (million US\$ } \\
\text { 2013 per year) }\end{array}$ \\
\hline $\begin{array}{l}\text { Houndekon and De Groote (1998); } \\
\text { Houndekon et al. (2006) }\end{array}$ & Niger & 1996 & A & 0.15 \\
\hline Ajayi et al. (2002) & Mali & 1999 & B & 1.58 \\
\hline Khan et al. (2002) & Pakistan & 2002 & C & 9.71 \\
\hline $\begin{array}{l}\text { Fleischer (1999); Waibel and } \\
\text { Fleischer (1998); Waibel et al. (1999) }\end{array}$ & Germany & 1996 & D & 168.26 \\
\hline Pretty et al. (2000, 2001) & $\begin{array}{l}\text { United } \\
\text { Kingdom }\end{array}$ & 1996 & E & 318.51 \\
\hline Praneetvatakul et al. (2013) & Thailand & 2010 & F & 357.28 \\
\hline Pimentel et al. (1980a, b) & United Sates & 1980 & G & 491.96 \\
\hline Jungbluth (1996) & Thailand & 1995 & F & 558.33 \\
\hline Pimentel et al. (1991a, b) & United States & 1991 & G & 2372.34 \\
\hline Steiner et al. (1995) & United States & 1991 & H & 3203.00 \\
\hline Pimentel and Hart (2001) & United States & 2001 & G & 3451.19 \\
\hline Pimentel and Greiner (1997) & United States & 1997 & G & 3751.06 \\
\hline $\begin{array}{l}\text { Pimentel (2005, 2009); Pimentel and } \\
\text { Burgess (2014) }\end{array}$ & United States & 2005 & G & 4229.13 \\
\hline Pimentel et al. (1992, 1993a, b) & United States & 1992 & G & 4319.01 \\
\hline Tegtmeier and Duffy (2004) & United States & 2002 & I & 4988.69 \\
\hline
\end{tabular}

${ }^{a}$ The same letter indicates a partial dependence of cost estimates

handlers, e.g. users, sellers and producers, when they have to comply with mandatory regulations (Ajayi et al. 2002).

The various types of regulatory costs considered in the 24 articles investigating those costs are given in Table 2.4. The sources of these costs were highly diverse, including campaigns to raise public awareness of the impact of pesticides, monitoring and control, and public research on pesticides. The considerable diversity of these items may go some way to explaining why none of the studies considered the entire set of costs and heterogeneity in the costs considered by the various studies. Several articles listed a large number of qualitatively different regulatory costs, but estimates were frequently lacking. For instance, Ajayi et al. (2002) mentioned extension services as one of the externalities of pesticide use, but they provided no estimate of the costs involved. Waibel et al. (1999) also considered several costs, including the costs of removing contaminated products from the market and the cost of administrative activities, e.g. laws and decrees, and researches, but these 
Table 2.4 Types of regulatory costs for pesticide use

\begin{tabular}{|c|c|c|c|c|c|c|c|c|c|c|c|c|c|c|c|}
\hline Type of cost & 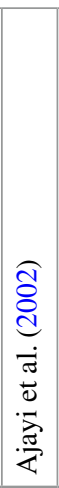 & 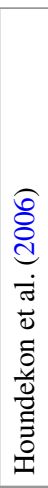 & 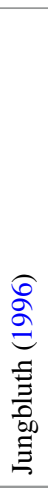 & 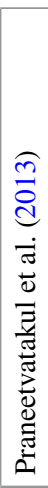 & 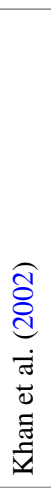 & 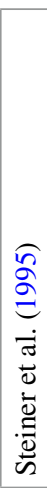 & 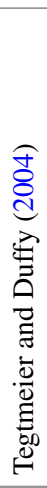 & 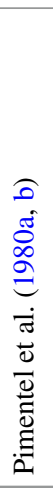 & 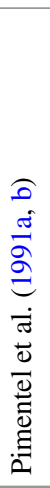 & 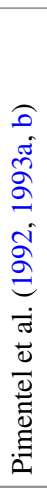 & 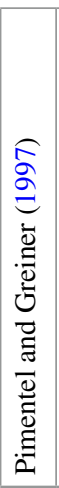 & 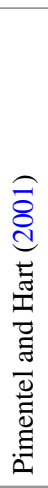 & 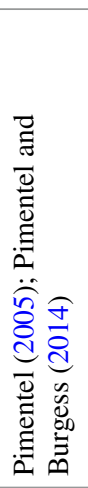 & 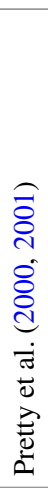 & 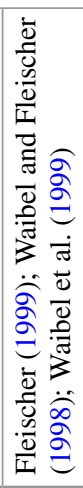 \\
\hline $\begin{array}{l}\text { Pesticide } \\
\text { registration, } \\
\text { regulation and } \\
\text { market } \\
\text { monitoring }\end{array}$ & $\mathrm{X}$ & & $\mathrm{X}$ & $X$ & & $\mathrm{X}$ & & & & & & & & & $\mathrm{X}$ \\
\hline $\begin{array}{l}\text { Public awareness } \\
\text { campaigns on } \\
\text { pesticide impact }\end{array}$ & & & & & $\mathrm{X}$ & & & & & & & & & $\mathrm{X}$ & $\mathrm{X}$ \\
\hline $\begin{array}{l}\text { Disposal of } \\
\text { obsolete and } \\
\text { leftover pesticides }\end{array}$ & $X$ & $\mathrm{X}$ & & & & $X$ & & & & & & & & & \\
\hline Farm work safety & & & & & & $X$ & & & & & & & & & \\
\hline \multicolumn{16}{|l|}{$\begin{array}{l}\text { Control \& } \\
\text { monitoring }\end{array}$} \\
\hline $\begin{array}{l}\text { Crop and/or } \\
\text { food }\end{array}$ & & & & & & & & & & $\mathrm{X}$ & $X$ & $\mathrm{X}$ & $\mathrm{X}$ & $\mathrm{X}$ & $\mathrm{X}$ \\
\hline $\begin{array}{l}\text { Water (surface, } \\
\text { underground } \\
\text { and/or wells) }\end{array}$ & & & & & & $\mathrm{X}$ & $\mathrm{X}$ & & $\mathrm{X}$ & $\mathrm{X}$ & $X$ & $\mathrm{X}$ & $\mathrm{X}$ & $X$ & $X$ \\
\hline Livestock & & & & & & & & & & & & & & $X$ & \\
\hline Wildlife & & & & & & & & $X$ & $\mathrm{X}$ & & & & & & \\
\hline Undefined & & & $X$ & $\mathrm{X}$ & & & & $X$ & $X$ & $\mathrm{X}$ & $X$ & $\mathrm{X}$ & $X$ & & \\
\hline $\begin{array}{l}\text { Water } \\
\text { decontamination }\end{array}$ & & & & & $X$ & & & & & $X$ & $X$ & $\mathrm{X}$ & $\mathrm{X}$ & $\mathrm{X}$ & $X$ \\
\hline $\begin{array}{l}\text { Public research } \\
\text { on pesticides }\end{array}$ & & & $X$ & $\mathrm{X}$ & & & & & & & & & & & \\
\hline $\begin{array}{l}\text { Extension } \\
\text { services }\end{array}$ & & & $X$ & & & & & & & & & & & & $\mathrm{X}$ \\
\hline \multicolumn{16}{|l|}{$\begin{array}{l}\text { Economic } \\
\text { shortfall }\end{array}$} \\
\hline Crop & & & $X$ & $\mathrm{X}$ & $X$ & & & $X$ & $\mathrm{X}$ & $\mathrm{X}$ & $X$ & $\mathrm{X}$ & $\mathrm{X}$ & & \\
\hline Water & $X$ & & & & & & & & & & & & & & $X$ \\
\hline Livestock & & & & & & & & $X$ & $X$ & & & & & & \\
\hline Milk & & & & & & & & $\mathrm{X}$ & $X$ & & & & & & \\
\hline Fishing & & & & & & & & $X$ & $X$ & & & & & & \\
\hline
\end{tabular}


costs were not quantified. Differences in public regulations between countries also underlie the considerable differences in the items considered between papers. For instance, Khan et al. (2002) pointed out that there was no monitoring program in Pakistan in 2002.

Most papers took into account the economic shortfall of crops exceeding the maximum residue limit or the costs of controls and monitoring (Table 2.4). Water decontamination, the regulation of pesticide registration and market monitoring costs were estimated in a small number of papers (Table 2.4) (Fig. 2.2). Other costs, such as those associated with governmental public information campaigns, economic shortfalls for water exceeding the maximum residue limit and public research on pesticides, were considered and estimated even less frequently (Table 2.4). However, these costs may account for a large proportion of the external costs of pesticides. For instance, public information campaigns accounted for about $10 \%$ of the total external costs estimated by Khan et al. (2002) in the Pakistan, and public research costs were estimated at about $10 \%$ of the total external costs by Praneetvatakul et al. (2013) in Thailand.

Finally, some costs, such as the time and money spent establishing regulations, have never been estimated. This is unfortunate, because it has been acknowledged that such costs may be high, due to the need for research and development, expert advice and a number of official tests (Ajayi et al. 2002; Waibel et al. 1999).

\subsubsection{Estimated Costs}

Estimates of total annual regulatory costs vary considerably, from US $\$ 150,000$ (2013) in Niger (Houndekon and De Groote 1998; Houndekon et al. 2006) to US\$5 billion (2013) in the United States (Tegtmeier and Duffy 2004) (Table 2.3). We did not carry out a meta-analysis to find the cause of this variation. However, as a first approximation, we can consider this variation to be due to the differences in the categories of costs considered, the detailed composition of each category and the geographic scale of the study. The costs of commonly considered categories were particularly variable and depended strongly on the subcategories included. For instance, monitoring and control costs were frequently considered, but different aspects of these costs were covered. The estimates obtained thus differed considerably between papers, depending, in particular, on whether or not they considered the control of underground water. For instance, Pimentel and coworkers began to consider the costs of monitoring underground water and wells in their papers published in 1991. The consideration of these costs led to an immediate increase in their estimates of the overall cost of pesticide regulations of more than $300 \%$, with these costs accounting for $90 \%$ of total regulatory costs for pesticide use (Pimentel et al. 1991a, b). Water decontamination and economic shortfalls due to crop contamination have 


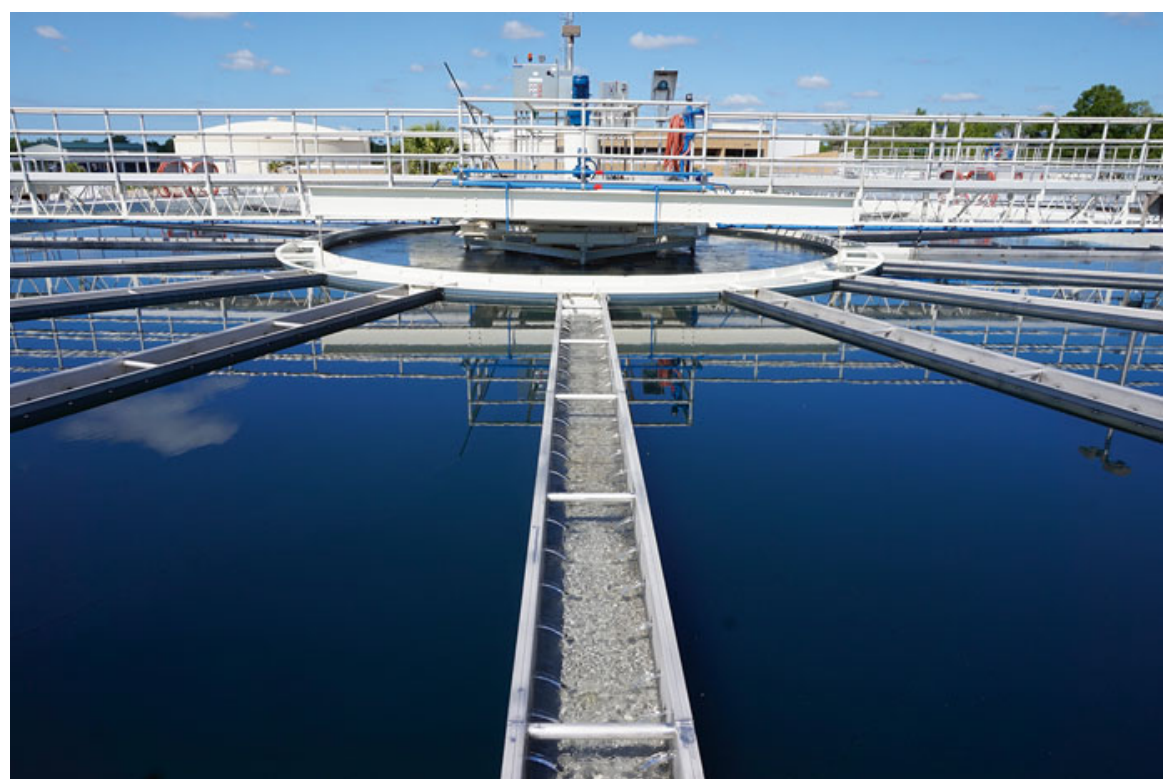

Fig. 2.2 Peace River Manasota Regional Water Supply Authority Water Treatment Plant facility. Water decontamination corresponds to one of the several regulatory costs induced by pesticide use. Estimates of regulatory costs differed considerably between studies, depending, in particular, on whether or not they considered the control of underground water. For instance, in the United States, Pimentel and coworkers began to consider the costs of monitoring underground water and wells in their papers published in 1991. The consideration of these costs led to an immediate increase in their estimates of the overall cost of pesticide regulations of more than $300 \%$, with these costs accounting for $90 \%$ of total regulatory costs for pesticide use (Pimentel et al. 1991a, b). Moreover Pimentel (2005, 2009) and Pimentel and Burgess (2014) estimated that the current monitoring of wells in the United States (about US $\$ 2$ billion per year) would have reached US $\$ 17$ billion per year if all the wells in the United States were monitored (Unmodified photography by Florida Water Daily, under Creative Common License CC BY (https://creativecommons.org/licenses/ by/2.0/))

been taken into account by Pimentel et al. since 1992. These costs accounted for about $40 \%$ of the externalities associated with pesticide use.

\subsubsection{Actual Versus Theoretical Costs}

Most estimates of regulatory costs were based on the actual expenditure of various stakeholders, including public authorities, manufacturers, distributors, sellers and farmers. No attempt was made to estimate non-monetary values. Due to the 'regulatory' nature of these costs, estimates were generally based on the official budget reports of public agencies. 
However, current costs may be much lower than the theoretical value. For instance, Pimentel (2005, 2009) and Pimentel and Burgess (2014) estimated the current monitoring of wells in the United States at about US\$2 billion per year, but indicated that this cost would have reached US\$17 billion per year if all the wells in the United States were monitored. Including these theoretical costs made a large difference, increasing the overall regulatory costs estimated by Pimentel (2005, 2009) and Pimentel and Burgess (2014) from US $\$ 4.2$ billion to almost US $\$ 22$ billion. Similarly, Jungbluth (1996) noted that costs related to pesticide residues in food in Thailand were difficult to estimate and were based on hypothetical scenarios rather than on real situations. In the absence of pesticide residue control for most food products, Jungbluth (1996) had to extrapolate the proportion of products exceeding the maximum residue limit from scarce data. Assuming that $10 \%$ of all fruits and vegetables were above the maximum residue limit and assuming that these products would be unsaleable according to regulations, Jungbluth (1996) obtained a cost of about five billion Baht in 1996. He considered this value - corresponding to almost $90 \%$ of the regulatory costs - as an upper limit for the costs truly paid by the corresponding stakeholders. Conversely, Jungbluth (1996) noted that if the maximum residue limit was not reached, then only the cost of control and monitoring should be taken into account, corresponding to 48.5 million Baht in 1996. This value should be taken as the lower limit of estimates. Along the same lines, Khan et al. (2002) distinguished between actual and potential costs. The potential costs they considered included the cost of establishing laboratories for pesticide residue analyses, residue monitoring programs, and training programs on the safe use of pesticides. These costs were largely theoretical, because there were no such activities in the region covered by their study in 2002, like in many developing countries (Ecobichon 1999). They reported the existence of regulations, but a lack of enforcement. They pointed out, in particular, that there was no comprehensive national monitoring system, and this may remain the case.

\subsubsection{Conclusions}

Regulatory costs, in particular, have been underestimated. We will see that this is also true for the other categories of "hidden" and external costs, but this underestimation may be particularly marked for regulatory costs. First, only 24 of the 61 articles assessing the external cost of pesticides included regulatory costs, and these 24 articles were actually based on only nine fully independent datasets. Second, each of these articles considered only a small number of regulatory costs. Finally, current costs are probably much lower than the costs that would have to be paid if the complete control, monitoring and decontamination of pesticide residues were to be undertaken and if all products exceeding the legal maximum residue limit had to be withdrawn from the market.

Although underestimated, regulatory costs could reach very large values such as US\$4 billion (2013) yearly in the United States in the 2000s. Our analysis shows 
that if all regulations were respected, these costs would have jumped to US\$22 billion (2013).

\subsection{Human Health Costs}

Despite strict regulations on the registration and use of pesticides, there are major concerns about their direct impact on human health following occupational exposure and the indirect exposure of non-occupationally exposed populations. Agricultural workers in fields and greenhouses are often occupationally exposed to pesticides, as they are responsible for preparing, mixing and loading pesticide preparations, spraying pesticides, sowing pesticide-treated seeds, harvesting sprayed crops, and cleaning and disposing of pesticide containers. Similarly, workers in the pesticide industry are also likely to experience occupational exposure. The families of farmers and other people living in rural areas in which pesticides are intensively used may also be indirectly exposed to these chemicals, through off-target pesticide drift from agricultural applications in particular (Lee et al. 2011) (Fig. 2.3). Finally, the overall population is also indirectly exposed to pesticides, through the consumption of food and drinking water contaminated with pesticide residues. Many pesticides can damage human health (Damalas and Eleftherohorinos 2011) and, for this reason, high doses over short periods (acute poisoning) and lower doses over longer periods of time (chronic exposure) may have an impact on human health. Karabelas et al. (2009) found that 84 of the 276 active substances authorized as plant protection products in Europe at the end of 2008 - 32 of the 76 fungicides, 25 of the 87 herbicides and 24 of the 66 insecticides - had at least one deleterious effect on health following acute and/or chronic exposure. These effects included acute toxicity, carcinogenicity, reproductive and neurodevelopmental disorders and endocrine disruption. Worldwide, pesticide use has resulted in thousands of cases of acute and chronic poisoning, with effects of varying severity on human health, from mild effects to death. In this section, we review the studies providing estimates of the economic consequences of human health impairment, from benign health damage to death, due to pesticide use.

\subsubsection{Several Studies Based on a Limited Number of Datasets}

We identified 57 articles providing monetary costs of the impact on health of pesticide exposure. These studies were published in diverse forms, including articles in scientific peer-reviewed journals (e.g. Choi et al. 2012), book chapters (e.g. Cole and Mera-Orcés 2003), PhD dissertations (e.g. Dung 2007), conference proceedings (e.g. Yanggen et al. 2003) and specific reports (e.g. Devi 2007). Some datasets were used as the basis of several publications. For instance, the dataset from the pioneering study by David Pimentel in the United States has been used in several 


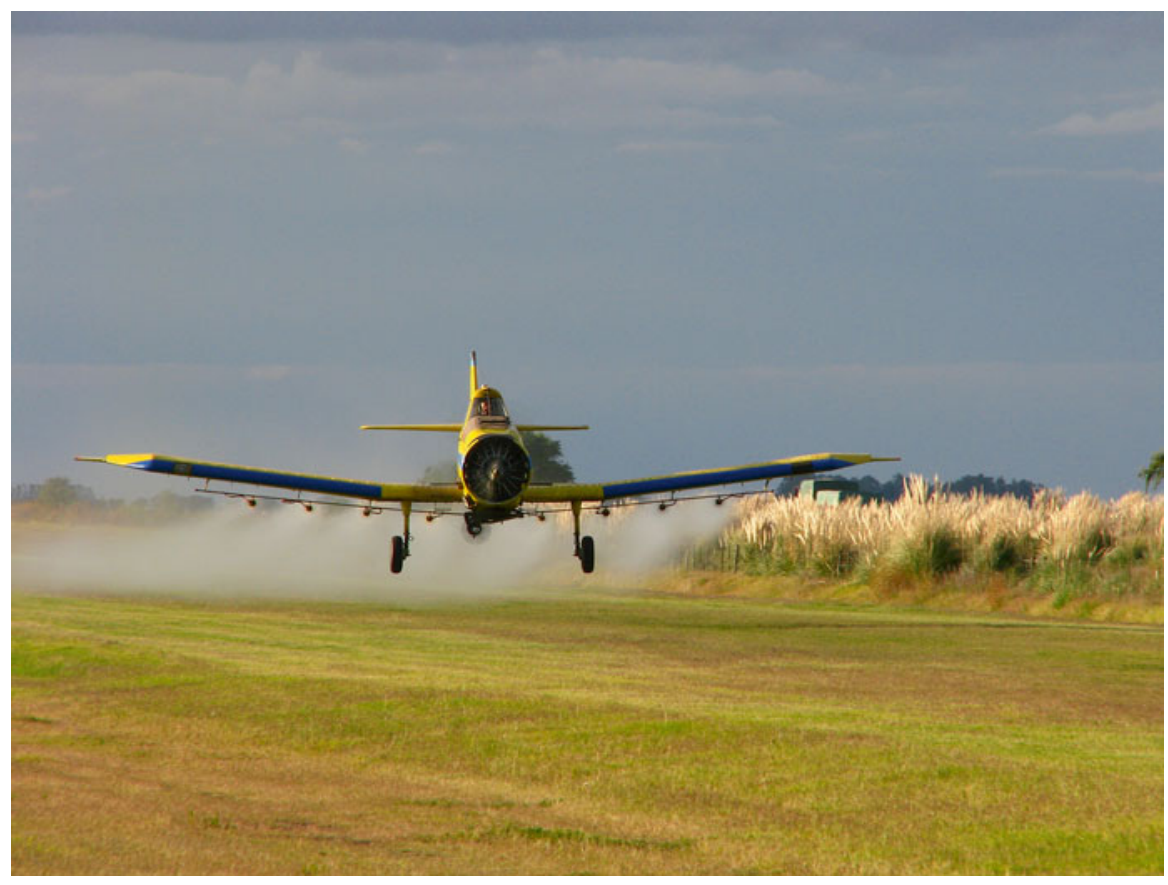

Fig. 2.3 Pesticides are sprayed in crop fields to protect them against agricultural pests. During these spray applications, these chemicals may disperse by drifting. They may therefore reach nontarget crops in neighbouring fields, weakening these plants and reducing yields. Such crop injuries have been reported, in particular, for aerial applications of glyphosate (e.g. Ding et al. 2011; Reddy et al. 2010). Families of farmers and other people living in rural areas in which pesticides are intensively used may also be indirectly exposed to these pesticides, through this off-target pesticide drift from agricultural applications. After spraying, pesticides can also seep into the soil (Gil and Sinfort 2005; Pimentel 1995). Once in the soil, some soluble pesticides may be washed out in runoff water and during soil erosion, resulting in leaching into rivers and lakes (Chopra et al. 2011) (Unmodified photography by Santiago Nicolau, under Creative Common License CC BY-SA (https://creativecommons.org/licenses/by-sa/2.0/))

publications reporting either the same estimates (Pimentel and Greiner 1997; Pimentel and Hart 2001) or providing new estimates (Pimentel et al. 1992; Pimentel and Greiner 1997; Pimentel 2005, 2009) but describing the same types of cost. Similarly, the original dataset of Clevo Wilson (1999a) has been used in several articles in scientific journals and in several book chapters (e.g. Wilson 1999b, 2000a, b, 2002a, b, 2003, 2005). These 57 articles thus actually correspond to 29 independent cost-of-illness studies, starting with two papers by Pimentel et al. published in 1980 and ending with a book chapter written by Pimentel and Burgess and published in 2014 (Table 2.5). All 29 datasets involved cost-of-illness analyses, but they were produced by different methodologies (Table 2.5). Some focused on occupational exposures, notably those of the individuals spraying pesticides, whereas others focused on the pesticide exposure of the whole population. Some authors 
provided direct estimates of the various health costs, whereas other inferred health costs indirectly, by complex statistical modeling (Table 2.5).

\subsubsection{Estimated Costs}

The economic impact on human health has been evaluated per case, per farmer (or household), per rural establishment and at regional or national levels. The detailed costs reported in the 29 independent studies are shown in Table 2.6.

The costs of pesticide poisoning were evaluated at between about US\$30 in Thailand and US\$600 in Costa Rica (2013) per case, with each farmer/household using pesticides incurring annual costs of US\$3 in China to US\$187 in Sri-Lanka (2013) per year. In Central America, several authors have reported annual costs of US\$32 to US\$100 (2013) (see Vaughan (1993) and Villagrán (1976) cited by García (1998) and Castillo and Appel (1990) and Alvarado et al. (1998) cited by Cole et al. (2000)). These costs may be as high as US\$850 (2013) per year for a rural establishment. At national level, health costs due to pesticide exposure have been estimated at US\$1.1 million in Italy to about US\$1.5 billion in the United States (2013) (Table 2.6).

These costs cannot be considered comparable, because they are influenced by several parameters, e.g. the type of pesticide used, the number of treatments applied, the degree to which farm staff spraying pesticides are protected etc., that may differ considerably between countries, with particularly marked differences between developed and developing countries. Moreover, in any given country, these costs have probably decreased over time, for two reasons. First, farmers have certainly become more aware of the effects of pesticide use on health and, therefore, probably protect themselves better against pesticide drifts. Second, some of the most dangerous pesticides have been withdrawn in many countries. Hence, on the one hand, costs actualized to 2013 values in US $\$$ could easily be considered overestimates of current costs. On the other hand, human health costs were probably greatly underestimated at the time at which these reports were published, for three reasons. First, the frequencies of illness and death triggered by chronic exposure to pesticides have rarely been evaluated (see Sect. 2.5.5). Second, acute poisoning events generate various types of costs, and none of the studies performed to date has taken all these costs fully into account (see Sect. 2.5.3). Third, not all pesticide-poisoning events are recorded in databases or reported by farmers, particularly in developing countries (e.g. Lekei et al. 2014; Shetty et al. 2011). Indeed, some of the individuals carrying out pesticide spraying consider the symptoms of poisoning to be 'normal' and do not, therefore, pay much attention to them. 
56

D. Bourguet and T. Guillemaud

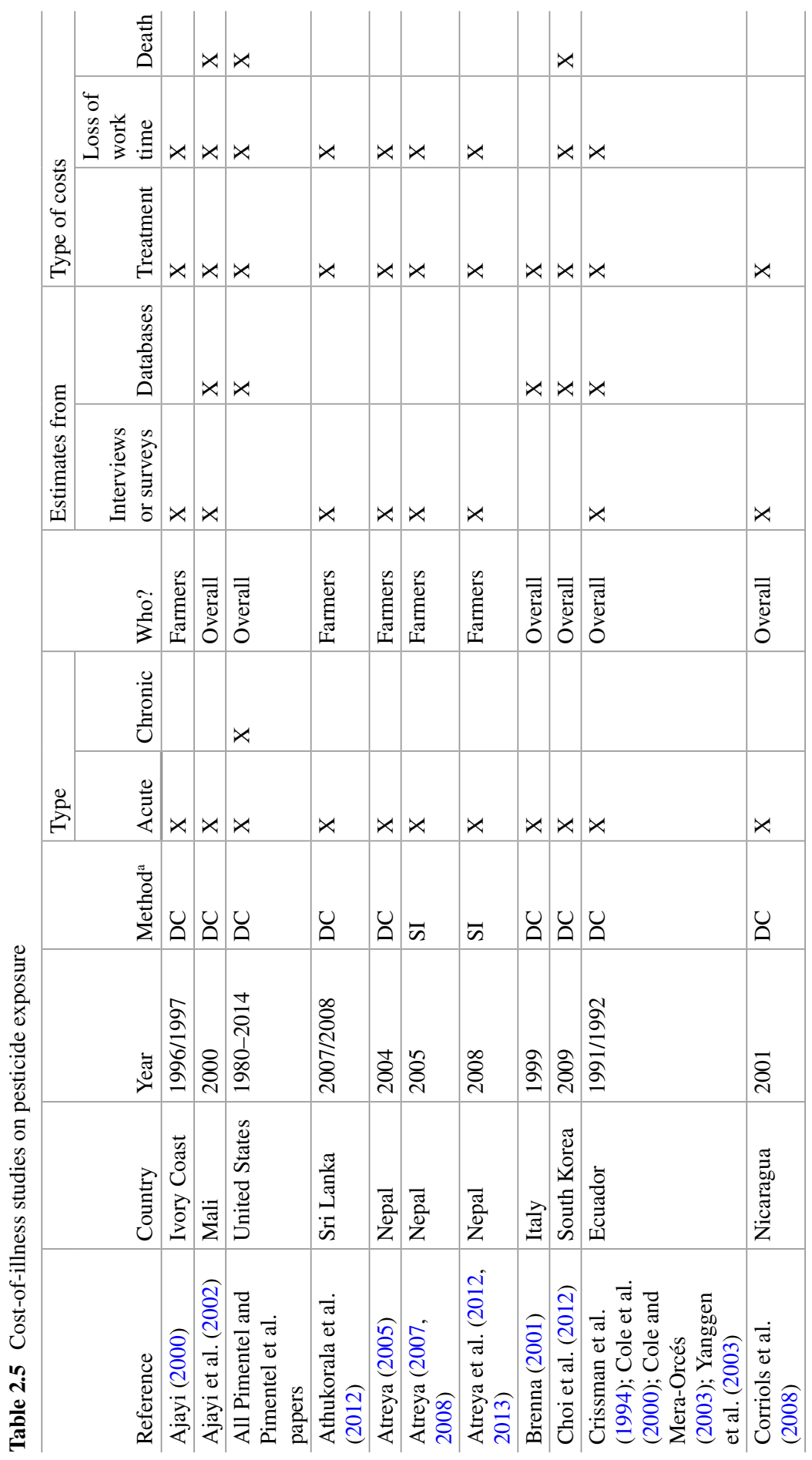




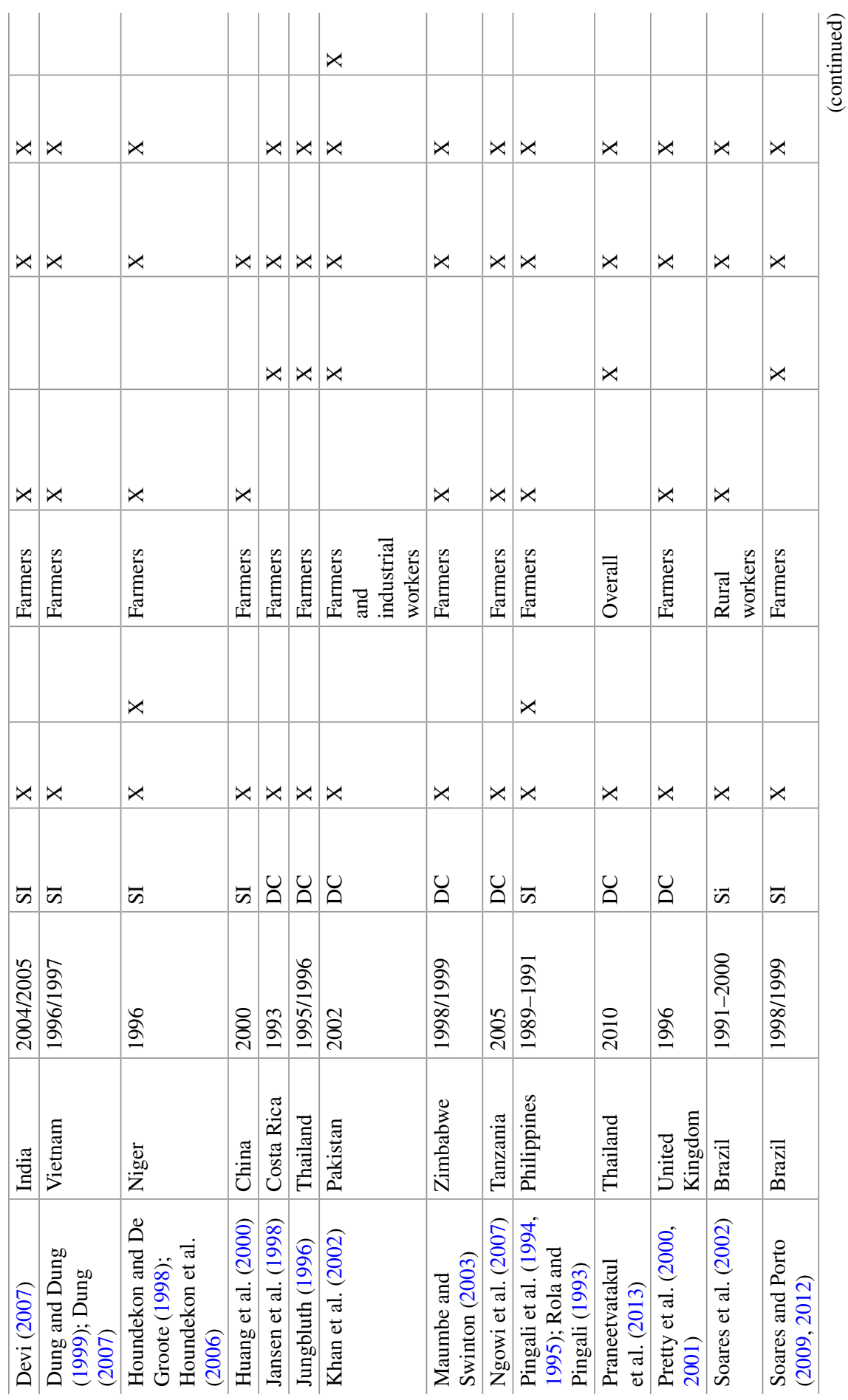




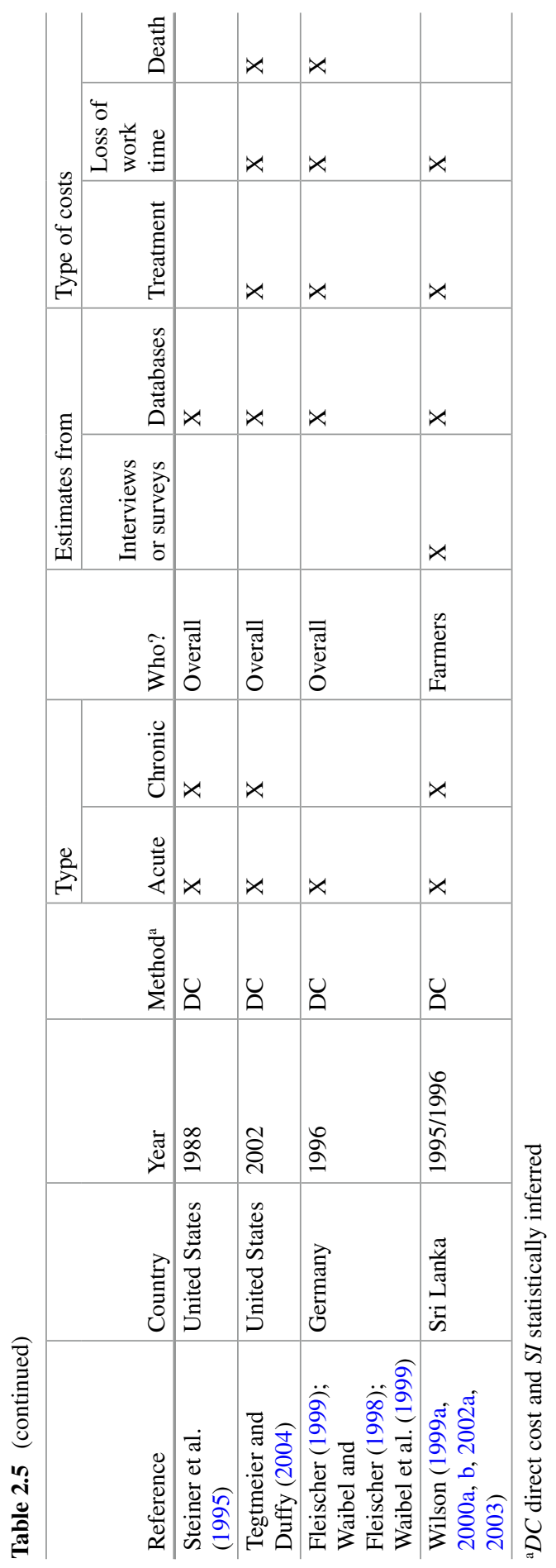




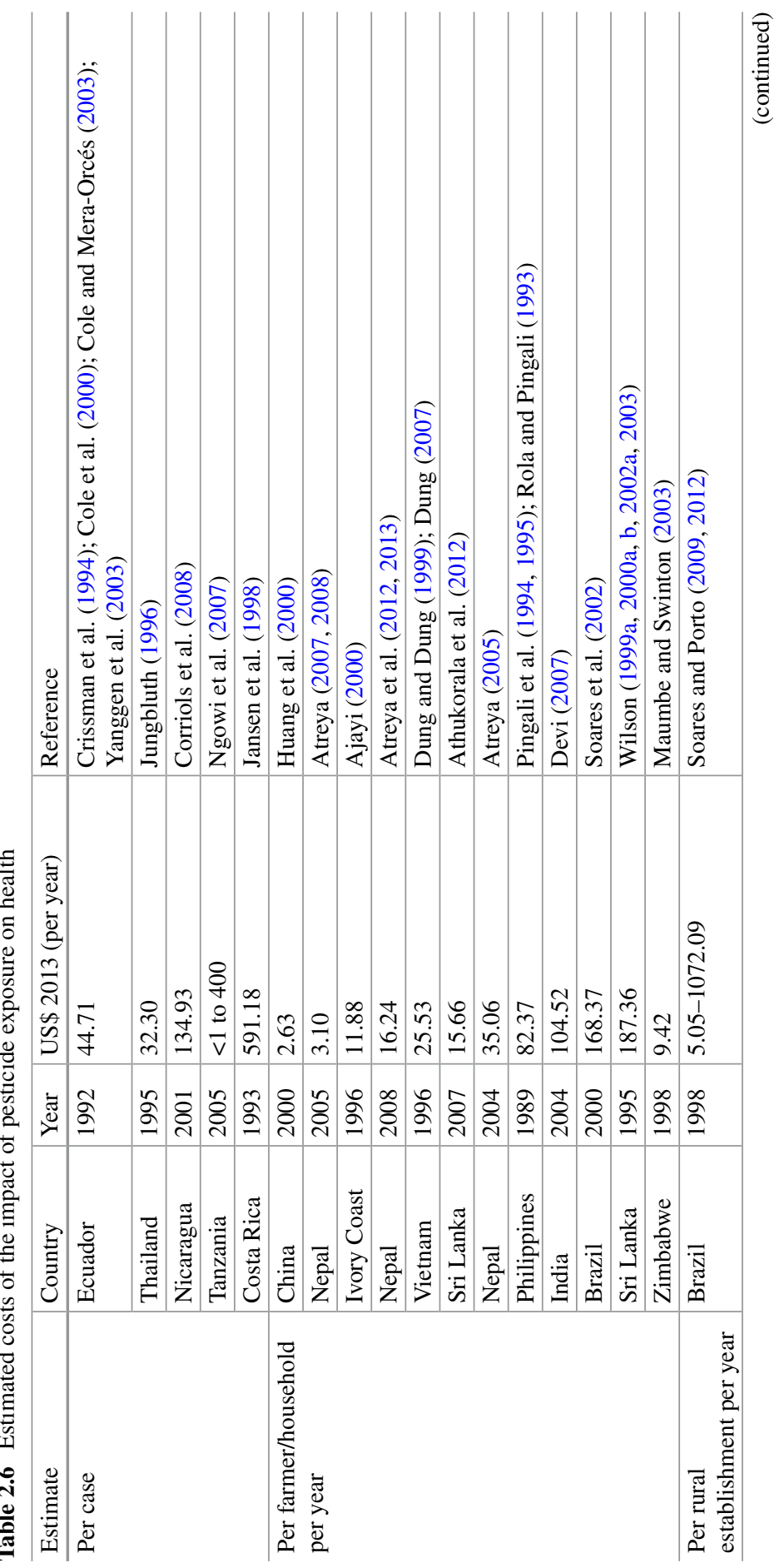




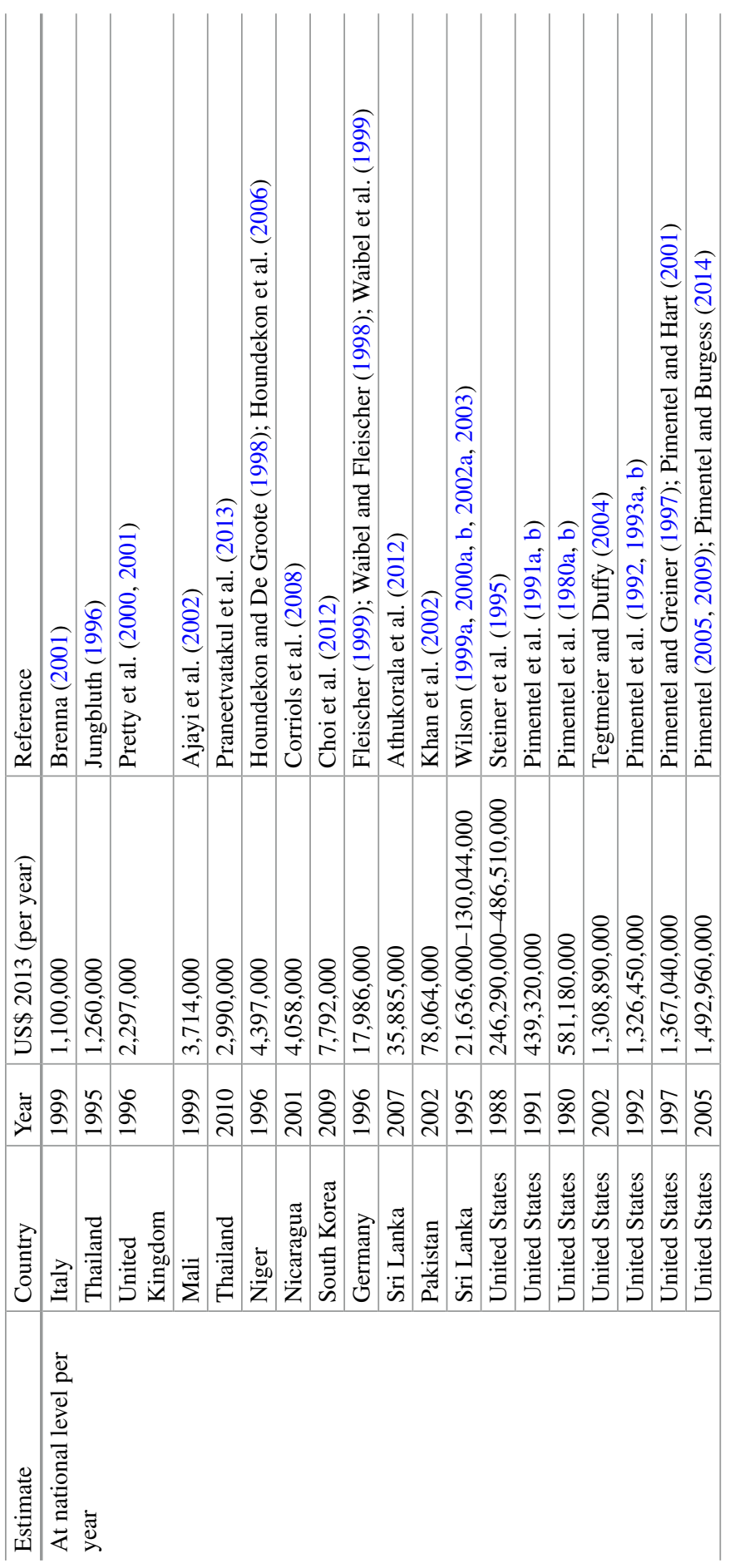




\subsubsection{Non-fatal Cases of Acute Poisoning}

Acute poisoning, leading to respiratory, gastrointestinal, allergic, and neurologic disorders, is commonly reported by farmers, and particularly by those carrying out pesticide applications (e.g. Hudson et al. 2014; Kishi et al. 1995). For instance, in a broad survey performed in 2010, Lee et al. (2012) found that $25 \%$ of South Korean male farmers had suffered acute occupational pesticide poisoning, suggesting that there may be more than 200,000 cases per year across South Korea. About $12 \%$ of these pesticide-poisoning cases led to the consultation of a medical doctor or hospitalization (Lee et al. 2012). In the United States, the incidence of pesticide poisoning events requiring medical care among the 3,380,000 agricultural workers is thought to be between 10 and 600/100,000 (Calvert et al. 2008 and references therein), corresponding to about 300-20,000 cases annually.

All the cost-of-illness studies took acute poisoning events into account, but they considered very different types of costs associated with such poisoning events. Both indirect and direct costs were incurred. Direct costs are paid either by the farmers themselves or by the society, if, for example, hospital admission is free of charge. Indirect costs correspond to the working time lost by poisoned individuals and their families during and after the poisoning event. This time, which many farmers may not have considered - $90 \%$ in the study by Athukorala et al. (2012) -, can be converted into wage loss and, therefore, into a monetary cost. All cost-of-illness studies took the cost of hospitalization and/or doctor fees into account (Table 2.7). By contrast, the costs of medication and of transport to and from hospital visits and medical consultation were explicitly included in only two thirds and one third, respectively, of the studies (Table 2.7). The economic burden due to the number of days taken off work to recover from poisoning events is the indirect cost classically identified in cost-of-illness studies. Almost all studies included this cost, paid by farmers, and some found that it outweighed, by far, the direct cost of acute poisoning (e.g. Wilson 1999a, 2000a, b, 2003)

However, absence from work to recover from illness is only one of the various indirect costs associated with pesticide poisoning. Indeed, Wilson (1999a, 2000a, b, 2002a, 2003), who generated what is probably the most comprehensive and complete list of indirect costs to date, also identified (i) a decrease in productivity for farmers not taking time off from work to recover and just after their return to work, (ii) impaired decision-making and (iii) a loss of leisure time (Table 2.7). However, he recognized that it would be difficult to estimate the number of leisure hours lost and the decrease in working efficiency. Leisure hours were defined as 'any time spent at home after work, such as time spent reading a newspaper, watching television, listening to the radio, playing a game or practicing a hobby, or time spent with the family'. As suggested by Becker (1965), Wilson evaluated leisure time costs on the basis of the hourly wage, given that any loss of leisure time would be likely to affect productivity at work.

Decreases in productivity at work and in decision-making abilities were estimated in a few other cost-of-illness studies (Table 2.7). However, none of these 


\begin{tabular}{|c|c|c|c|c|c|}
\hline 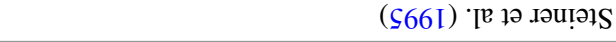 & & 。 & & & \\
\hline 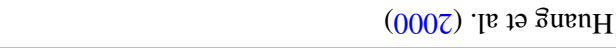 & & $\sigma$ & & & \\
\hline 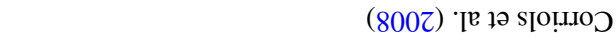 & & 0 & & & \\
\hline ( I00z) виuәлg & & $x$ & & & \\
\hline (ZI0Z ‘600Z) olıod pur səreos & & $x$ & & & $x$ \\
\hline 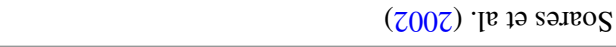 & & $x$ & & & $x$ \\
\hline 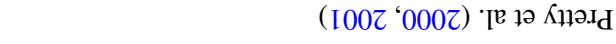 & & $x$ & & & $x$ \\
\hline ( & & $x$ & & & $x$ \\
\hline (966I) чฉnцqจิunf & & $x$ & & & $x$ \\
\hline 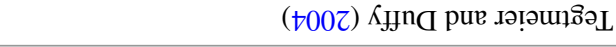 & & $x$ & & & $x$ \\
\hline 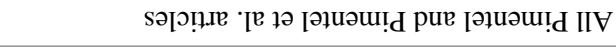 & & $x$ & & & $x$ \\
\hline (Z00乙) ' & & $x$ & & $x$ & $x$ \\
\hline 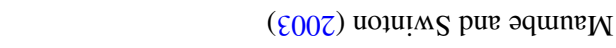 & & $x$ & $x$ & & $\approx$ \\
\hline 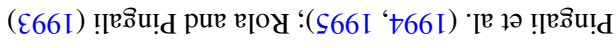 & & $x$ & $x$ & & $x$ \\
\hline 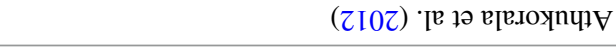 & & $x$ & $x$ & & $x$ \\
\hline 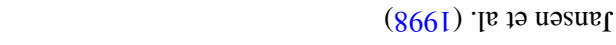 & & $x$ & $x$ & & $x$ \\
\hline 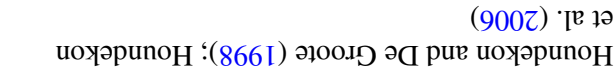 & & $x$ & $x$ & & $x$ \\
\hline 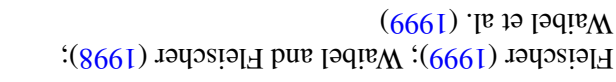 & & $x$ & $x$ & & $x$ \\
\hline (L00Z) ônd ؛(666I) ŝund pur sund & & $x$ & $x$ & & $x$ \\
\hline (Z00Z) ( $)$ & & $x$ & $x$ & & $x$ \\
\hline$(L 00 Z) \cdot\left[\begin{array}{lll}R \\
\end{array}\right.$ & & $x$ & $x$ & $x$ & $x$ \\
\hline$(L 00 乙) ! \Lambda ə \mathrm{C}$ & & $x$ & $x$ & $x$ & $x$ \\
\hline (乙І0乙) ' & & $x$ & $x$ & $x$ & $x$ \\
\hline 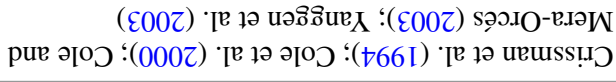 & & $x$ & $x$ & $x$ & $x$ \\
\hline (000Z) $)$ ! $/ \mathrm{R} ! \mathrm{V}$ & & $x$ & $x$ & $x$ & $x$ \\
\hline 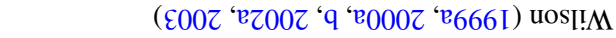 & & $x$ & $x$ & $x$ & $x$ \\
\hline 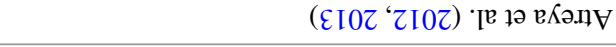 & & $x$ & $x$ & $x$ & $x$ \\
\hline 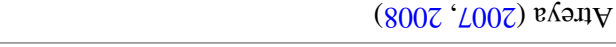 & & $x$ & $x$ & $x$ & $x$ \\
\hline 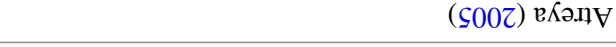 & & $x$ & $x$ & $x$ & $x$ \\
\hline $\begin{array}{l}0 \\
0 \\
0 \\
0 \\
0 \\
0 \\
0\end{array}$ & 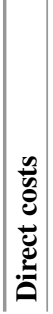 & 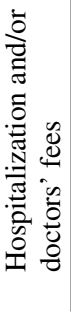 & 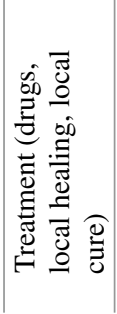 & 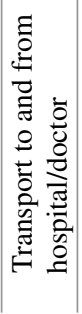 & 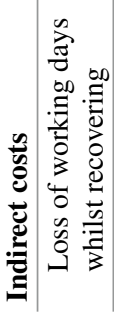 \\
\hline
\end{tabular}




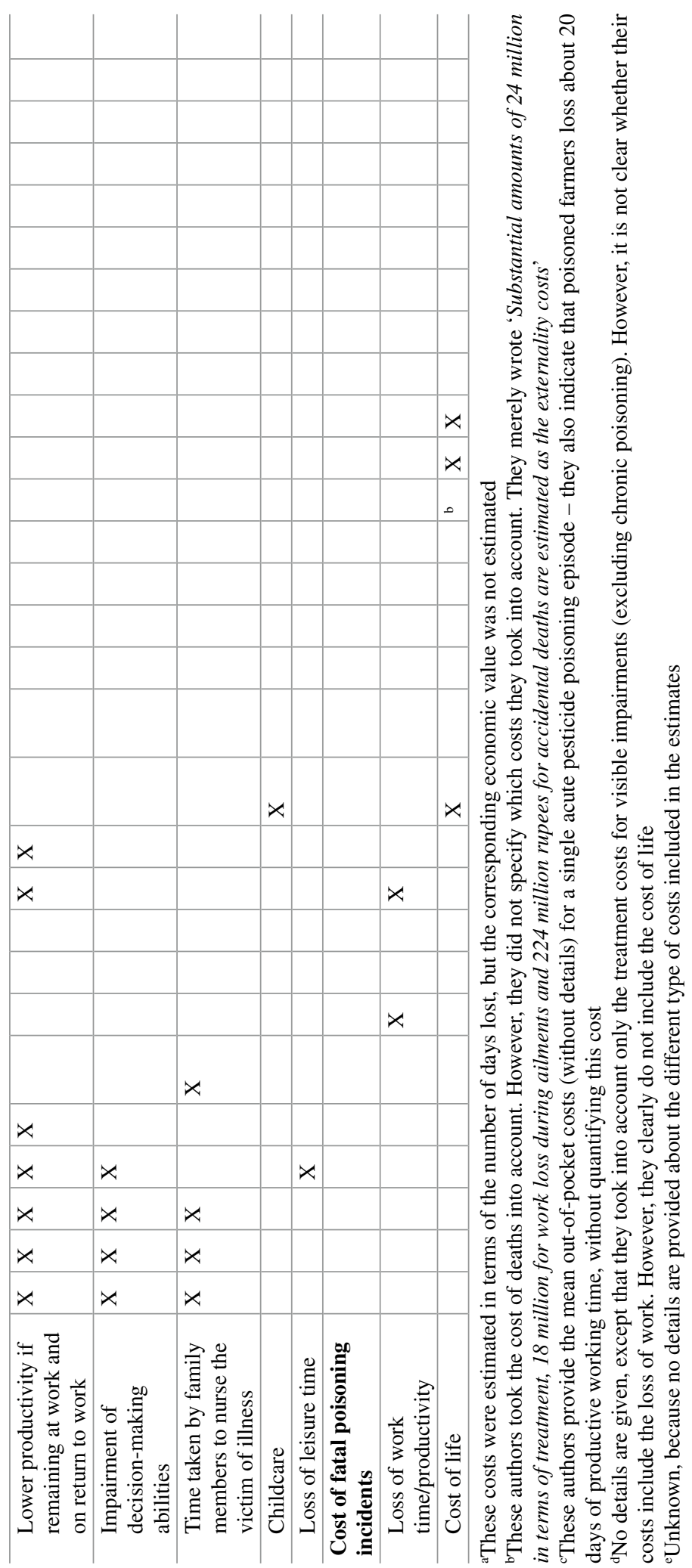


other studies evaluated the loss of leisure time as in the study by Wilson. However, Wilson did not estimate all the indirect costs due to pesticide poisoning and recognized that 'the costs to the family were not taken into account'. These costs, including the time taken by family members to nurse the victim of illness, were investigated in cost-of-illness studies performed in Nepal (Atreya 2005, 2007, 2008; Atreya et al. 2012, 2013) and Ecuador (Cole et al. 2000; Cole and Mera-Orcés 2003; Crissman et al. 1994; Yanggen et al. 2003). The cost of childcare, which was estimated by Fleischer and coworkers (Table 2.7), is another indirect cost that was not considered by Wilson. Finally, an additional indirect cost, identified but not estimated by Devi (2007), is the time spent traveling to seek medical help. Thus, none of the cost-ofillness studies performed to date fully took into account all the various costs associated with acute pesticide poisoning.

\subsubsection{Fatal Cases of Acute Poisoning}

Suicide accounts for most of the fatal cases of acute poisoning. Gunnell et al. (2007) estimated that 250,000 people die from voluntary pesticide ingestion each year, accounting for $30 \%$ of all suicides. The costs associated with such deaths cannot be considered an externality of pesticide use. Nevertheless, accidental pesticide poisoning, mostly in the occupational setting, may be fatal in some cases and the costs associated with such deaths can be treated as external costs. Fatal accidents due to occupational pesticide poisoning are very rare in some countries, such as the United States (1 case recorded from 1998 to 2005, Calvert et al. 2008), but may concern several tens or hundreds of workers per year in other countries with higher levels of pesticide use or in which workers are less well equipped with personal protection equipment (Fig. 2.1). For instance, Santana et al. (2013) reported that 2052 deaths, excluding homicides and suicides, were recorded as due to pesticide poisoning in Brazil, between 2000 and 2009. Half of these deaths concerned agricultural workers and most of them were caused by poisoning with organophosphate and carbamate pesticides.

The cost of fatal cases of accidental poisoning was estimated in only six sets of cost-of-illness studies: Ajayi et al. (2002), Choi et al. (2012), Khan et al. (2002), Tegtmeier and Duffy (2004), Pimentel and coworkers and Fleischer and coworkers (Table 2.7). Fatal cases have generally been ignored, mostly due to the type of costof-illness studies performed. Indeed, several of these studies involved interviews with a sample of farmers about the costs they incurred during pesticide poisoning incidents (Table 2.5). By definition, studies of this type cannot take deaths into account and, therefore, did not assess the cost of fatal poisoning events.

Two studies estimated the cost of these deaths, by evaluating the corresponding loss of work time. Ajayi et al. (2002) economically quantified the loss of life as the decrease in agricultural gross domestic product per habitant during the mean duration of an economically active life in agriculture set, in their study, at $50 \%$ of 30 years. Similarly, Choi et al. (2012) estimated the loss of productivity loss due to 
premature death. Age- and sex-specific mean wages and employment rates were used as surrogates for per capita productivity for each sex and age group. Like Ajayi et al. (2002), Khan et al. (2002) included fatal injuries in their overall estimate of health costs. They attributed an overall cost of 224 million Rupees (US\$15.1 million (2013)) to such injuries, but provided no details about how this cost was estimated.

David Pimentel and coworkers also considered the cost of fatal cases of pesticide poisoning. They used different sources for their estimates, based on the reasoning that no-one can place a precise monetary value on a human life. In their first estimate, Pimentel et al. (1980a, b) estimated the value of an individual human life at about US\$1 million (about US\$3.2 million (2013)). This value was considered to be the amount of money that industry and government might reasonably spend to prevent a death, but Pimentel et al. (1980a, b) wrote that 'obviously it is much less than the true value of a human life'. In their article published in 1992, Pimentel et al. used the monetary ranges computed by the insurance industry and used an estimate of US\$2 million (about US\$3.4 million (2013)), which they considered to be conservative. Pimentel and Greiner (1997) and Pimentel and Hart (2001) used an estimate of US\$2.2 million (about US\$3.2 million (2013)) per human life, corresponding to the mean value of the damages paid to the surviving spouses of slain policemen in New York City, which they again considered to be a conservative estimate. Finally, Pimentel (2005, 2009) and Pimentel and Burgess (2014), in their most recent re-evaluation of pesticide externalities, used the United States Environmental Protection Agency standard of US\$3.7 million (about US\$4.7 million (2013)) per human life. Finally, Fleischer and coworkers estimated the cost of acute fatal poisoning events in Germany, using the estimate of US\$2 million per life taken by Pimentel et al. (1993a) (see Waibel and Fleischer 1998).

\subsubsection{The (Almost) Uncounted Costs of Chronic Exposure}

The most striking feature of cost-of-illness studies on pesticide use is the lack of data concerning the long-term effects of chronic exposure. Several studies have highlighted the possible occurrence of severe health impairment, e.g. cancers, diabetes, depression, neurological deficits, respiratory diseases, fertility problems, cutaneous effects, effects on the unborn embryo, blindness, polyneuropathy, associated with chronic exposure to these chemicals. However, only six estimated the monetary costs of such impairment (Table 2.5). The other studies mostly stated that it was not possible to estimate costs due to chronic exposure because the corresponding illnesses, such as cancers, are multifactorial, making it difficult to estimate the number of cases directly due to pesticide exposure.

The six studies including the costs of health impairment due to chronic exposure provided very rough and incomplete estimates. Steiner et al. (1995) merely considered the cost of chronic illnesses to be as high as that associated with acute poisoning. Pimentel and coworkers based their estimates of the costs of chronic pesticide 
exposure on a rough estimate of the number of cancers per year. This number varied from $0.5 \%$ of all cancers (Pimentel et al. 1980a, b, 1991a) to 6000 (Pimentel et al. 1991b), <10,000 (Pimentel et al. 1992, 1993a, b), <12,000 (Pimentel and Greiner 1997), 10,000 (Pimentel and Hart 2001) and between 10,000 and 15,000 cases (Pimentel 2005, 2009; Pimentel and Burgess 2014). All but one of these estimates were based on a personal communication from David Schottenfeld indicating that 'US cases of cancer associated with pesticides in human are less than $1 \%$ of the nation's total cancer cases' (see Pimentel et al. 1980a, 1992). Tegtmeier and Duffy (2004) did not provide another estimate for the United States: they incorporated the estimate of Pimentel et al. (1992) into their overall externalities of pesticide use. Houndekon and De Groot (1998) and Houndekon et al. (2006) took chronic exposure into account to some extent in their estimates, but it is impossible to determine to what extent. Indeed, they asked farmers how much money they spent on medication and medical consultations and how many working days per year they lost to illness, without specifying the type of health effect (acute or chronic and, for chronic effects, the illnesses concerned). Similarly, Pingali et al. (1994, 1995) and Rola and Pingali (1993) performed medical tests, providing an assessment of the ailments of each farmer or respondent and their seriousness. Such ailments may or may not be related to chronic exposure to pesticides. Finally, Wilson (1999a, 2000a, b, 2003) considered long-term illness diagnosed by a physician as arising from pesticide exposure. Given the small number of farmers examined $(n=203)$, long-term illnesses were probably underdetected.

This lack of counts is certainly the major flaw of all cost-of-illness studies performed to date. Indeed, there are good reasons to think that the costs of chronic exposure may be not only as high as those of acute poisoning, as stated by Steiner et al. (1995), but probably higher. One reason for this is that sufferers of irreversible illnesses, e.g. blindness, not only undergo short-term treatments, but may also incur long-term costs over a number of years, sometimes until they die. In their most recent re-evaluation of externalities, Pimentel (2005, 2009) and Pimentel and Burgess (2014) estimated the costs of chronic exposure to pesticides, restricted to cancers, reached US\$1 billion, a value four times that estimated for the cost of acute poisoning events. However, this estimate did not include the loss of working days and the cost of death. By taking a death rate of $20 \%$ for people suffering from cancers (Siegel et al. 2014) and a rather conservative estimated 3 months of absence from work for cancer treatment and recovery, and using the same costs of death as for acute poisoning, the costs of chronic exposure estimated by Pimentel and coworkers would have reached US\$10.2 billion per year in 2005, 45 times the cost of acute poisoning. 


\subsubsection{Conclusions}

The cost-of-illness studies reviewed here clearly show that the external costs relating to human health associated with pesticide use have always been strongly underestimated. First, most studies considered only the costs associated with short-term effects following acute poisoning events. This resulted in a considerably lower estimate of the overall costs, because severe illnesses, e.g. cancers, diabetes, depression, blindness, potentially triggered by chronic pesticide exposure are probably associated with much higher costs than acute poisoning incidents. The few studies to have taken serious illnesses into account yielded only partial and very crude estimates, for only one of the multiple possible illnesses, cancers, and only some of the costs concerned. Moreover, the cost-of-illness studies generally ignored several direct and indirect costs due to acute poisoning.

Another major flaw in cost estimates to date is the lack of consideration of fatal cases of pesticide exposure. Pesticide exposure-related deaths have sometimes been counted for assessments of accidental acute poisoning incidents, but deaths due to chronic pesticide exposure have been completely ignored. Indeed, even though some authors, such as Pimentel et al. estimated the number of cancers, they did not estimate the corresponding number of deaths. In addition, the value of life has probably been underestimated in the past. Pimentel and coworkers increased the estimate of this cost from US\$1 to 3.7 million between 1980 and 2005, but, surprisingly, they retained this value (the value provided by the United States Environmental Protection Agency in the early 2000s) in their reassessments published in 2009 (Pimentel 2009) and 2014 (Pimentel and Burgess 2014). There is no standard concept or tool for placing a precise monetary value on a human life, but the reviews and meta-analyses of Kniesner et al. (2012), Lindhjem et al. (2011), Viscusi and Aldy (2003), and Viscusi et al. (2014) converged on a mean of US\$9 to 10 million in 2013, which would correspond to a value of US\$7.4 million in 2005. The human health costs estimated by Pimentel (2005, 2009) and Pimentel and Burgess (2014) should therefore be re-evaluated. If we use the re-evaluation of the estimated cost of chronic pesticide exposure of Pimentel (2005) proposed above, then overall human health costs in the article published by Pimentel in 2005 would have reached US\$15.65 billion (2005), rather than US\$1.23 billion (2005) as originally estimated.

Our review shows that health costs studies generally did not take into account fatal cases due to chronic exposure such as fatal outcomes of cancers. Doing so would increase those health costs by up to tenfold, e.g. US $\$ 15$ billion instead of US $\$ 1.5$ billion (2013) in the United States in 2005. 


\subsection{Environmental Costs}

We found 26 articles providing 15 different monetary estimates of environmental impacts of pesticide use (Table 2.8). These studies, based on 11 fully independent datasets, either focused on a particular impact or attempted to provide a complete valuation of these impacts. Not only are there only a limited number of studies on this topic, but most were carried out in the 1990s. We found only five studies based on data recorded after 2000 and only one article published since 2006 (Table 2.8).

Table 2.8 Costs of the environmental impact of pesticide use

\begin{tabular}{|c|c|c|c|c|}
\hline Reference & Country & Year & $\begin{array}{l}\text { Fully } \\
\text { independent } \\
\text { dataset }^{\mathrm{a}}\end{array}$ & $\begin{array}{l}\text { Overall costs } \\
\text { (million US\$ } 2013 \\
\text { per year) }\end{array}$ \\
\hline James (1995) & Canada & 1993 & A & $0.27-30.73$ \\
\hline $\begin{array}{l}\text { Houndekon and De } \\
\text { Groote (1998); } \\
\text { Houndekon et al. (2006) }\end{array}$ & Niger & 1996 & B & 0.89 \\
\hline Jungbluth (1996) & Thailand & 1995 & $\mathrm{C}$ & 5.58 \\
\hline $\begin{array}{l}\text { Fleischer (1999); Waibel } \\
\text { and Fleischer (1998); } \\
\text { Waibel et al. (1999) }\end{array}$ & Germany & 1996 & $\mathrm{D}$ & 9.31 \\
\hline $\begin{array}{l}\text { Praneetvatakul et al. } \\
(2013)\end{array}$ & Thailand & 2010 & $\mathrm{E}$ & 16.88 \\
\hline Ajayi et al. (2002) & Mali & 1999 & $\mathrm{~F}$ & 38.11 \\
\hline Pretty et al. $(2000,2001)$ & \begin{tabular}{|l} 
United \\
Kingdom
\end{tabular} & 1996 & G & 62.74 \\
\hline Steiner et al. (1995) & United States & 1991 & $\mathrm{H} / \mathrm{J}$ & $203.85-4029.46$ \\
\hline Khan et al. (2002) & Pakistan & 2002 & I & 815.12 \\
\hline Pimentel et al. (1991a, b) & United States & 1991 & $\mathrm{~J}$ & 948.94 \\
\hline $\begin{array}{l}\text { Tegtmeier and Duffy } \\
\text { (2004) }\end{array}$ & United States & 2002 & $\mathrm{~K} / \mathrm{J}$ & $1469.74-1507.62$ \\
\hline Pimentel et al. (1980a, b) & United States & 1980 & $\mathrm{~J}$ & 1621.17 \\
\hline $\begin{array}{l}\text { Pimentel (2005, 2009); } \\
\text { Pimentel and Burgess } \\
(2014)\end{array}$ & United States & 2005 & $\mathrm{~J}$ & 5973.50 \\
\hline $\begin{array}{l}\text { Pimentel and Greiner } \\
\text { (1997); Pimentel and } \\
\text { Hart (2001) }\end{array}$ & United States & 1997 & $\mathrm{~J}$ & 6993.99 \\
\hline $\begin{array}{l}\text { Pimentel et al. (1992, } \\
1993 a, b)\end{array}$ & United States & 1992 & $\mathrm{~J}$ & 7967.84 \\
\hline
\end{tabular}

${ }^{a}$ The same letter indicates a partial dependence of cost estimates 


\subsubsection{Various Types of Environmental Impact}

Several types of environmental impact have been considered, but there have been few attempts to classify these impacts into a particular framework (but see Khan et al. 2002). In addition, the costs of these environmental impacts were poorly differentiated from regulatory costs. For instance, several authors considered water monitoring costs and the costs of water decontamination to be costs associated with environmental impact (Pimentel et al. 1980a, b, 1991a, b, 1992, 1993a, b; Pimentel and Greiner 1997; Pimentel and Hart 2001; Pimentel 2005, 2009; Pimentel and Burgess 2014). In this review, we have considered the impact of pesticide use on surface and underground waters as regulatory costs, because these controls and decontamination processes are, in most countries, mandatory. Similarly, the costs of crops and livestock (meat, milk, eggs etc.) contaminated with pesticides to levels exceeding the maximum residue limit, resulting in their mandatory withdrawal from the market and destruction, are considered here as regulatory rather than environmental costs. Finally, we found that environmental impacts could be classified into two main categories: (i) damage to animals (vertebrates and invertebrates), plants, algae and microorganisms and (ii) pest resistance to pesticides (Table 2.9).

\subsubsection{Damage to Animals, Plants, Algae and Microorganisms}

The main environmental impact of pesticides is probably the direct or indirect damage they cause to animals, plants and microorganisms, varying from minor injuries to death. This impact is not restricted to the area in and around fields. Indeed, during applications, pesticides drift away in the air and seep into the soil (Gil and Sinfort 2005; Pimentel 1995). Once in the soil, some soluble pesticides may be washed out in runoff water and during soil erosion, resulting in leaching into rivers and lakes (Chopra et al. 2011).

\section{Damage to Vertebrates}

Pesticide use has two main unintentional effects on vertebrate (mammals, birds, fish, reptiles and amphibians) wildlife: (i) deaths due to direct or indirect, e.g. feeding on contaminated plants and/or prey, exposure to high doses and (ii) poorer survival, growth and reproduction due to exposure to sublethal doses and a decline in or the elimination of habitats and food sources due to pesticides (Gibbons et al. 2014; Guitart et al. 2010; Sánchez-Bayo 2011).

Pesticides have a particularly strong impact on birds (Mitra et al. 2011), through direct deaths and the reduction or elimination of habitats and food sources. The indirect effects of insecticides, herbicides and fungicides have been identified as one of the main factors contributing to the decline of farmland birds in several European countries (Geiger et al. 2010). For example, herbicides and insecticides, together 


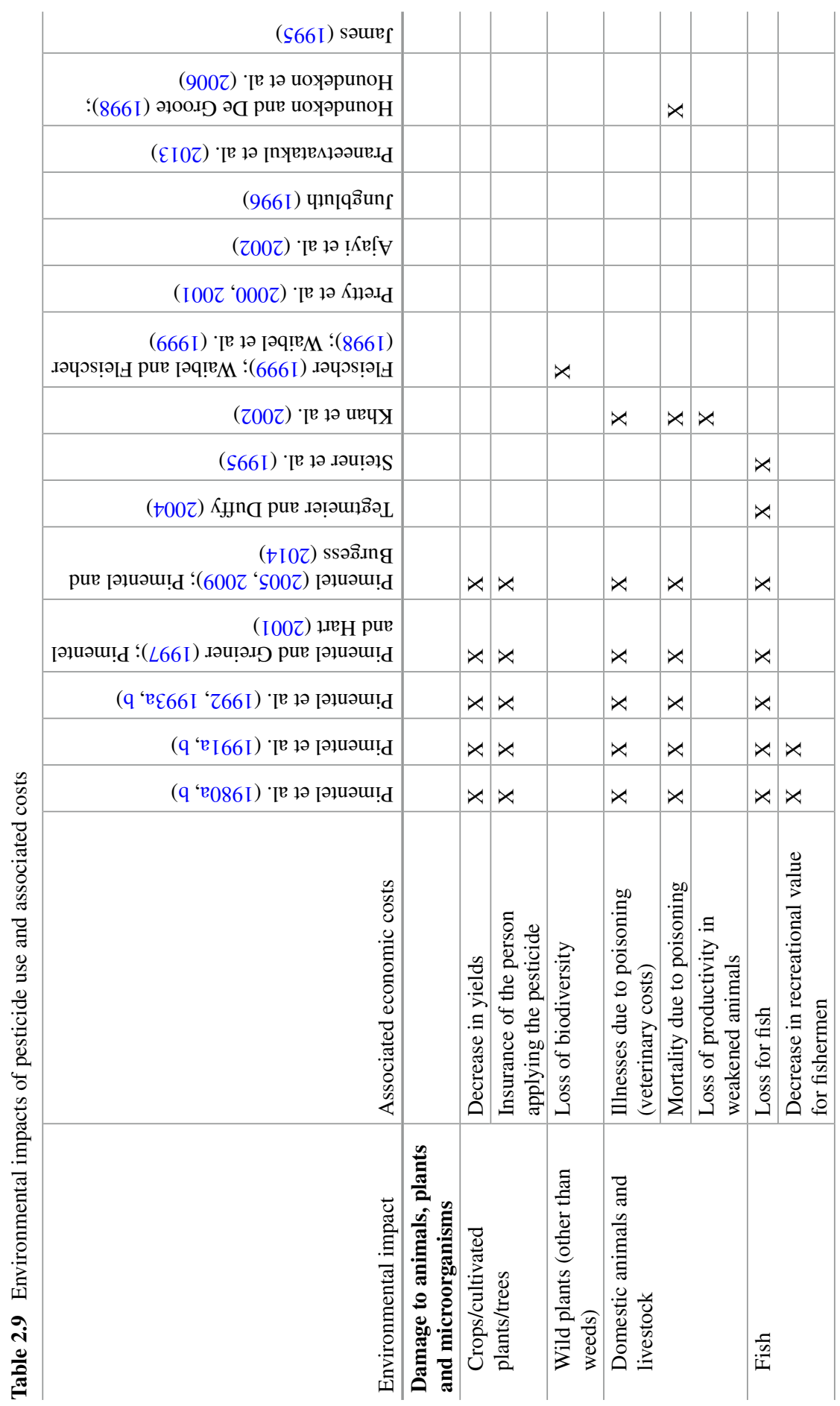




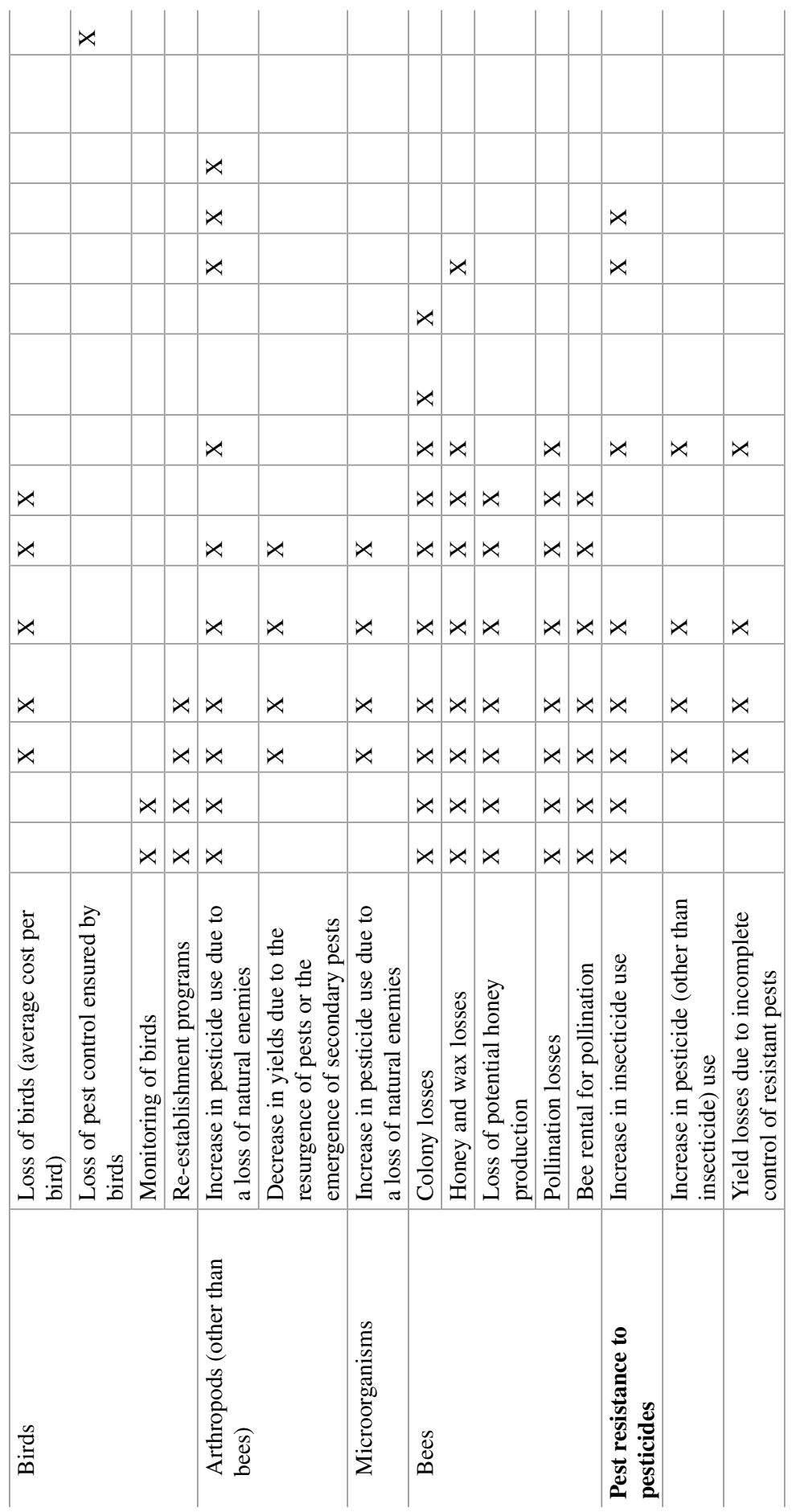


with certain agricultural practices, decrease levels of cereal grains, weed seeds and arthropods, thereby potentially contributing to the decline of bird species dependent on these resources for survival, e.g. Wilson et al. (1999) for granivorous birds and Hallmann et al. (2014) for insectivorous birds. In North America, the decline of several grassland birds, including songbirds in particular, is thought to be mostly due to a direct impact of insecticides (Mineau (2002) and Mineau et al. (2005) for Canada; Mineau and Whiteside (2006, 2013) for the United States). Birds are particularly susceptible to cholinesterase-inhibiting pesticides, e.g. organophosphates and carbamates, mostly because, unlike mammals, they have low levels of anticholinesterase detoxifying enzymes (Walker 1983). The extensive use of carbofuran, a carbamate, through a granular form resembling plant grains in North America has been reported to lead to the death of millions of birds annually (Mineau et al. 2012) (Fig. 2.4). Other birds, such as those predating on rodents, e.g. owls and other birds of prey, are also directly or indirectly poisoned by rodenticides in many developed countries (Christensen et al. 2012; Elliott et al. 2014; Langford et al. 2013; Thomas et al. 2011).

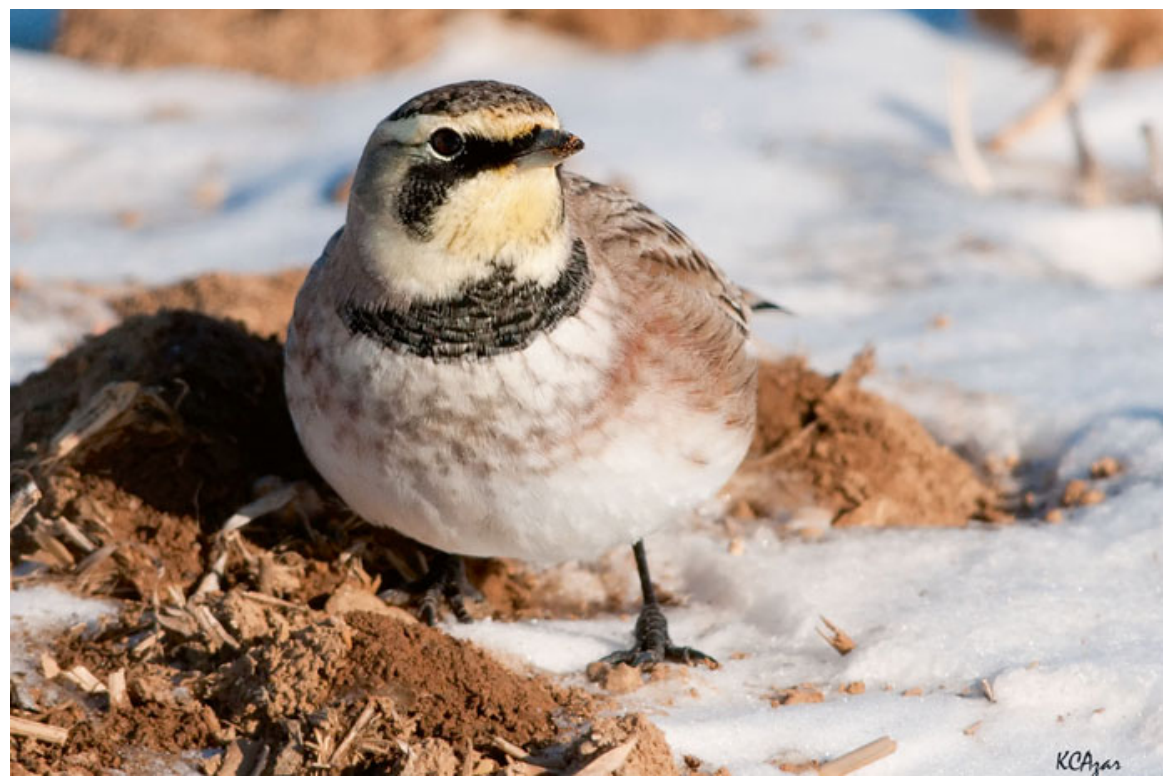

Fig. 2.4 The extensive use of carbofuran, a carbamate, through a granular form resembling plant grains in North America has been reported to lead to the death of millions of birds - like the horned lark Eremophila alpestris - annually (Mineau et al. 2012). The ban on these granular formulations of carbofuran introduced in 1991 (Heier 1991) and effective by 1994, in particular, probably had a considerable beneficial effect on bird survival in farmland. The estimate of 17-91 million birds killed per year during the 1980s was therefore almost certainly, as stated by Mineau (2005), the "worst-case" impact of pesticides on birds in an agricultural setting'. The current impact of pesticide use on birds is probably much lower (Unmodified photography by Kelly Colgan Azar, under Creative Common License CC BY-ND (https://creativecommons.org/licenses/by-nd/2.0/)) 
Many studies have documented direct and indirect effects of both high and sublethal doses of pesticides on several wild vertebrates other than birds. Herbicide treatments can be lethal for amphibians. For instance, one of the surfactants added to glyphosate, the most widely used herbicide worldwide, has been shown to be highly toxic to several species of amphibians in North America (Relyea 2005). Recent reviews and meta-analyses have confirmed that several pesticides decrease amphibian survival (Baker et al. 2013; Egea-Serrano et al. 2012). It has also been shown that pesticides have indirect and sublethal effects on this class of vertebrates, reducing their growth (Baker et al. 2013; Egea-Serrano et al. 2012) and increasing the frequency of abnormalities (Egea-Serrano et al. 2012). For instance, the herbicide atrazine, one of the most commonly used pesticides worldwide, adversely affects amphibians by disrupting metamorphosis, reducing antipredator behavior, decreasing immune function and increasing the frequency of infection (Rohr and McCoy 2010). The endocrine disruptor activities of atrazine, which decreases both time to metamorphosis and size at metamorphosis, can be enhanced by the presence of insecticides and fungicides. The effects of such mixtures of pesticides have probably played a major role in the global decline of amphibians (Hayes et al. 2006). Atrazine also disrupts several life history traits in fish (Rohr and McCoy 2010). Several pesticides, including atrazine, have been shown to have immunotoxic effects (Dunier and Siwicki 1993) and to cause oxidative stress (Slaninova et al. 2009) in fish, and these compounds can also interfere with olfaction in these organisms (Tierney et al. 2010).

Finally, pesticides also injure wild and domestic mammals. Rodenticides, particularly second-generation compounds, kill not only target pests, but many nontarget rodent species (Elliott et al. 2014; Fournier-Chambrillon et al. 2004). Species abundance and diversity in rodent communities can also be altered by herbicides, particularly in situations in which these chemicals are used to convert bushwood to grassland (Freemark and Boutin 1995). Pesticides can also poison several domestic mammals (Wang et al. 2007; Berny et al. 2010). In the United States, and probably also in many European countries, the incidence of poisoning is highest in cats and dogs (Berny et al. 2010). These animals often wander freely around homes and farms. They are therefore much more likely to come into contact with pesticides than other domesticated animals. The presence of sprayed chemicals on fodder or of pesticide residues in feed for livestock may lead to fatal poisoning events in domestic farm animals, particularly in developing countries (Ajayi et al. 2002).

\section{Damage to Invertebrates}

Insecticide treatments controlling pests also have damaging effects on many nontarget terrestrial arthropods in agroecosystems, including the natural enemies (predators, parasites and parasitoids) of agricultural pests (Croft and Brown 1975). Damage to these species may be greater than initially thought, because such damage can occur even at low non-lethal doses of insecticides (Desneux et al. 2007). For instance, sublethal doses of neonicotinoids (a new generation of insecticides) have 
clearly been shown to affect the foraging success, survival, colony growth, and queen production of honey and bumble bees (Henry et al. 2012; Schneider et al. 2012; Whitehorn et al. 2012) (Fig. 2.5). Beneficial arthropods are also affected by herbicides. This impact may be direct (Norris and Kogan 2000), but it is generally indirect. By killing weeds and non-target plants, herbicides reduce the fitness of many of the arthropods developing or resting on weeds, thereby decreasing the growth of their populations (Freemark and Boutin 1995; Norris and Kogan 2005). Even if herbicides do not actually kill non-target plants, they may still suppress flower formation in some species (Schmitz et al. 2014a), or markedly delay flowering time and decrease flower production in many other species (Boutin et al. 2014). As a consequence, herbicide treatments may indirectly decrease the fitness of pollinating insects in non-crop habitats during periods in which crop plants are unavailable for pollination. Egan et al. (2014) showed that changes in the structure and function of arthropod communities depend on species composition, crop rotation patterns and the timing of herbicide exposure.

Pesticides can also have an impact on aquatic invertebrates (Rasmussen et al. 2013), particularly during pulses of contamination triggered by surface runoff and

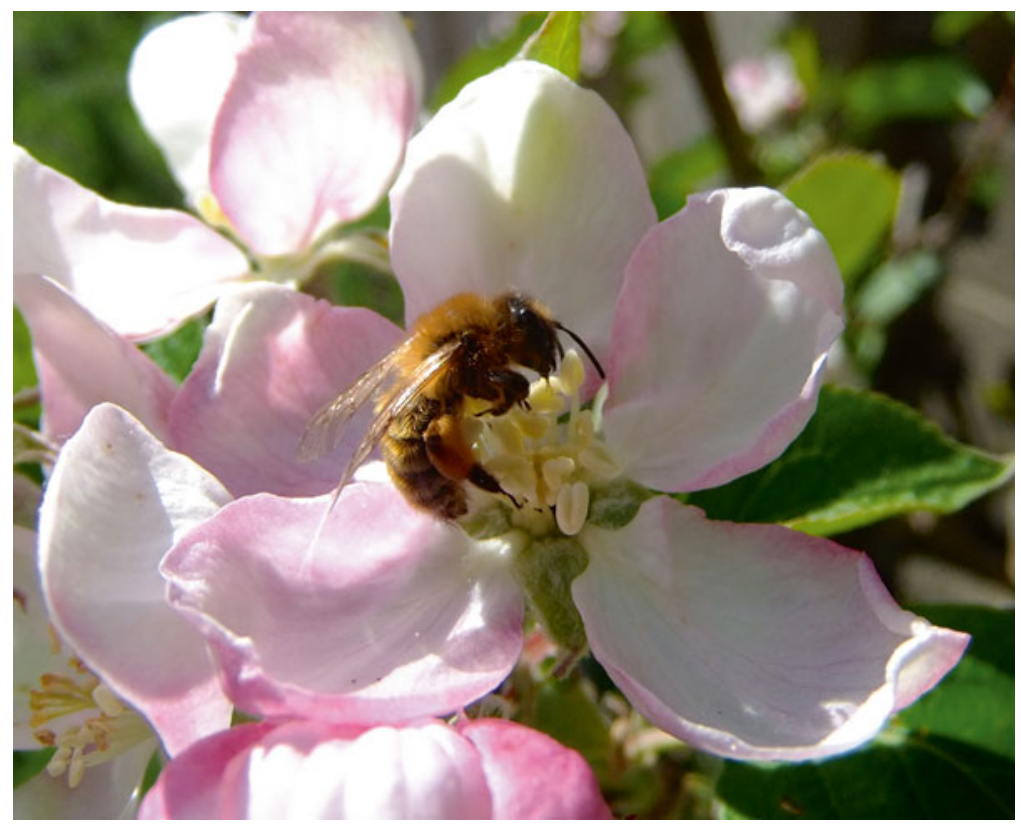

Fig. 2.5 Honey bee on apple blossom in Bedfordshire, United Kingdom. Damage to non-target terrestrial arthropods in agroecosystems may be greater than initially thought, because such damage can occur even at low non-lethal doses of insecticides (Desneux et al. 2007). Sublethal doses of neonicotinoids (a new generation of insecticides) have clearly been shown to affect the foraging success, survival, colony growth, and queen production of honey and bumble bees (Henry et al. 2012; Schneider et al. 2012; Whitehorn et al. 2012) (Unmodified photography by Orangeaurochs, under Creative Common License CC BY (https://creativecommons.org/licenses/by/2.0/)) 
through tile drains during heavy rain. Invertebrates may also be injured during short pulses of contamination due to pesticide desorption from suspended solids or sediment particles. Finally, they can be poisoned via the ingestion of "polluted" particles. Several studies have found associations between pesticide concentrations and decreases in the numbers and abundances of taxa and changes to invertebrate community structure (e.g. Friberg et al. 2003; Liess and von der Ohe 2005; Schäfer et al. 2007, 2011, 2012). These studies were performed at many sites in Europe, Siberia and Australia, and the authors concluded that there was little doubt that pesticides were responsible for the observed changes in aquatic invertebrate communities. Liess and von der Ohe (2005) and Schäfer et al. (2007) showed that the number and abundance of aquatic invertebrate taxa could be compensated, probably through recolonization from undisturbed sections of the stream. Nevertheless, Beketov et al. (2013) found that pesticides had significant effects on regional species and family richness in Germany, France and Australia, with up to $42 \%$ of the taxa from the recorded taxonomic pools lost. Furthermore, in Europe, effects were detected at concentrations considered environmentally benign in current legislation (Beketov et al. 2013).

\section{Damage to Plants, Algae and Corals}

Pesticides can accidentally injure crops. First, the crops protected by the pesticide may be damaged by it. In particular, some pesticides may disrupt photosynthesis, thereby decreasing both growth and yield. Such an effect has been shown for several fungicides, on many crops (Petit et al. 2012), and for some herbicides, on cotton (Reddy et al. 1990) and soybean (Hagood et al. 1980). Similarly, insecticide treatments may also lower yields when applied to lettuce (Toscano et al. 1982) and cotton (Youngman et al. 1990). Second, pesticides may disperse by drifting during spray applications. They may reach non-target crops in neighboring fields, weakening these plants and reducing yields. Such crop injuries have been reported, in particular, for aerial applications of glyphosate (e.g. Ding et al. 2011; Reddy et al. 2010). Third, as some herbicides persist in the soil, other crops (notably vegetables) in the rotation may be affected and display lower yields (e.g. Felix et al. 2007; Mahmoudi et al. 2011). These carryover injuries may be accentuated in fields previously treated with several herbicides. For instance, the addition of atrazine to mesotrione treatments in the year before planting has been shown to increase injury rates by $3-55 \%$ in broccoli, carrot, cucumber, onion, and potato (Robinson 2008).

In some agroecosystems, field margins and boundaries (e.g. hedgerows, woodlots, etc.) are the only remaining habitats for many wild plant species, some of which are beneficial, considered of heritage value or protected (Türe and Böcük 2008). The long-term maintenance of their populations, particularly close to edges of crop fields, may be jeopardized by the drift of herbicide treatments. Several studies have shown that non-target plants are affected by herbicides (e.g. Freemark and Boutin 1995; Gove et al. 2007; Schmitz et al. 2014a), leading to short- and longterm changes in the richness and/or structure of plant communities (e.g. Egan et al. 
2014; Gove et al. 2007; Schmitz et al. 2014b). Changes also occur among weed communities within crop fields (e.g. Andreasen and Streibig 2011). These changes in the composition of weed plant communities may reflect lower rates of reproduction in the species most affected by herbicides, as demonstrated by Boutin et al. (2014).

Aquatic plants, algae and coral species may also be affected by pesticide use. The large distances between sprayed fields and bodies of fresh and inshore waters should theoretically provide some protection, through the adsorption of some of the drift by bank vegetation and, probably, also through the dilution of the herbicides in water. In some ecosystems, aquatic and algal species are, indeed, considered to be not necessarily at risk (e.g. Cedergreen and Streibig 2005). However, there may be a major impact on aquatic species in bodies of water subject to intense agricultural runoff (Fabricius 2005). A textbook example is provided by the inshore waters of the Australian Great Barrier Reef. This lagoon has World Heritage status, but is widely contaminated with insecticides and herbicides (Haynes et al. 2000; Lewis et al. 2009; Packett et al. 2009). Kroon et al. (2012) estimated that $>30,000 \mathrm{~kg}$ of herbicides enter the Great Barrier Reef lagoon each year. Despite their dilution in the water, concentrations exceeding $1 \mu \mathrm{g} \mathrm{L}^{-1}$ have been reported for some herbicides within the lagoon (Lewis et al. 2009). These concentrations may be high enough (Lewis et al. 2012) to have deleterious effects on corals (Cantin et al. 2007; Jones et al. 2003; Negri et al. 2011), seagrasses (Flores et al. 2013), foraminifera (van Dam et al. 2012), benthic microalgae (Magnusson et al. 2008, 2010, 2012) and coralline algae (Negri et al. 2011). The Great Barrier Reef is probably the most widely studied ecosystem threatened by pesticides, but other species in several other coastal water systems are also threatened by the effects of pesticide runoff. The ecosystems concerned include Chesapeake Bay in the United States (Hartwell 2011), the Seto Inland Sea (Balakrishnan et al. 2012) and two lagoons (Yamamuro 2012) in Japan.

\section{Damage to the Soil Community}

The effects of pesticides on earthworms (Yasmin and D'Souza 2010), microarthropods (Adamski et al. 2009), nematodes (Zhao et al. 2013), fungi (Morjan et al. 2002) and microorganisms (viruses, protozoa and bacteria) (Imfeld and Vuilleumier 2012; Lo 2010) within the soil may have major environmental consequences. The soil community plays a critical role in crop production and crop protection (Barrios 2007). These small organisms are essential to the functioning of all ecosystems, because they break down waste, thereby recycling the chemical elements required for life. Bacteria and fungi make nitrogen and other elements available to plants (Bonfante and Anca 2009) and, like nematodes, some soil-borne fungi are natural enemies of pest insects (Kaya and Gaugler 1993; Klingen and Haukeland 2006). Earthworms, which are widely recognized as 'ecosystem engineers', contribute to several ecosystem services through pedogenesis, the development of soil structure, water regulation, nutrient cycling, primary production, climate regulation, the remediation of pollution and cultural services (Blouin et al. 2013). 


\section{Damage Due to Interactions Between Species and Between Stressors}

Species are not isolated from their environment or from other interconnected species. Pesticide exposure may, therefore, have indirect effects on biotic interactions, such as host-parasite relationships (Köhler and Triebskorn 2013). For instance, Rohr et al. (2008) showed that atrazine use was the best predictor of the abundance of larval trematodes (parasitic flatworms) in the declining northern leopard frog Rana pipiens. Pesticides can also increase the frequency of deformities associated with trematode infection in amphibians (Kiesecker 2002). More generally, interactions between pesticides and other environmental stressors may play a key role in the decline of amphibian populations (Mann et al. 2009). Synergistic effects of pesticides and natural stressors, such as heat, desiccation, oxygen depletion and pathogens, have already been documented in many other classes of animals (Holmstrup et al. 2010). Pesticides can also affect food webs and competition between species (Köhler and Triebskorn 2013). For instance, benomyl, a widely used fungicide, suppresses populations of arbuscular mycorrhizal fungi in grasslands, altering floral display at the patch level. Such changes have been shown to induce a shift in the community of floral visitors, from large-bodied bees to small-bodied bees and flies, and to decrease the total number of visits to flowers (Cahill et al. 2008).

\subsubsection{Pest Resistance to Pesticides}

The second main environmental consequence of pesticide use is the selection of pesticide resistance. The impact of such resistance is well documented, for all classes of pests targeted and for almost all types of insecticides, herbicides and fungicides (REX Consortium 2013). More than 10,000 cases of resistance to 300 insecticide compounds have been reported in about 600 species of arthropods (Arthropod Pesticide Resistance Database; www.pesticideresistance.com). Similarly, 300 cases of field resistance to 30 fungicides have been reported in 250 species of phytopathogenic fungi (Fungicide Resistance Action Committee database; http://www.frac. info). The International Survey of Herbicide-Resistant Weeds (http://www.weedscience.com) has suggested that there are currently about 429 biotypes resistant to 153 herbicides in 234 weed species.

\subsubsection{Economic Consequences Considered to Date}

The environmental impacts described above are obviously costly, in many ways. The various economic consequences considered in the 15 sets of studies are shown in Table 2.9.

Pimentel et al. (1980a, b, 1991a, b, 1992, 1993a, b), Pimentel and Greiner (1997), Pimentel and Hart (2001), Pimentel (2005), Pimentel and Burgess (2014), followed by Steiner et al. (1995), Khan et al. (2002) and Tegtmeier and Duffy (2004), tried to carry out a complete evaluation of the economic consequences of pesticide exposure 
in bees (Table 2.9). They evaluated colony losses, but also considered (i) losses of honey and wax due to bee colonies being either seriously weakened by pesticides or suffering losses when moved by beekeepers to minimize the risk of pesticide damage, (ii) losses of potential honey production because heavy pesticide applications on some crops may result in beekeepers being excluded from sites otherwise suitable for beekeeping, (iii) the lack of pollination due to losses of bee colonies and (iv) bee rental to compensate for this lack of pollination. Pollination losses were the greatest loss by far, accounting for more than $60 \%$ of the total economic impact of pesticide exposure in bees.

A thorough analysis, such as that performed for bees, has never been undertaken for plants, microorganisms or animals other than bees. Considerations of the economic consequence of arthropod and microorganism depletion have focused on the loss of natural enemies of agricultural pests (Table 2.9). This loss of beneficial arthropods, fungi, bacteria and viruses increases pest pressure on crops. First, such losses allow the primary pests themselves to occur at higher densities. Several outbreaks of primary pests have been accounted for by the depletion of their natural enemies by pesticides (Bommarco et al. 2011; Hardin et al. 1995; Wilson et al. 1998). Second, many secondary pests, i.e. species that were once minor or unimportant crop pests, may become major pests if no longer controlled by their natural enemies (Hardin et al. 1995; Eveleens et al. 1973). Primary and secondary pest outbreaks due to the depletion of natural enemies have two main economic consequences: they increase pesticide use and decrease yields.

Pesticide resistance increases the amount of pesticide used, because higher doses are required to kill resistant pests. The use of alternative pesticides to which the resistant pests are still susceptible, or of a mixture of pesticides, which may be more expensive, may prove necessary. Resistance also decreases yields, because some pests become so resistant that they can no longer be fully controlled by pesticides or because the larger amounts of pesticides required to control resistant pests damage the crops treated.

The annual cost of mortality in birds and fish has been evaluated by multiplying the number of individuals actually killed due to direct or indirect exposure to pesticides by the estimated mean price of the individuals concerned. For birds, two additional types of environmental costs have been considered: the monitoring of species threatened by pesticide exposure and the re-establishment of endangered species, e.g. the bald eagle, Haliaeetus leucocephalus, affected by pesticides (Table 2.9).

Three economic consequences have been associated with damage to domesticated animals: the cost of illness, e.g. veterinary fees, the cost of dead livestock and the loss of productivity of animals weakened by poisoning, with affected individuals producing less milk, meat or eggs, for example (Table 2.9).

Yield loss is the principal economic consequence of accidental injury to crops from pesticide use. Contractors applying pesticides can be sued for damage to the crop during or after treatment. In many states of the United States, contractors applying pesticides must provide evidence of financial responsibility before spraying. Most are insured, to protect themselves against expensive lawsuits, and this increases the environmental cost of pesticide use. 


\subsubsection{Counting Environmental Costs: From Specific to Overall Costs}

Some studies have focused on a particular impact. For instance, James (1995) specifically estimated the cost of bird losses in Canada. Some studies have been devoted to a specific crop in a specific area, such as the Punjabi cotton zones in Pakistan (Khan et al. 2002). Others have focused on externalities sensu stricto: Steiner et al. (1995) and Tegtmeier and Duffy (2004) in the United States and Pretty et al. (2000, 2001) for the United Kingdom. Steiner et al. (1995) therefore chose to ignore the costs associated with pesticide resistances and the loss of natural enemies, because these costs are mostly met by users (see also Pearce and Tinch 1998). Finally, Pimentel et al. (1980a, b, 1991a, b, 1992, 1993a, b), Pimentel and Greiner (1997), Pimentel and Hart (2001), Pimentel (2005) and Pimentel and Burgess (2014) in the United States, Jungbluth (1996) in Thailand and Ajayi et al. (2002) in Mali assessed the total environmental costs associated with pesticide use on all crops at the national level.

Estimates of economic costs due to environmental damages are therefore highly variable, from US\$270,000 (2013) for the birds killed in Canada (James 1995) to about US\$8 billion (2013) for total environmental impact in the United Sates (Pimentel et al. 1992, 1993a, b) (Table 2.8).

The two main environmental costs considered stemmed from the increase of pesticide use due to pest resistance and the number of birds killed by pesticide exposure. In the study by Pimentel et al. (1992), these two categories accounted for $35 \%$ and $40 \%$ of the total environmental costs. However, it is particularly difficult to assess the costs associated with bird losses. Pimentel et al. (1992), Pimentel and Greiner (1997), Pimentel (2005) and Pimentel and Burgess (2014) reported that the cost of a bird's life in the United States could be estimated at $\$ 0.40, \$ 216$ or $\$ 800$. As pointed out by Bowles and Webster (1995), the techniques used to evaluate this cost were not described. In fact, these values correspond, to the cost per bird for bird watching, bird hunting and for rearing and releasing a bird of an affected species in the wild, respectively. In 1992, Pimentel et al. decided to take an average cost of $\$ 30$ per bird (Table 2.10). Surprisingly, this cost of $\$ 30$ was never updated and has remained constant in all the papers since published by Pimentel and coworkers. This resulted in a decrease in the estimated annual cost of bird losses from US\$3.37 billion (2013) in Pimentel et al. (1992) to US\$2.55 billion (2013) in Pimentel and Burgess (2014) (Table 2.10). Based on the estimate of Pimentel et al. (1992), Tegtmeier and Duffy (2004) decided to take the lowest monetary value assigned per bird (US\$0.40 in 1992 - re-evaluated to US\$0.51 in 2004). This resulted in estimated costs of US $\$ 45$ million (2013) per year, almost two orders of magnitude lower than the estimates provided by Pimentel et al. in 1992 (Table 2.10). Finally, Steiner et al. (1995) indicated that the cost of a bird may vary between the lower limit of US\$0.40 to the mean value of US\$30 chosen by Pimentel and coworkers, resulting in annual costs of about US\$47 million to US\$3.5 billion (2013) (Table 2.10). 


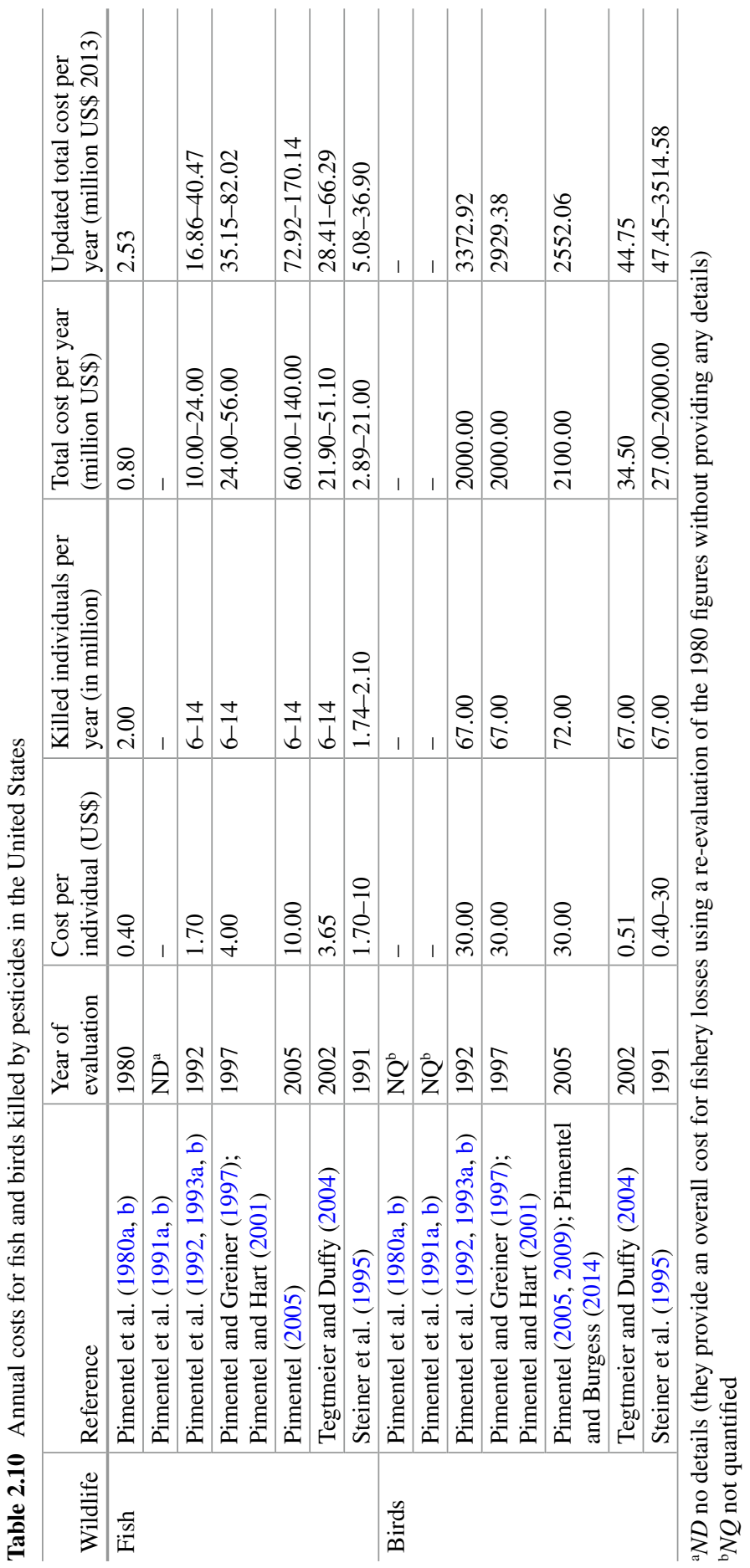


Similar variations were observed in estimates of fish losses in the United States. The cost of a fish varied from US\$0.40 to US\$10 between papers, resulting in estimates of the annual cost of fishery losses of between US\$2.53 million (2013) in 1980 and US\$170 million (2013) in 2005, 2009 and 2014, in studies by the same authors (Table 2.10).

\subsubsection{Underestimated and Uncounted Costs}

The costs provided by these studies are probably far from the actual costs. There are, indeed, several reasons for thinking that the counted costs were underestimated. In addition, several types of environmental damage have yet to be assessed.

\subsubsection{Most Costs Were Probably Underestimated}

Pimentel et al. (1980a) considered their estimate of the cost of domesticated animal poisoning to be low because it was based only on poisoning cases reported to veterinary surgeons. They indicated that in cases of poisoning in which little can be done for the animal, veterinary surgeons are rarely called.

They also considered their estimates of fish deaths to be low, for many reasons. They indicated that $20 \%$ of the reported fish kills gave no estimate of the number of fish killed and that fish kills often cannot be investigated quickly enough to determine whether they result from pesticide exposure. Furthermore, the fast-moving water in rivers dilutes pollutants, making it difficult to identify the chemical involved, and washes away the poisoned fish. Finally, many dead fish sink to the bottom or are eaten by other fish and therefore cannot be counted. Perhaps most importantly, unlike direct kills, few, if any, of the widespread, low-level pesticide poisoning events result in dramatic manifestations and these events are, therefore, not recognized or reported.

The total numbers of birds killed by pesticides is difficult to determine because, like most vertebrate species, they are often secretive, camouflaged, highly mobile and, as pointed by Pimentel et al. (1980a), they do not conspicuously 'float to the surface' as fish do. They often live in dense grass, shrubs, and trees. Dead birds disappear quickly, well before they can be found and counted (Mineau and Collins 1988). Scavengers have been shown to remove $>90 \%$ of bird carcasses placed in farmland overnight (Prosser et al. 2008). Furthermore, field studies seldom account for birds dying outside the treated areas, but birds often hide and die in inconspicuous locations. Estimates of bird mortality do not include birds that die due to the death of one of their parents or the deaths of the nestlings. They do not include nestlings killed because they were fed contaminated arthropods and other foods either. Mineau (2005) considered the estimate of Pimentel et al. (1992) - a mortality of 67 million birds per year in the United States - to be too conservative. Indeed, he estimated that, at the start of the 1980s, 17-91 million songbirds were dying annually 
in the United States Corn Belt, purely due to the use of a granular formulation of carbofuran in corn. However, Mineau (2005) felt that this figure was still too conservative, because it did not include birds dying in other crops treated with granular carbofuran, such as soybean, sorghum, groundnut, tobacco, cotton or sunflower, or the lethal impact of all the other pesticides, including rodenticides, on birds. Based on the analysis of Mineau (2005), there were probably more than 100 million birds lost annually in the United States between 1978 and 1985.

Crop losses due to pesticides are also probably underestimated because, for many losses, the parties involved come to an out-of-court settlement, and the losses are therefore never reported to the state and federal agencies (Pimentel et al. 1993a). In addition, pesticide damage to target crops due to the application of larger doses to kill pesticide-resistant pests, has probably been underestimated.

\subsubsection{Several Costs Have Never Been Evaluated}

Production and storage sites may be particularly polluted (Elfvendahl et al. 2004; Jit et al. 2010), but this pollution has never been taken into account. Half a million tons of obsolete pesticides are stored throughout the developing world (Food and Agriculture Organization 2011a), often outdoors, in leaky containers, resulting in particularly high levels of pollution of the surrounding soil and water (Ahad et al. 2010; Dvorská et al. 2012). Similarly, the sites at which pesticides are prepared and loaded into sprayers and at which tractors and sprayers are washed may be highly polluted (Helweg et al. 2002). Some costs are covered by the chemical companies themselves. However, this pollution generates externalities sensu stricto, through decreases in the price of land, houses and recreational activities close to the sites concerned (Epp et al. 1977).

The cost of damage to wildlife has been counted only for birds and fishes. However, as indicated in Sect. 2.6.1.1, many other non-human vertebrates are also damaged by pesticide use. Similarly, the monetary cost of pesticide impact on aquatic invertebrates, plants, algae and the soil community has never been estimated.

The direct costs of bird and fish losses have been estimated, but several indirect costs associated with these losses have yet to be analyzed. Indeed, birds and fish provide several ecosystem services. Birds make a significant contribution to the four principal types of ecosystem services defined by the United Nations Millennium Ecosystem Assessment: provisioning, regulating, cultural and supporting services. In agricultural ecosystems, they control pests, by eating arthropods, rodents and weeds (Whelan et al. 2008). Interestingly, James (1995) estimated the cost of bird losses in Canada, by setting the cost of an individual bird at the cost of achieving the same level of insect control with insecticides, if the birds were absent. This clearly corresponds to only part of the economic advantage birds provide to humans. Indeed, in addition to their contribution to pest control, birds also play significant roles in pollination, seed dispersal, and scavenging (Whelan et al. 2008). 
Arthropods also provide substantial ecosystem services. However, the studies performed to date have considered only the lack of pest control provided by natural enemies killed by pesticides. However, like bees, 'wild' insects provide other services in addition to pest control, including pollination, dung burial and food for wildlife (Losey and Vaughan 2006).

\subsubsection{Conclusions}

The cost of the environmental impact of pesticides has been poorly investigated to date. Only 15 sets of studies have evaluated these costs, and these studies were actually based on only 11 independent datasets. Only six studies provided an overall cost assessment at national level. The pioneering work of David Pimentel in the United States remains the key reference, but this work dates from the 1980s and 1990s, with a partial update published in 2005, 2009 and 2014. Although Pimentel and coworkers provided the most complete evaluation of environmental impairment available, we have shown that this assessment was probably highly incomplete, with a strong underestimation of costs.

It should be borne in mind that the current environmental impact of pesticide use is probably very different from that during the 1980s and 1990s (see Sect. 2.8.4). In North American and European countries, the most dangerous and persistent pesticides (e.g. DDT, carbofuran) have been banned and partly replaced by less toxic and less persistent compounds, strongly decreasing the impact on birds and fish. However, other countries, such as India and China, are still producing, exporting and using DDT (van den Berg et al. 2012). Moreover, pesticide resistance has steadily increased over the last 30 years (Rex Consortium 2013). The doses of pesticides applied to many crops are, therefore, almost certainly higher than in the past, resulting in a greater impact on the environment.

To conclude on environmental costs of pesticide use, we show that they suffered large underestimation and most of them were never considered in the literature. They were nevertheless estimated to up to US\$8 billion (2013) in the United States in 1992.

\subsection{Defensive Expenditures}

The aversive behavior approach estimates the amount that someone is willing to pay to reduce their environmental exposure to hazardous chemicals, such as pesticides (Dickie 2003). This expenditure can be seen as an investment, to protect against both short- and long-term illnesses. As for the cost-of-illness approach, different names have been given to the costs due to aversive behavior: averting costs, precautionary costs, mitigating costs, revealed willingness to pay for safety and defensive 
expenditures (Wilson 1999a). In this review, we will use the term "defensive expenditures". Defensive expenditures can be either private if incurred by the farmers themselves or external if incurred by consumers (Pearce and Tinch 1998) (Table 2.1). Defensive expenditures may be incurred due to several types of aversive behavior, such as wearing protective clothes when applying pesticides for farmers, monitoring and removing pesticides from drinking water for consumers, and eating organic food to avoid, or at least reduce the levels of pesticide residues on food for consumers.

\subsubsection{Defensive Expenditures for Pesticide Handling and Spraying}

Farmers take safety measures when handling and applying pesticides to their crops, to decrease or prevent direct exposure to these chemicals. The defensive expenditures taken into account include costs associated with precautions taken to reduce direct exposure to pesticides, such as masks, caps, shoes/boots, handkerchiefs, longsleeved shirts/pants (Table 2.11). These products may have multiple uses, but only products purchased specifically for the use and handling of pesticides are considered and their costs are generally annualized according to the expected lifespan of the product (e.g. Atreya 2008). Wilson (1999a, 2000b, 2003, 2005) considered the hiring of personnel to spray pesticides as a defensive activity, and therefore included this expense as defensive expenditures.

Only 13 articles have estimated the cost of defensive expenditures, and these estimates were based on only seven independent datasets (Table 2.1). This small number of studies considering defensive expenditures may be accounted for by defensive expenditures not being an externality sensu stricto. These costs are paid by farmers, which accounts for their lack of inclusion in studies focusing on the external costs of pesticide use such as those performed by Pimentel and coworkers.

Two groups of authors, in particular, have explored the defensive expenditures of farmers: Clevo Wilson (Wilson 1999a, b, 2000b, 2002b, 2003, 2005) and Athukorala et al. (2012) in Sri Lanka and Kishor Atreya (Atreya 2005, 2007, 2008 and Atreya et al. 2012, 2013) in Nepal. We were able to identify only one other studying exploring defensive expenditures, by Ajayi et al. (2002), in Mali.

In Nepal and Sri Lanka, farmers were found to spend a mean of between US\$6 and US\$32 (2013) per year on defensive expenditures (Table 2.11). Ajayi et al. (2002) estimated that farmers in Mali would need to spend US\$30 to US\$60 (2013) per year on equipment to ensure that they were protected against pesticide exposure. Wilson (Wilson 1999a, 2000b, 2003, 2005) and Athukorala et al. (2012) used data obtained directly from farmers to estimate the annual cost for the whole of Sri Lanka. They estimated these costs at between US $\$ 1$ million (2013) if only $5 \%$ of the farmers used pesticides and US\$10 million (2013) if $20 \%$ of the farmers used pesticides (Table 2.11). 

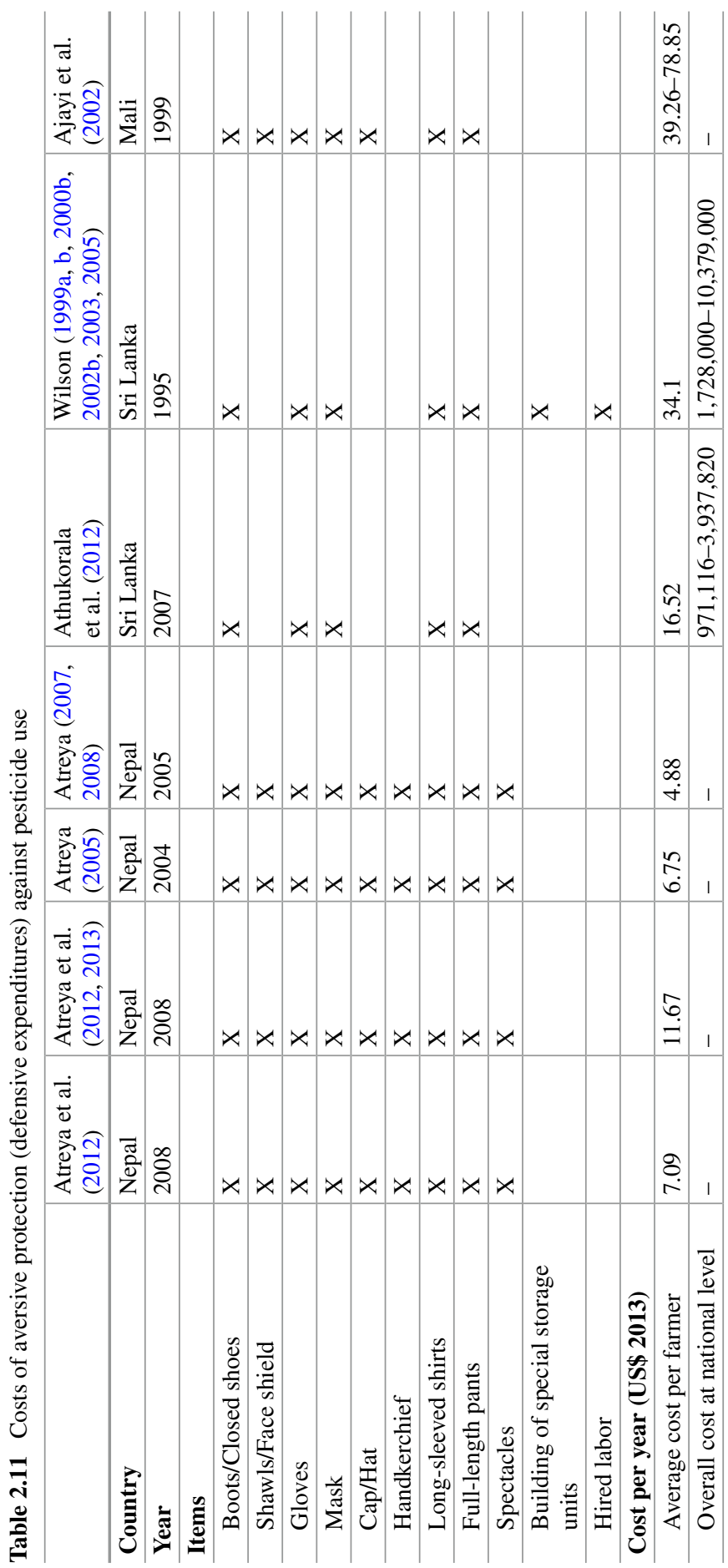
In Nepal, defensive expenditures accounted for about $15 \%$ of the total cost of pesticide use and $27 \%$ of pesticide expenditure, i.e. the amount spent on purchasing pesticides in a year. Defensive expenditures were slightly higher (Atreya 2008) or slightly lower (Atreya et al. 2012, 2013) than the cost-of-illness, but essentially of a similar magnitude. In Sri Lanka, Athukorala et al. (2012) found these costs to be one quarter those for medical expenditure and one seventh the loss of earnings; costof-illness was thus 11 times higher than defensive expenditures (Wilson 1999a). Nevertheless, in this country, annual defensive expenditures corresponded to $12 \%$ of the monthly income of a farmer (Athukorala et al. 2012; Wilson 1999a, 2000b, 2003, 2005). These costs, although low, could be a significant burden to farmers, whose incomes fluctuate greatly, due to adverse biotic, e.g. pest and disease damage, and abiotic, e.g. weather conditions, crop price fluctuations, conditions.

Several types of defensive expenditures have not been considered, probably due to data, time and financial constraints. The elements not analyzed include the purchase of more expensive sprayers less likely to malfunction and place the user at risk of exposure. They also include the time spent purchasing, cleaning and fixing defensive/protective equipment, and reading 'warnings and instructions'. Precautionary drug treatment to protect against pesticide exposure and leisure time given up in favor of aversive behavior should also be taken into account. The estimates to date therefore almost certainly constitute the lower limit of the range of actual defensive expenditures paid by farmers to reduce their exposure to pesticides.

Moreover, in developing countries, these costs could probably be increased to levels much higher than those currently observed, as pesticide users often adopt few protective measures (Food and Agriculture Organization 2011b). Spraying is sometimes carried out without protection and even those farmers who do try to protect themselves generally limit this protection to the wearing of long-sleeved shirts and long pants. Low levels of income, awareness and education, the hot and humid climate, cultural taboos, fashion and discomfort are significant factors accounting for the lack of personal protection (Atreya et al. 2013) (Fig. 2.1).

Sivayoganathan et al. (1995) reported that some Sri Lankan farmers were keen to use protective measures but did not do so due to cultural taboos, such as wearing shoes in the field. The field is seen as a sort of "temple" because the land within it produces food. Another cultural taboo mentioned concerned the wearing of long pants during pesticide applications, which many farmers, especially the elderly, were reluctant to do, due to their low socioeconomic status.

Finally, not only might farmers be unable to afford adequate precautionary/ defensive measures, but the protective gear required may be unavailable as it may not be sold by any shop to which the farmer has access. Hence, defensive expenditures have never been correctly counted, both because the actual expenses were not fully estimated and because they could potentially be much higher than they currently are, particularly in developing countries. 


\subsubsection{Defensive Expenditures for Safe Drinking Water}

The presence of pesticides in tap water may be one of the key reasons for consumers buying bottled water or drinking purified or filtered water. These sources of water are much more expensive for the consumer than tap water. The excess costs of purified or bottled water over tap water could be considered as both a private cost borne by farmers if they drink such water and as an external costs to non-farming consumers buying such water. The production and transportation of bottled water also require the consumption of massive amounts of fossil fuels (Gleick and Cooley 2009). Finally, the bottles degrade slowly, and their incineration can produce toxic byproducts. Bottled water thus has an environmental impact between 90 and 1000 times greater than that of tap water (Jungbluth 2005). The resulting pollution can be considered as a negative externality for society as a whole. However, if the production, transportation and purchase of bottled water and all devices for water purification or filtration are to be considered as defensive expenditures, and hence as external costs, these expenditures should be made specifically to protect against pesticide residues. This relationship is anything but simple.

Consumers choose to drink bottled, purified or filtered water for two main reasons: because they think this water tastes better and/or is safer than tap water (Doria 2006; Doria et al. 2009; Dupont et al. 2010). Several factors are known to influence the public perception of drinking water quality: organoleptic properties, risk perception, attitude towards water chemicals, past problems attributed to water quality, trust in water companies, information from the mass media and family members (Doria 2010). Hence, the presence of pesticides, whether real or imagined, in tap water may be only one of a number of factors pushing people to buy bottled water and/or to drink purified or filtered water. Unfortunately, we were able to identify no study specifically exploring this question. Studies on factors influencing drinking behavior have considered chemical pollutants either as a general entity, i.e. with no specification of the type of chemical substance (e.g. Auslander and Langlois 1993), or have concentrated on lead, chlorine and/or water hardness, e.g. the survey of Statistics Canada (2009), which specifically mentioned chlorine. Pesticides, like other chemical substances including fluoride, nitrates, heavy metals and industrial chemicals, are sometimes specified, but, according to Doria (2010), their relevance to the perception of drinking water safety appears to be very limited or restricted to specific locations.

No specific data are available for pesticides, but several studies have explored the influence of chemicals on the water-drinking behavior of consumers, notably in Canada. In Toronto, $73 \%$ of those questioned felt that tap water contained "some" or "a lot" of chemical pollutants, but half the households overall rated this source of water as "good" or "very good" (Auslander and Langlois 1993). In a more recent national survey of a representative sample of 1633 Canadians, $62 \%$ felt that tap water posed no problem for health (Dupont et al. 2010). Only $12 \%$ and $3 \%$ believed that this source of water posed moderate or serious problems for health, respectively. In their study focused in one Canadian province, McLeod 
et al. (2014) also found that no more than $12 \%$ of the 2000 respondents believed tap water to be unsafe to drink. Noteworthy, those respondents who believed tap water to be unsafe appeared more likely to choose bottled water (McLeod et al. 2014). In other countries with reliable supplies, surveys generally indicate that most people perceive the risk associated with drinking tap water to be small (Doria 2006). In low- and medium-income countries, in which tap water quality is often poorer, surveys of the motives for choosing bottled water over tap water have not been performed. However, in such countries, the average per capita consumption of bottled water is low.

In conclusion, the extra cost of drinking bottled, purified and filtered waters, rather than tap water, cannot be firmly attributed to the presence of pesticides. Of course, consumers indirectly pay for the monitoring and elimination of pesticides from the tap water they use, as these costs are passed on by water companies, through the billing process. We decided to count these costs as regulatory rather than as defensive expenditures because, as indicated in Sect. 2.4, monitoring and decontamination processes are mandatory in most countries: see the United States Safe Drinking Water Act (http://water.epa.gov/lawsregs/rulesregs/sdwa/index.cfm), for example.

Pesticides trigger defensive expenditures when they are detected in tap water at levels beyond the threshold considered acceptable, thus causing a decrease in quality. The monitoring of private wells, which are generally not regulated by public authorities, and the use of filtering/purifying devices for detecting and eliminating pesticides from these wells can also be considered as defensive expenditures.

Water quality violations may trigger aversive behavior, such as the purchase of bottled water. When such violations are due to pesticide contamination (e.g. Zaki et al. 1982), the increased in the purchase of bottled water in the area concerned may be considered defensive expenditures. Zivin et al. (2011) estimated that, in 2005, United States citizens spent US\$47.15 million (2005) in response to element/chemical violations of water quality. They indicated that this estimate probably constituted the lower limit of the cost of defensive expenditures, because they only considered bottled water consumption and did not include other responses to violations, such as purchasing alternative beverages, e.g. juice, other actions people may have taken, e.g. boiling water, and more permanent responses, e.g. installing water filters. Zivin et al. (2011) did not provide details of the elements/chemicals responsible for the quality violations. We know only that they did not include nitrate, which was counted separately. It is therefore difficult to determine what proportion of the costs corresponded to pesticide contamination. Similarly, Dupont and Jahan (2012) estimated that Canadian households spent almost US\$600 (2010) per year on tap water substitutes (purchase of bottled water and devices for filtering/purifying tap water), to decrease the perceived health risks associated with tap water consumption. Unfortunately, the influence of pesticides on this perception was not investigated.

The second type of defensive expenditures concerns the monitoring and decontamination of private wells and small-scale public systems. As indicated above, in the United States, state and federal authorities do not generally regulate these sources of drinking water. The householders concerned therefore pay for the detec- 
tion of pesticides in these wells and their elimination. In the United States, 15 million households regularly obtain drinking water from their own private wells (United States Environmental Protection Agency 2002) and the groundwater in those wells may be contaminated with pesticides, particularly in rural areas (Toccalino et al. 2014). Pesticides, such as atrazine, deethylatrazine, simazine, metolachlor, and prometon are, indeed, regularly detected in groundwater and wells (Goss et al. 1998; Hallberg 1989; Ritter 1990, 2001; Toccalino et al. 2014). However, pesticide concentrations in North American domestic wells were found to be generally low. In Ontario, for instance, only six of the 1292 water-wells surveyed contained pesticide residues at concentrations above the maximum acceptable value (Goss et al. 1998). Similar findings were reported for the United States: for the 1993-2011 period, pesticide concentrations exceeded human-health benchmarks in only $1.8 \%$ of the 2541 samples collected from 1271 wells in well networks distributed nationwide (Toccalino et al. 2014). However, pesticide contamination rates and concentration may reach higher values in some countries. In the Netherlands, several pesticides were detected in $27 \%$ of groundwater samples taken from 771 monitoring wells. In $11 \%$ of these samples, the concentration exceeded the upper regulatory limit (Schipper et al. 2008).

Worldwide, the most important contaminant of groundwater and private wells, in terms of health concerns, is arsenic (Nordstrom 2002). Arsenic contamination may have diverse sources, some of which are entirely natural, as in Bangladesh (Nickson et al. 1998). However, arsenic contamination may also result from local anthropogenic activities, such as mining (Mukherjee et al. 2006). In Canada and the United States, significant amounts of arsenic contamination result from the use of arsenicbased pesticides (Smedley and Kinniburgh 2002; Wang and Mulligan 2006).

According to the Massachusetts Department of Environmental Protection, testing a well for arsenic costs US $\$ 15$ to US $\$ 30$. Treatment systems for removing arsenic (reverse osmosis, activated alumina) cost at least US\$400 per year (Sargent-Michaud et al. 2006). In addition to the costs of monitoring and testing, the presence of arsenic may also increase the consumption of bottled water (Jakus et al. 2009). As arsenic comes from diverse sources, which may vary over space and time, it is not easy to evaluate defensive expenditures due to arsenic-based pesticides. However, in the United States, where 15 million households regularly obtain drinking water from their own private wells, this cost might reach several hundred million US\$ per year.

\subsubsection{Defensive Expenditures to Avoid Pesticide Residues in Food: The Purchase of Organic Food}

Consumers choose to purchase organic food for several reasons, some of which are linked to the externalities of pesticides and to a demand for pesticide-free food (Fotopoulos and Krystallis 2002; Misra et al. 1991; Squires et al. 2001; Tsakiridou et al. 2008; Williams and Hammitt 2001) (Fig. 2.6). Most consumers of organic 


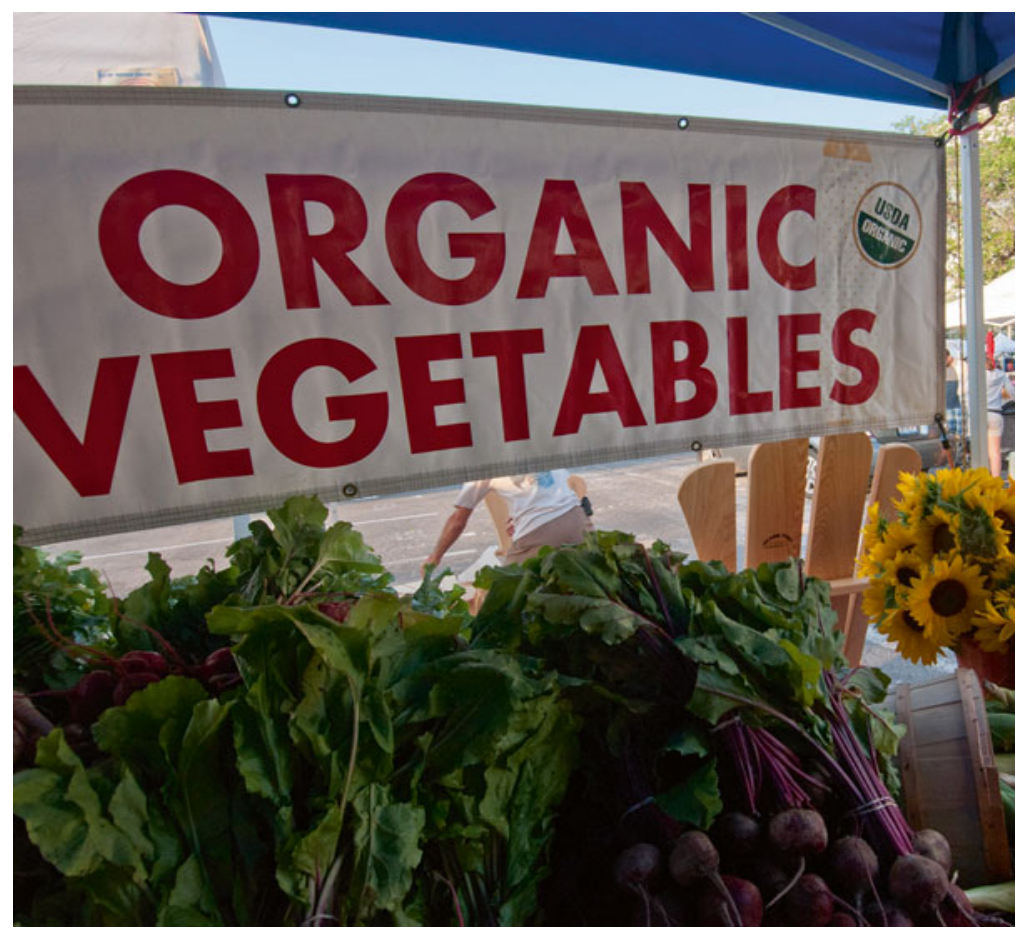

Fig. 2.6 Consumers choose to purchase organic food for several reasons, but partly as a consequence of the perceived negative risk of pesticides to the environment and to the consumer. The world market for organic food has grown considerably over the last 15 years: it almost tripled between 2000 and 2008 and continued to grow thereafter, from US\$50 billion in 2008 to US\$64 billion in 2012 (Sahota 2014). Assuming that prices in this market are $20 \%$ higher than those of conventional food and that about $50 \%$ of the reasons for consumers choosing organic food are directly linked to the avoidance of pesticide risk (e.g. Schifferstein and Oude Ophuis 1998), then the added cost of pesticide use may be about US\$6.4 billion (2013) worldwide (Unmodified USDA photography courtesy of Sam Jones-Ellard, under creative common license CC BY (https://creativecommons.org/licenses/by/2.0/))

food declare that the main reasons for this choice are connected to personal health and the avoidance of environmental damage (e.g. Huang 1996; Hughner et al. 2007; Magnusson et al. 2003; Saba and Messina 2003; Schifferstein and Oude Ophuis 1998; Schlegelmilch et al. 1996; Squires et al. 2001; Tregear et al. 1994; Wier et al. 2008). In Greece, about $90 \%$ of general consumers consider organic food to be healthier than conventionally farmed food, and $75 \%$ think that it is better for the environment; even higher percentages were recorded among the consumers of organic food (Tsakiridou et al. 2008). Animal well-being, taste or simply fashion are other factors less frequently proposed by consumers to explain their choices (Pearson et al. 2011). Parents of young children and babies are among those most likely to consume organic food, as a proactive measure, to prevent health problems (Pearson et al. 2011). Another reason cited for buying organic food is also linked to 
health, with some ill individuals choosing to buy organic food because they hope that it will help them to recover more rapidly (Pearson et al. 2011). Health is thus a key motive behind organic food consumption. Another reason often given for purchasing organic food is that it decreases damage to the environment, and this idea is generally supported by scientific evidence (e.g. Mäder et al. 2002; Gomiero et al. 2011). Buying organic food is thus partly a consequence of the perceived negative risk of pesticides to the environment and to the consumer.

Organic food consumption can thus be considered, at least in part, as an externality of pesticide use if organic food is more expensive than non-organic, conventional foods. Comparisons of the organic and conventional food markets show that organic food is generally more expensive than conventionally produced food (e.g. BontiAnkomah and Yiridoe 2006). The excess cost of organic food varies considerably between countries and products (Bonti-Ankomah and Yiridoe 2006) and is dependent on several factors. However, according to several studies, the lower limit for this price premium would lie somewhere between $10 \%$ and $20 \%$ (e.g. BontiAnkomah and Yiridoe 2006; Rodríguez et al. 2008), although price premiums of between $50 \%$ and more than $100 \%$ were reported in the United States in 2013 for fruits and vegetables, respectively (see the web page on Organic prices of the United States Department of Agriculture Economic Research Service: http://www.ers.usda. gov/data-products/organic-prices.aspx\#.VAmF0mTV_sk). This price premium, paid by the consumers of organic food thus corresponds, at least in part, to the consumers' willingness to pay for avoiding pesticide risks (Onozaka et al. 2006) and, more precisely, to the hedonic estimation of willingness to pay for a reduction of the presence of pesticides in food. The range of values for the mean price premium of organic food has been confirmed by studies of the willingness to pay for organic food carried out with the contingent valuation technique. Consumers were asked to set a value on the premium they would be prepared to pay for organic food rather than conventionally produced food. These studies also highlighted considerably variability in the responses obtained (e.g. Zehnder et al. 2003; reviewed by BontiAnkomah and Yiridoe 2006), but they frequently suggested that the minimum value was about 10-20\% (e.g. Bonti-Ankomah and Yiridoe 2006; Gil et al. 2000; Onozaka et al. 2006; Rodríguez et al. 2008).

The worldwide organic food market was of the order of US\$64 billion in 2012 (Sahota 2014), equally split between Europe (US\$29 billion) (Schaack et al. 2014) and the United States (US\$29 billion) (Fitch Haumann 2014). In Europe, the organic food market in 2012 represented about US\$9 billion in Germany, US\$5 billion in France and US $\$ 2.5$ billion in the United Kingdom (Schaack et al. 2014). The world market for organic food has grown considerably over the last 15 years: it almost tripled between 2000 and 2008 and continued to grow thereafter, from US\$50 billion in 2008 to US\$64 billion in 2012 (Sahota 2014).

If we assume that prices in this market are $20 \%$ higher than those of conventional food and that about $50 \%$ of the reasons for consumers choosing organic food are directly linked to the avoidance of pesticide risk (e.g. Schifferstein and Oude Ophuis 1998), then the added cost of pesticide use is about $10 \%$ of the total market value of organic food. This amounts to US\$2.9 billion for the United States and 
Europe, and about US $\$ 0.9$ billion for Germany, US\$0.5 billion for France, and US $\$ 0.25$ billion for the United Kingdom. Griffith and Nesheim (2008) used hedonic prices and purchase quantities for 2003 and 2004 in the United Kingdom to estimate the aggregate lower limit of willingness to pay for organic products. They obtained a value of about $22 \%$ of the annual expenditure on organic products, corresponding to about US $\$ 0.55$ billion, based on the figures obtained for the organic market in the United Kingdom in 2012. Griffith and Nesheim (2008) estimated that about $20 \%$ of the lower limit of the willingness to pay was directly linked to health and environmental concerns - about US\$110 million, corresponding to $44 \%$ of our estimate of US\$0.25 billion.

\subsubsection{Conclusion}

Defensive expenditures have rarely been considered among the external and "hidden" costs of pesticide use. For instance, we found no study considering the defensive expenditures of both farmers and consumers. In particular, the consumption of organic food as a defensive action against pesticide residues has never been fully considered as a negative externality of pesticide use. Indeed, all studies to date on the economics and rationale of organic food consumption have been completely disconnected from studies analyzing the benefit-cost ratio of pesticide use.

In general, aversive actions have been little studied and, when considered, they have generally been restricted to the protection of the body and respiratory system by farmers handling or applying pesticides. However, these costs are only part of the costs directly borne by farmers.

Furthermore, aversive actions could be carried out on a much wider scale than is currently the case. This is certainly true for protective clothing, which is rarely worn by farmers in most developing countries, and for the monitoring and decontamination of drinking water. If all owners of private wells carried out monitoring and were equipped with a filter/purifier, or if the consumption of bottled water continues to grow, then defensive expenditures to avoid residues in drinking water could rise exponentially. However, it should be borne in mind that these costs are somewhat linked to cost-of-illness. If tap water contains pesticide residues at levels that may injure human health, then an increase in defensive expenditures should lead to a decrease in cost-of-illness. Put another way, some of the current cost-of-illness could be due to a lack of aversive action. Alternatively, an increase in defensive expenditures might decrease the overall cost of pesticide use if these additional defensive expenditures are overcompensated by the decrease in cost-of-illness they trigger. Similarly, an increase in the consumption of organic food might decrease the cost-of-illness by reducing chronic illness although the relationship between exposure to low pesticide doses and chronic illnesses remains very difficult to quantify.

Here, we show that defensive expenditures have rarely been considered in the literature of pesticide use cost. These costs include at least the extra cost of organic food consumption due to aversive behavior linked to pesticide use. This cost reached more than US\$6.4 billion worldwide in 2012. 


\subsection{Overall Hidden and External Costs}

Pesticide use has a marked positive impact on agriculture (Cooper and Dobson 2007; Gianessi 2009; Gianessi and Reigner 2005, 2007) and human health (Cooper and Dobson 2007). However, as highlighted above, it also has a significant negative impact on the environment and on human health, and entails economic costs linked to regulations and defensive actions. It is therefore worthwhile estimating the global cost of pesticide use, for comparison with the economic benefits, with a view to reevaluating the overall economic balance of pesticide use (see Sects. 2.9.1 and 2.9.2). This is a prerequisite for the evaluation of public policies concerning pesticide use, including the reduction of pesticide use (e.g. Barzman and Dachbrodt-Saaydeh 2011; Löfstedt 2003). Unfortunately, several current policies relating to the reduction of pesticide use are based on estimates that do not consider the global cost of pesticide use, including external costs, but only the benefits in terms of agricultural production, e.g. the Ecophyto 2018 plan of the French government, which aims to halve pesticide use over a 10-year period (Jacquet et al. 2011). In evaluations of the consequences of regulations aiming to decrease pesticide use, very different conclusions may be reached depending on whether the global costs of pesticide use are (Pimentel et al. 1993b; Pimentel 2005; Pimentel and Burgess 2014) or are not (Gianessi 2009; Gianessi and Reigner 2005, 2007; Jacquet et al. 2011) taken into account. This section reviews the few studies that have tried to estimate the overall hidden and external costs at national level. We will see that such costs are underestimated and that the available estimates are out-of-date. By comparing different datasets and estimating the specific costs that were not estimated in previous studies, we tried to perform a more complete evaluation of the hidden and external costs of pesticide use in the United States at the beginning of the 1990s.

\subsubsection{A Small Numbers of Estimates}

We found only ten independent groups of papers combining estimates of regulatory, environmental and human health costs at the national level. These groups of studies are those of Ajayi et al. (2002) for Mali, Houndekon and De Groot (1998) and Houndekon et al. (2006) for Niger, Jungbluth (1996) and Praneetvatakul et al. (2013) for Thailand, Khan et al. (2002) for Pakistan, Pimentel and coworkers (Pimentel et al. 1980a, b, 1991a, b, 1992, 1993a, b; Pimentel and Greiner 1997; Pimentel and Hart 2001; Pimentel 2005; Pimentel and Burgess 2014), Steiner et al. (1995) and Tegtmeier and Duffy (2004) for the United States, Pretty et al. (2000, 2001) for the United Kingdom, and Fleischer and coworkers (Fleischer 1999; Waibel and Fleischer 1998; Waibel et al. 1999) for Germany.

These articles revealed considerable heterogeneity for overall hidden and external costs, which ranged from US\$5.4 million (2013) in Niger in 1996 (Houndekon and De Groote 1998; Houndekon et al. 2006) to US\$13.6 billion (2013) in the 
United States in 1992 (Pimentel et al. 1992, 1993a, b) (Table 2.12). For the United States, the estimates of Pimentel and coworkers also varied over time. They reported overall hidden and external costs of US\$2.7, 3.7, 13.6, 11.8 to 12.1 and 11.7 billion (2013) in 1980, 1991, 1992, 1997 and 2005, respectively (Table 2.12). These differences mostly reflected differences in the types of costs taken into account. Hence, from 1991, Pimentel and coworkers included the cost of monitoring wells and groundwater, accounting for $55 \%$ of the external costs. From 1992, they also estimated the cost of bird losses, accounting for $25 \%$ of the external costs, and reevaluated the cost of pesticide resistance from about $7-17 \%$ of the external costs.

\subsubsection{Overall Costs Are Underestimated}

The overall hidden and external costs reported above are underestimated for two reasons. First, none of the available estimates include defensive expenditures (Table 2.13). Second, as shown above, they did not take into account some, or even in some cases most of the specific costs within the other three cost categories, i.e. environmental impact, human health and regulatory actions (Table 2.13). For instance, losses of reptiles, amphibians, soil and aquatic communities and wild vertebrates other than birds and fish have never been evaluated (Table 2.13). Similarly, the costs of the human health impact of pesticide use have not been fully explored. Pimentel et al. estimated the costs of cancer treatment, but they did not calculate the cost of deaths due to these cancers (Table 2.13). Finally, none of the estimates took into account major environmental disasters associated with pesticide production and disposal sites. The dramatic pesticide industry accidents at Bhopal in India (Mishra et al. 2009) (Fig. 2.7) and Seveso in Italy (Consonni et al. 2008), together with less severe incidences, such as the James River kepone disaster in the United States (Huggett and Bender 1980), caused thousands of deaths and long-term disorders in humans, together with damage to the soil, animals and plants that could probably be estimated at several billion of US\$.

This bias towards an underestimation of external costs is not related to a lack of rigor on the part of the authors conducting these studies. Instead, it results principally from the difficulties involved in estimation of the economic costs of the unintentional impacts of pesticide use, particularly for goods without market values. Indeed, Pimentel and Greiner (1997) pointed out that the scarcity of data made their assessments of the external costs inaccurate, such that the costs themselves had to be considered incomplete. Hence, as indicated by Waibel et al. (1999), most estimates of external costs performed to date must be considered as minimum costs. 


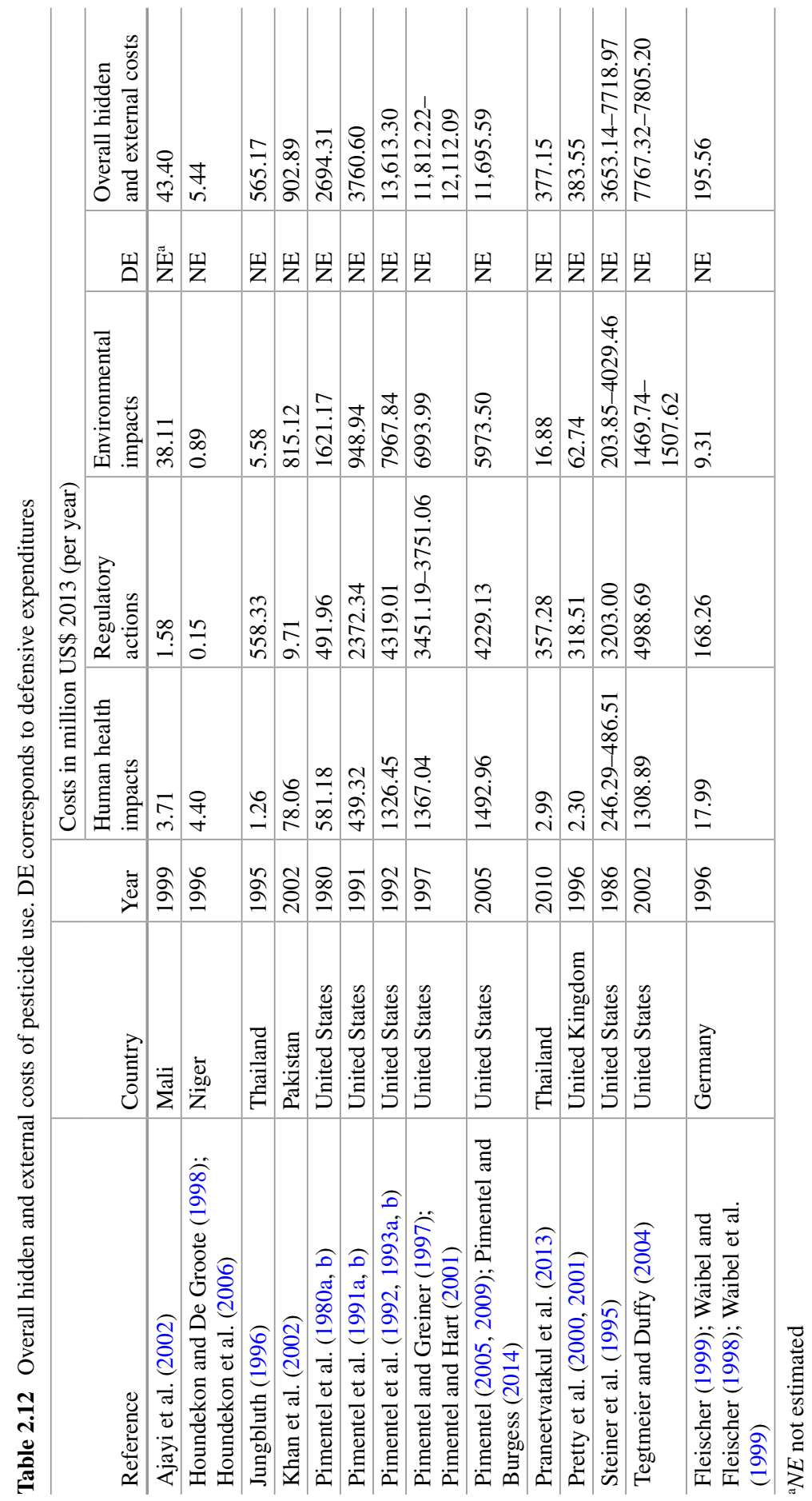


Table 2.13 Cost taken (green) or not (red) into account in the estimates of the overall cost of pesticide use

\begin{tabular}{|c|c|c|c|c|c|c|c|c|c|c|c|c|}
\hline Category of cost & 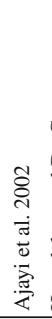 & 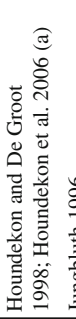 & 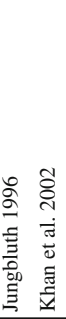 & 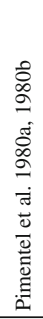 & 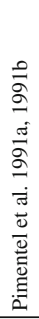 & 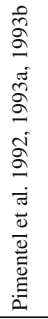 & 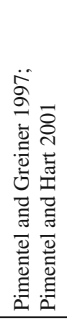 & 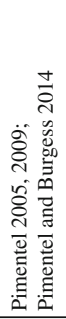 & 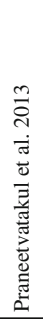 & 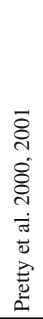 & 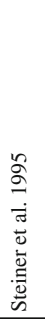 & 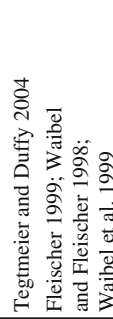 \\
\hline
\end{tabular}
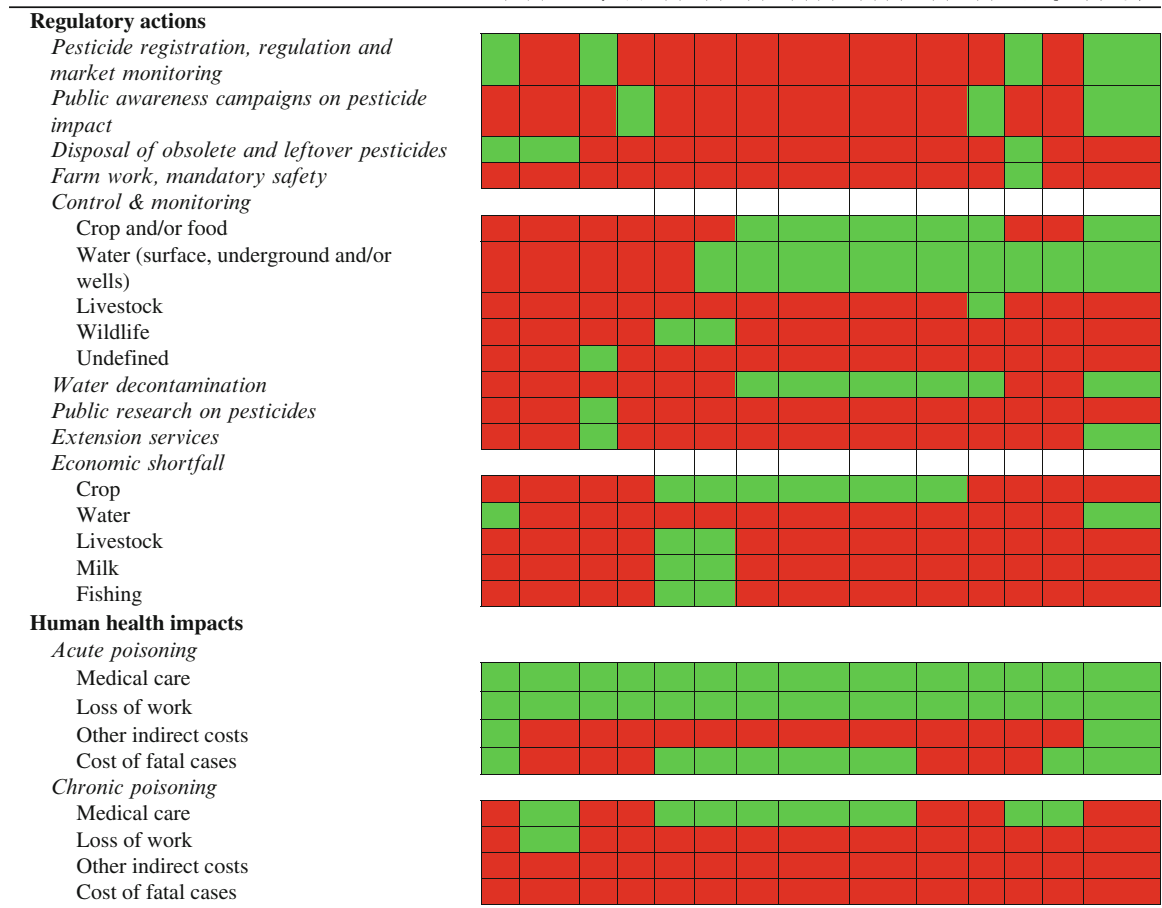

\section{Environmental impact}

Damageto animals, plants, algae and microorganisms

Crops/cultivated plants/trees

Wild plants (other than weeds)

Domestic animals and livestock

Fish

Birds

Wild vertebrates (other than birds and fish)

Bees

Natural enemies

Invertebrates (other than bees and

natural enemies)

Soil community

Aquatic communities (other than fish)

Pest resistance to pesticides
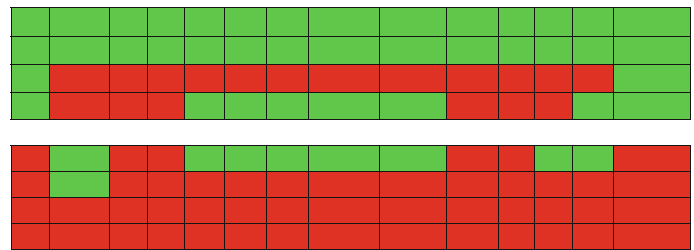

Defensive expenditures (DE)

$D E$ for pesticide handling and spraying

DE for safe drinking water

Purchase of organic food

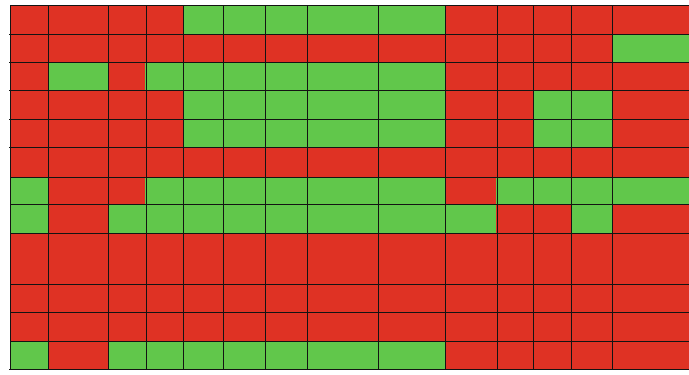

${ }^{a}$ Houndekon et al. (2006) took chronic poisoning partly into account in their estimates, but it is impossible to know the extent to which this was done. Indeed, they merely asked farmers to state how much money they spent on medication, consultations and loss of working days during the year, without specifying the type of health effect (acute or chronic, and, for chronic effects, the corresponding illnesses) 


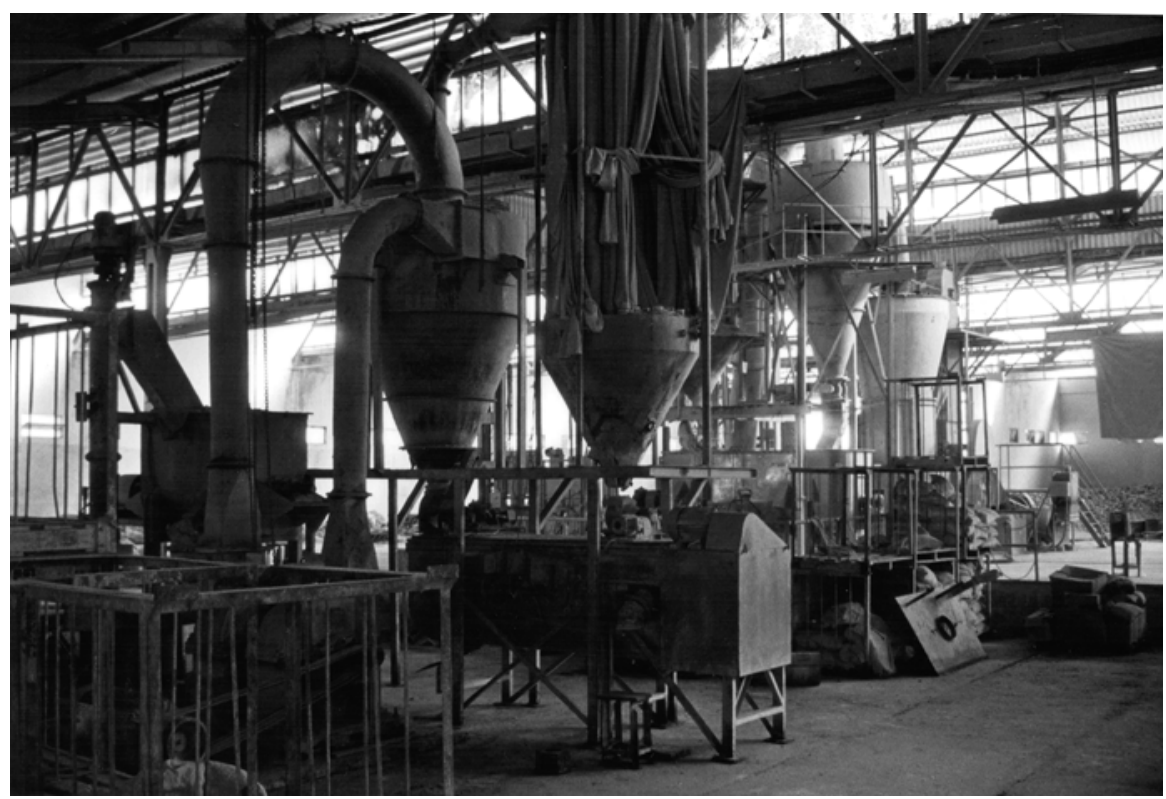

Fig. 2.7 The Abandoned Union Carbide Pesticide Plant, Bhopal, India. This production site gave probably the most dramatic pesticide industry accidents of the history (Mishra et al. 2009). This disaster led to the death of several thousands of people and induced long-term disorders in humans, together with damage to the soil, animals and plants that could probably be estimated at several billion of US\$ (Unmodified photography by Bhopal Medical Appeal, under Creative Common License CC BY-SA (https://creativecommons.org/licenses/by-sa/2.0/))

\subsubsection{A Re-evaluation of the Overall Costs for the United States at the Start of the 1990s}

As authors sometimes evaluate different impacts, we felt that it would be possible to perform a more complete evaluation of the external cost of pesticide use in the United States at the start of the 1990s (Table 2.14). For this purpose, we used the estimates of Pimentel et al. (1992), but we (i) actualized some external costs already estimated by these authors, e.g. honeybee and pollination losses, (ii) corrected some of their costs by taking additional data into account, e.g. bird losses, (iii) included several costs that were not evaluated by Pimentel et al. (1992), e.g. deaths due to chronic poisoning, the purchase of organic food, and (iv) removed costs that were theoretical rather than actual, e.g. wells and groundwater monitoring and decontamination, economic shortfall due to crop contamination and the disposal of contaminated crops. We ended up with a cost of US\$35.2 billion (2013) (Table 2.14), a value 2.5 times higher than the original value of US\$13.6 billion (2013) estimated by Pimentel et al. in 1992 (Table 2.12).

This new estimate is more complete, but it remains conservative because a number of costs, e.g. the loss of reptiles, amphibians, soil and aquatic communities and 
wild vertebrates other than birds and fish, the costs of acute and chronic poisoning, the purchase of bottled water and purifying devices to protect consumers against pesticide exposure, are still not included. In addition, we decided to remove from the overall sum the costs of monitoring and decontaminating wells and groundwater, and the economic shortfall due to crop contamination (Table 2.14). We removed these economic shortfalls due to crop contamination because they were conditional on the absolute respect of United States regulations, which would be unrealistic (Pimentel 2005). Pimentel et al. (1992) calculated the cost of monitoring and decontaminating all wells and groundwater, even though these activities were not actually carried out. As indicated above, it should be borne in mind that some of the human health costs to society would disappear if all wells and groundwater were effectively cleaned. If we take some of these costs into account, the overall costs would probably have been between US $\$ 35.2$ billion and US $\$ 39.5$ billion (2013) at the end of the 1980s/start of the 1990s.

\subsubsection{Most, If Not All Overall Costs Are Out-of-Date}

The articles reviewed here were retrieved from more than 30 years of studies on the costs of pesticide use. Over this period, there has been a massive, rapid change in pesticide use, as a consequence of changes in governmental legislation, i.e. the establishment of higher standards for pesticide registration, and efficiency issues, i.e. due to the exponential increase in pesticide resistance within pest and pathogen populations. This has led to a change in the panel of active ingredients used, which is currently very different from that employed 10,20 or 30 years ago. DDT, one of the most noxious pesticides ever used, was one of the first agents to be banned, initially in the United States in 1972, and then in most other countries. In Europe, as in the United States, older pesticides are being reassessed one-by-one, to ensure that they meet the new regulatory standards (Damalas and Eleftherohorinos 2011). This re-registration process has already resulted in a substantial decrease in the number of pesticides available on the market: in an 8 year period (2001-2008), 704 pesticides were banned in Europe, $26 \%$ of which were insecticides, $23 \%$ herbicides and $17 \%$ fungicides (Karabelas et al. 2009). Of the 276 pesticides authorized for use in Europe in 2009, 194 existed before 1993 and 82 had been released onto the market in the last 20 years (Karabelas et al. 2009). However, two factors may limit the benefits expected from prohibition of the most dangerous active ingredients. First, resistance to pesticides has resulted in the need for higher doses to be applied. Second, pesticides are sometimes used after they are banned (Shetty et al. 2011).

In any case, the current impact of pesticides is necessarily different from that in the past. Hence, while reporting the impact of insecticide use on the decline of many grassland birds in the United States, Mineau and Whiteside (2013) wrote that their 'analysis considered bird trends from 1980 to 2003' and that 'there is evidence that the acute lethal risk to birds was already dropping during the second half of that period'. Indeed, Mineau and Whiteside (2006) noted that 'the lethal risk to birds 
Table 2.14 Re-evaluation of the overall hidden and external costs of pesticide use in the United States

\begin{tabular}{|c|c|c|c|c|}
\hline & \multicolumn{3}{|c|}{ In million US\$ } & \multirow[b]{2}{*}{ Reference } \\
\hline & $\begin{array}{l}\text { Original } \\
\text { estimate }\end{array}$ & $\begin{array}{l}\text { Year of } \\
\text { estimate }\end{array}$ & $\begin{array}{l}\text { Updated } \\
\text { estimates } \\
(2013)\end{array}$ & \\
\hline \multicolumn{5}{|l|}{ Cost } \\
\hline \multicolumn{5}{|l|}{ Human health } \\
\hline $\begin{array}{l}\text { Acute health effect (treatment } \\
\text { plus loss of work) }\end{array}$ & 61 & 1988 & 123 & $\begin{array}{l}\text { Steiner et al. } \\
(1995)^{\mathrm{a}}\end{array}$ \\
\hline Chronic (treatment of cancer) & 707 & 1992 & 1192 & $\begin{array}{l}\text { Pimentel et al. } \\
\text { (1992) }\end{array}$ \\
\hline $\begin{array}{l}\text { (loss of work for the person } \\
\text { with cancer) }\end{array}$ & - & - & 87 & Own calculations ${ }^{\mathrm{b}}$ \\
\hline Death due to acute poisoning & - & - & 405 & Own calculations ${ }^{\mathrm{c}}$ \\
\hline Death due to chronic poisoning & - & - & 18,000 & Own calculations ${ }^{\mathrm{d}}$ \\
\hline \multicolumn{5}{|l|}{\begin{tabular}{|l|l} 
Environmental impact & \\
\end{tabular}} \\
\hline $\begin{array}{l}\text { Domestic animal and livestock } \\
\text { death }\end{array}$ & 30 & 1992 & 51 & $\begin{array}{l}\text { Pimentel et al. } \\
\text { (1992) }\end{array}$ \\
\hline $\begin{array}{l}\text { Increase in pesticide use due to } \\
\text { the destruction of natural } \\
\text { enemies }\end{array}$ & 260 & 1992 & 439 & Pimentel (2005) \\
\hline $\begin{array}{l}\text { Crop losses due to pesticide } \\
\text { resistance }\end{array}$ & 1400 & 1992 & 2361 & $\begin{array}{l}\text { Pimentel et al. } \\
\text { (1992) }\end{array}$ \\
\hline Colony losses due to pesticides & 13 & 1992 & 22 & $\begin{array}{l}\text { Pimentel et al. } \\
\text { (1992) }\end{array}$ \\
\hline Honey and wax losses & 25 & 1992 & 43 & $\begin{array}{l}\text { Pimentel et al. } \\
\text { (1992) }\end{array}$ \\
\hline $\begin{array}{l}\text { Loss of potential honey } \\
\text { production }\end{array}$ & 27 & 1992 & 46 & $\begin{array}{l}\text { Pimentel et al. } \\
\text { (1992) }\end{array}$ \\
\hline Bee rental for pollination & 4 & 1992 & 7 & $\begin{array}{l}\text { Pimentel et al. } \\
\text { (1992) }\end{array}$ \\
\hline Pollination losses & 200 & 1992 & 337 & $\begin{array}{l}\text { Pimentel et al. } \\
\text { (1992) }\end{array}$ \\
\hline $\begin{array}{l}\text { Crop losses due to pesticide } \\
\text { injury }\end{array}$ & 136 & 1992 & 229 & $\begin{array}{l}\text { Pimentel et al. } \\
\text { (1992) }\end{array}$ \\
\hline $\begin{array}{l}\text { Crop losses due to the } \\
\text { destruction of natural enemies }\end{array}$ & 260 & 1992 & 439 & Pimentel (2005) \\
\hline $\begin{array}{l}\text { Insurance of the person } \\
\text { applying the pesticide }\end{array}$ & 245 & 1992 & 413 & $\begin{array}{l}\text { Pimentel et al. } \\
\text { (1992) }\end{array}$ \\
\hline Fishery losses & 100 & 2005 & 122 & Pimentel (2005) \\
\hline Bird losses & - & - & 5903 & Own calculations ${ }^{\mathrm{e}}$ \\
\hline $\begin{array}{l}\text { Re-establishement of } \\
\text { endangered birds }\end{array}$ & 102 & 1992 & 172 & $\begin{array}{l}\text { Pimentel et al. } \\
\text { (1992) }\end{array}$ \\
\hline \multicolumn{5}{|l|}{ Regulatory actions } \\
\hline $\begin{array}{l}\text { Monitoring and } \\
\text { decontamination of pesticide- } \\
\text { polluted groundwater }\end{array}$ & 1800 & 1992 & 3036 & $\begin{array}{l}\text { Pimentel et al. } \\
(1992)^{\mathrm{f}}\end{array}$ \\
\hline
\end{tabular}


Table 2.14 (continued)

\begin{tabular}{|c|c|c|c|c|}
\hline & \multicolumn{3}{|c|}{ In million US\$ } & \multirow[b]{2}{*}{ Reference } \\
\hline & $\begin{array}{l}\text { Original } \\
\text { estimate }\end{array}$ & $\begin{array}{l}\text { Year of } \\
\text { estimate }\end{array}$ & $\begin{array}{l}\text { Updated } \\
\text { estimates } \\
(2013) \\
\end{array}$ & \\
\hline $\begin{array}{l}\text { Pesticide registration, } \\
\text { certification, cancellation, } \\
\text { training and farm work safety }\end{array}$ & 757 & 1991 & 1330 & $\begin{array}{l}\text { Steiner et al. } \\
(1995)^{\mathrm{g}}\end{array}$ \\
\hline $\begin{array}{l}\text { Government funds for } \\
\text { monitoring the pesticide } \\
\text { contamination of fruits, } \\
\text { vegetables, grains, meat, milk, } \\
\text { water, and other items }\end{array}$ & 400 & 2005 & 486 & Pimentel (2005) \\
\hline $\begin{array}{l}\text { Pesticide monitoring in } \\
\text { wildlife }\end{array}$ & 5 & 1980 & 16 & $\begin{array}{l}\text { Pimentel et al. } \\
(1980 a, b)\end{array}$ \\
\hline \multicolumn{5}{|l|}{ Economic shortfalls } \\
\hline Crops & 1000 & 2005 & 1215 & Pimentel $(2005)^{\mathrm{h}}$ \\
\hline Livestock & 3 & 1980 & 9 & $\begin{array}{l}\text { Pimentel et al. } \\
(1980 a, b)\end{array}$ \\
\hline Milk & $<1$ & 1980 & 1 & $\begin{array}{l}\text { Pimentel et al. } \\
(1980 a, b)\end{array}$ \\
\hline Fish & 5 & 1980 & 15 & $\begin{array}{l}\text { Pimentel et al. } \\
(1980 \mathrm{a}, \mathrm{b})\end{array}$ \\
\hline \multicolumn{5}{|l|}{ Defensive expenditure } \\
\hline Purchase of organic food & 2900 & 2012 & 2961 & Own calculations $\mathrm{s}^{\mathrm{i}}$ \\
\hline Overall cost & & & 35,208 & \\
\hline
\end{tabular}

${ }^{a}$ Cost for 1988, see Table 10.3 of Steiner et al. (1995). For the cost in 2013, we considered the lower limit of 61 million dollars in 1988

${ }^{\mathrm{b}}$ Based on 10,000 cases of cancer per year (Pimentel 2005) and 3 months (90 days) of recuperation per person with a cost per day of recuperation $=\$ 80$ in 2005 (Pimentel 2005)

${ }^{\mathrm{c}}$ Based on 45 deaths per year (Pimentel 2005) and a cost of 9 million US\$ per life in 2013 (Viscusi et al. 2014)

${ }^{\mathrm{d}}$ Based on 10,000 cancers per year (Pimentel 2005), a mortality rate of $20 \%$ amongst individuals with cancer (Siegel et al. 2014) and a cost of life of US\$9 million per life in 2013 (Viscusi et al. 2014)

${ }^{\mathrm{e}}$ Based on 100 million bird deaths annually (see Mineau 2005), with a cost of 30 dollars per bird (Pimentel et al. 1992). This price relates purely to recreational value. We can add a value of 5 dollars for the protection against insects provided by the birds lost (see James 1995). Hence, the cost in 1992 would be $100 \times 35=$ US $\$ 3.5$ billion

${ }_{\mathrm{f}}^{\mathrm{f} A s s u m i n g}$ that monitoring and decontamination were actually carried out. Theoretical rather than actual cost. Not included in the overall cost

gThe original estimate is for 1991, but expressed in 1986 US\$ (see Table 10.1 in Steiner et al. 1995) ${ }^{\mathrm{h}}$ Assuming that all the crops and crop products exceeding the regulatory thresholds were disposed of. Theoretical rather than actual cost. Not included in the overall cost

${ }^{i}$ Considering that the United States organic food market represented US\$29 billion in 2012 and assuming that prices in this market are $20 \%$ higher than the price of conventional food and that about $50 \%$ of the incentives of consumers to buy organic food are directly linked to pesticide risk avoidance (e.g. Schifferstein and Oude Ophuis 1998). See Sect. 2.7.3 
has generally declined over the last decade in most crops /.../ The reasons for this improvement vary from crop to crop, but usually entail the replacement of older more hazardous products with newer ones with lower acute toxicity to birds'. The ban on granular formulations of carbofuran introduced in 1991 (Heier 1991) and effective by 1994, in particular, probably had a considerable beneficial effect on bird survival in farmland. The estimate of 17-91 million birds killed per year during the 1980s was therefore almost certainly, as stated by Mineau (2005), the "worst-case' impact of pesticides on birds in an agricultural setting'. The current impact of pesticide use on birds is probably much lower.

The cost of the impact of pesticide use on human health may not have decreased in recent years. The trend towards the use of less dangerous chemicals may have decreased the frequency and severity of acute poisoning events. However, the illnesses resulting from chronic exposure, such as cancers in particular, may take years to appear. As an example, Cohn et al. (2007) showed that DDT exposure in young women during the period of peak DDT use in the United States predicts breast cancer later in their life (Cohn et al. 2007). Cohn et al. (2015) also showed that a larger exposition to DDT in utero is associated with an increased risk of breast cancer in adult women. As the authors stated, these findings are relevant "even in countries in which DDT is not currently used". This delayed effect is reinforced by the fact that "DDT remains a global environmental contaminant, even in places where it has been banned, due to its environmental persistence and semivolatility". Illnesses due to chronic exposures may therefore occur long after the chemicals that played an active role in triggering them have been banned. This time lag effect may have resulted in such illnesses being more frequent and, thus, more costly now than they were in the past. Similarly, most of the benefits to human health of the current process of pesticide re-registration may not appear for some time.

Our synthesis shows that overall hidden and external costs ranged from US\$5.4 million (2013) in Niger in 1996 to US\$13.6 billion (2013) in the United States in 1992 and were strongly underestimated. Performing an updated and more complete evaluation of these costs in the United States at the start of the 1990s, we show that overall hidden and external costs probably reached the value of US $\$ 39.5$ billion (2013) per year.

\subsection{Conclusions and Perspectives}

\subsubsection{Benefit-Cost Ratio Analysis of Pesticide Use: A Necessary...}

The use of pesticides is economically justified if the benefit-cost ratio of pesticide use is greater than 1 , indicating that the benefits are greater than the costs. The issue of how to measure pesticide productivity has been addressed in a large number of articles within the field of agricultural economics, although most did not consider 
the externalities of pesticide use. Fernandez-Cornejo et al. (1998) reviewed the estimates of the marginal product of pesticide use (the product obtained from one additional unit of pesticide use expressed in $\$ / \$$ pesticide expenditure). These estimates, obtained between 1963 and 1991, were highly variable, ranging from less than 1 to more than 10 and tending to decrease over time, with a mean value, since the 1980s, of about 4. All the papers by Pimentel and coworkers were based on these estimates (those of Headley 1968) and took into account a benefit-cost ratio of 4 . This value has become the most widely cited benefit-cost ratio for pesticide use. Yancy (2005) proposed a benefit-cost ratio of about 3 for herbicide use. In their highly cited paper published in Science, Zilberman et al. (1991) noted that 'a \$1 increase in aggregate pesticide expenditures has been estimated to raise gross agricultural output from $\$ 3$ to $\$ 6.50^{\prime}$. Based on the estimated benefits of pesticide use calculated by Gianessi (2009) and Gianessi and Reigner (2005, 2007), Popp (2011) proposed a benefit-cost ratio of about 6.5 .

However, this ratio did not include the external and hidden internal costs of pesticide use reviewed above. Any fair calculation of this ratio must include not only the usual internal costs to farmers (pesticide market costs and application costs), but also the external costs and hidden internal costs corresponding to the "other internal costs" defined in Sect. 2.2 (see also Table 2.1). However, it should exclude the hidden internal costs resulting in either an increase in the usual internal costs, such as costs linked to pesticide resistance, or a decrease in benefits, such as a reduced pollination. Indeed, these last two types of cost are already accounted for in estimates of the usual internal cost of pesticides or the gross value of agricultural production.

Some of the papers estimating the overall costs of pesticide use also provided estimates of the benefits of pesticide use (Khan et al. 2002; Pimentel et al. 1980a, b, 1992, 1993a; Pimentel and Greiner 1997; Pimentel and Hart 2001; Pimentel 2005; Pimentel and Burgess 2014; Waibel and Fleischer 1998). This enabled us to reevaluate the benefit-cost ratio of pesticide use, by calculating the overall costs to be included in this ratio as the sum of the usual internal costs, the hidden internal costs generating "other internal costs" and external costs. The resulting ratios are given in Table 2.15.

In most cases, the ratio was higher than 1 (Table 2.15), but some of the ratios obtained were close to 1 (Waibel and Fleischer (1998) for Germany, and Pimentel et al. (1992, 1993a) for the United States) and one was below 1 (Khan et al. (2002) for Pakistan), indicating that overall costs have sometimes outweighed the benefits of pesticide use in agriculture. Hence, Pingali et al. (1994) concluded that 'When health costs are explicitly considered for a risk-neutral farmer, the net benefits of insecticides applied are negative. In other words, the positive production benefits of applying insecticides are exceeded by the increased health costs'. This may have been the case, even in developed countries. Based on our re-evaluation of the overall costs of pesticide use for the United States in Sect. 2.8.3, the benefit-cost ratio in this country at the start of the 1990s was 0.70 (Table 2.15). In 1992, Pimentel et al. concluded 'complete long-term cost/benefit analysis of pesticide use would reduce the 


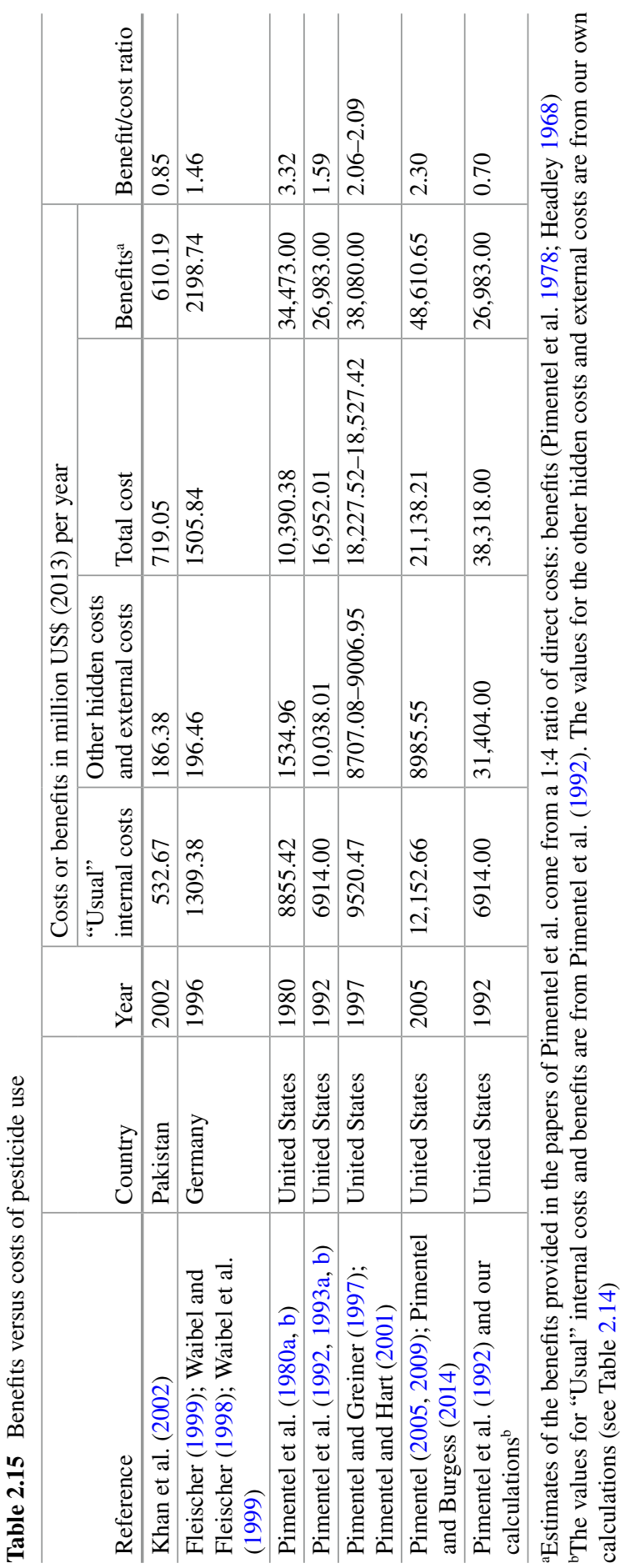


perceived profitability of pesticides'. The re-analysis of their data shows that the profitability of pesticides has, indeed, undoubtedly been overestimated in the past. Hence, pesticide use, at the doses applied, may have entailed costs exceeding the profits generated.

\subsection{2 … Yet Difficult Approach}

When estimating the benefit-cost ratio of pesticide use, we need to bear in mind the alternative farming system to which pesticide use may be compared. Only benefit or cost items differing between the two types of agriculture should then be considered. For instance, conventional food production with pesticide use is often compared with organic farming, as pesticide use is lower in organic systems. In this review, we decided to include the purchase of organic food in the external cost of pesticide use (see Sect. 2.7.3) because (i) the alternative mode of production is not necessarily organic farming, e.g. it could be farming based on genetically modified crops, and (ii) the price premium of organic food would probably decrease considerably in a totally organic farming system.

The estimates of the benefits used to determine the benefit-cost ratio in the previous section were restricted to internal benefits, i.e. agricultural production. They did not include external benefits, such as reduced morbidity and mortality or a decrease in biological invasions (Felsot 2011). The estimation of external benefits is a difficult task that has been attempted by few authors (but see Felsot 2011). One of the difficulties is that the list of external benefits may, like that of external costs, be very long. For instance, conventional agriculture based on chemical pesticides has a positive effect on the activity of research laboratories in chemistry, the chemical industry, chemical sellers, agricultural advisors specializing in chemical usage, chemical waste disposal and treatment. It even has a positive effect on research into the cost of pesticide use, e.g. such as the analyses on which this review is based and this review itself.

As for costs, the most meaningful way to describe the external benefits of pesticide use is to compare conventional agriculture involving pesticide use with an alternative farming system. Only the benefit items differing between the two types of farming considered should then be compared. For instance, when comparing pesticide use as a tool for integrated pest management or organic farming, food production is often considered to be constant between strategies and is not considered as an adjustment variable. Thus, the external benefits, such as positive health effects linked to sufficient food production, are also common to the different strategies considered. However, other external benefits, such as the positive effects on health of a high sanitary quality of food, side effects on invasion biology, and the positive economic consequences of a developed pesticide industry compared to the developed work force in the field may differ between modes of agricultural production. 


\subsubsection{Chronic Exposure, Severe Illnesses and Death: The Cornerstones of Externalities}

Our literature review provided evidence to suggest that hidden and external costs have been underestimated. The key parameter is probably the cost of illnesses and deaths due to pesticide use, notably due to chronic exposure. The benefit-cost ratio may easily fall below 1 if the costs of chronic illness and acute fatal poisoning events due to pesticide use are taken into account, because human life is clearly of great value. Our re-analysis of the data of Pimentel et al. suggested that each percent of cancers attributable to pesticides was associated with a cost of about 20 billion dollars annually.

Unfortunately, it is very difficult to estimate the cost of chronic diseases. A relationship has been found between exposure to some pesticides over a number of years and several severe illnesses (see Baldi et al. 2013). Several reviews and/or meta-analyses of case-control and/or long-term epidemiological surveys have shown that (i) occupational exposure is associated with an increase in the frequencies of Parkinson's disease (Van Maele-Fabry et al. 2012), amyotrophic lateral sclerosis (Malek et al. 2012), non-Hodgkin lymphoma (Schinasi and Leon 2014), the impairment of several neurobehavioral functions (Mackenzie-Ross et al. 2013), disorders of the reproductive system (notably low sperm concentration and quality) (Martenies and Perry 2013; Mehrpour et al. 2014) and several cancers (Alavanja and Bonner 2012; Alavanja et al. 2013) and (ii) the risks of brain cancer, leukemia and lymphoma in childhood are also significantly associated with parental exposure to pesticides (Vinson et al. 2011; Van Maele-Fabry et al. 2010, 2013).

However, the development of most illnesses, including cancers in particular, is generally multifactorial. Hence, despite the significant association between pesticide exposure and such illnesses, it is difficult to prove a causal effect of pesticides. According to Andersson et al. (2014), the conclusion of Dich et al. (1997) warning that ' $\mathrm{few}$, if any of the associations (between pesticide exposure and cancers) can be considered established and causal' still holds in 2014, for most, if not all long-term human disorders. Even if certain pesticides were clearly proved to be involved in these disorders, their contribution relative to other factors would still be difficult to determine. There may also be a general reluctance of the epidemiologists to compute and publish the health burden attributable to specific factors. Doing so 'takes epidemiologists as impartial scientists and thrusts them more clearly into the political arena of public health' (Steenland and Armstrong 2006). This, together with more technical causes, probably explains why we found no study providing scientifically based estimate of the number of cancers and other severe illnesses that could actually be attributed to pesticide exposure, not only among farmers, but also for the whole population.

In March 2015, the International Agency for Research on Cancer held a meeting in Lyon. This World Health Organization agency concluded that the herbicide glyphosate (Fig. 2.8), the insecticides malathion and diazinon were probably 


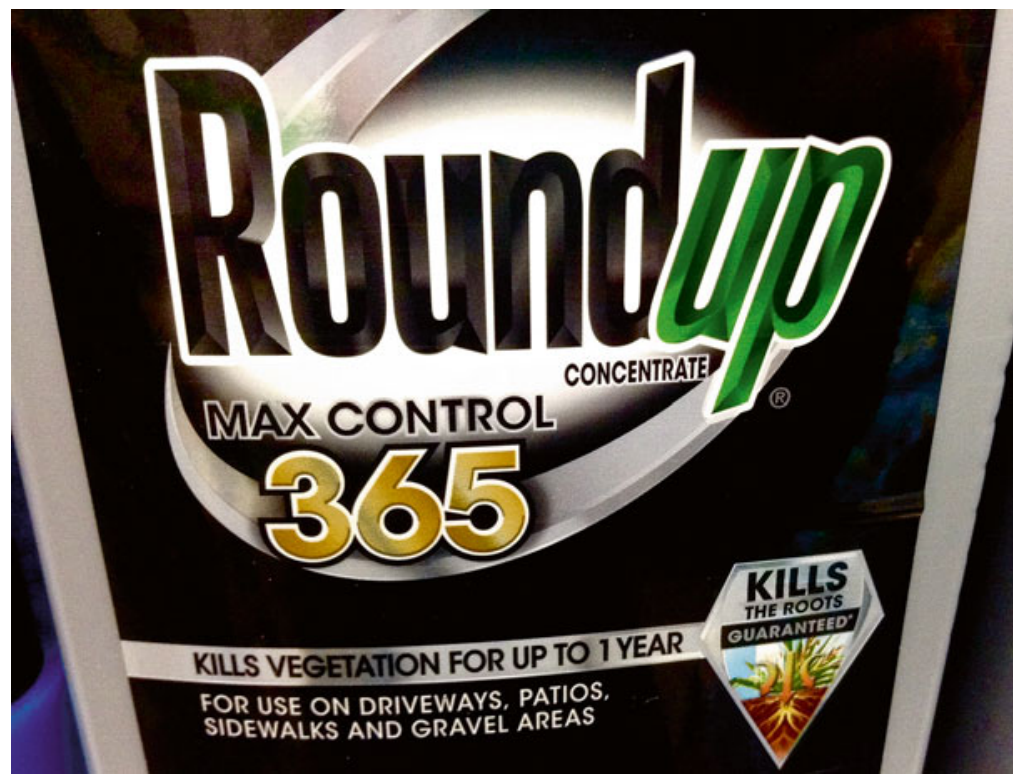

Fig. 2.8 In March 2015, the herbicide glyphosate - contained in the widely known Roundup herbicide by Monsanto - has been classified "probably carcinogenic to humans" by the International Agency for Research on Cancer (Unmodified photography by Mike Mozart, under Creative Common License CC BY (https://creativecommons.org/licenses/by/2.0/))

carcinogenic to humans and that the insecticides tetrachlorvinphos and parathion were classified as possibly carcinogenic to humans (Guyton et al. 2015).

Based on the increasing body of evidence suggesting a tight association between some cancers and pesticide exposure, attributable risk estimates may be proposed soon. This would make it possible to revise, either upward or downward, the estimate of 0.5-1 \% used by David Pimentel and coworkers as the basis of their estimations over the last 35 years. In any case, such data would bring us closer to the actual overall costs of pesticide use and would provide policy makers with tangible elements to guide their decisions.

Meanwhile, our re-evaluation of past benefit-cost ratio of pesticide use in various countries reveals that the costs of pesticide use might have outreached its benefits in the past, e.g. in the United States at the start of the 1990s. We finally advocate that the key impact to be evaluated is the illnesses and deaths due to chronic exposure to pesticides. Taking into account the costs they generate could drastically decrease the benefit-cost ratio of pesticide use. The quantification of this key cost is therefore urgently required for a more accurate evaluation of pesticide use and for regulatory purposes.

Acknowledgments We thank Christine Silvy and Bruno Pierrel for their help recovering relevant articles. We also thank Julie Sappa from Alex Edelman \& Associates for editing the English manuscript. 


\section{References}

Adamski Z, Bloszyk J, Piosik K, Tomczak K (2009) Effects of diflubenzuron and mancozeb on soil microarthropods: a long-term study. Biol Lett 46:5-15

Ahad K, Mohammad A, Khan H, Ahmad I, Hayat Y (2010) Monitoring results for organochlorine pesticides in soil and water from selected obsolete pesticide stores in Pakistan. Environ Monit Assess 166:191-199

Ajayi OC (2000) Pesticide use practices, productivity and farmers' health: the case of cotton-rice farmers in the Côte d'Ivoire, West Africa. Pesticide Policy Project, special issue publication series No 3. University of Hannover

Ajayi OC, Camera M, Fleischer G, Haidara F, Sow M, Traore A, Van Der Valk H (2002) Socioeconomic assessment of pesticide use in Mali. Pesticide Policy Project, special issue publication series No 6. University of Hannover

Alavanja MC, Bonner MR (2012) Occupational pesticide exposures and cancer risk: a review. J Toxicol Environ Health, Part B 15:238-263

Alavanja MC, Ross MK, Bonner MR (2013) Increased cancer burden among pesticide applicators and others due to pesticide exposure. CA Cancer J Clin 63:120-142

Andersson H, Tago D, Treich N (2014) Pesticides and health: a review of evidence on health effects, valuation of risks, and benefit-cost analysis, No 825. Institut d'Économie Industrielle (IDEI), Toulouse

Andreasen C, Streibig JC (2011) Evaluation of changes in weed flora in arable fields of Nordic countries - based on Danish long-term surveys. Weed Res 51:214-226

Athukorala W, Wilson C, Robinson T (2012) Determinants of health costs due to farmers' exposure to pesticides: an empirical analysis. J Agric Econ 63:158-174

Atreya K (2005) Health costs of pesticide use in a vegetable growing area, central mid-hills, Nepal. Himal J Sci 3:81-83

Atreya K (2007) Pesticide use in Nepal: understanding health costs from short-term exposure. Working paper No 28-07. South Asian Network for Development and Environmental Economics (SANDEE), Kathmandu

Atreya K (2008) Health costs from short-term exposure to pesticides in Nepal. Soc Sci Med 67:511-519

Atreya K, Johnsen F, Sitaula B (2012) Health and environmental costs of pesticide use in vegetable farming in Nepal. Environ Dev Sustain 14:477-493

Atreya K, Sitaula BK, Bajracharya RM (2013) Distribution of health costs of pesticide use by household economy. Environ Dev Sustain 15:827-839

Auslander BA, Langlois PH (1993) Toronto tap water: perception of its quality and use of alternatives. Can J Public Health 84:99-102

Baker NJ, Bancroft BA, Garcia TS (2013) A meta-analysis of the effects of pesticides and fertilizers on survival and growth of amphibians. Sci Total Environ 449:150-156

Balakrishnan S, Takeda K, Sakugawa H (2012) Occurrence of diuron and irgarol in seawater, sediments and planktons of Seto Inland Sea, Japan. Geochem J 46:169-177

Baldi I, Cordier S, Coumoul X, Elbaz A, Gamet-Payrastre L, Le Bailly P, Multigner L, Rahmani R, Spinosi J, Van Maele-Fabry G (2013) Pesticides, effets sur la santé. Expertise collective, synthèse et recommandations. Les éditions INSERM, Paris. http://www.inserm.fr/actualites/ rubriques/actualites-societe/pesticides-effets-sur-la-sante-une-expertise-collective-de-1inserm. Accessed 1 Sept 2014

Barrios E (2007) Soil biota, ecosystem services and land productivity. Ecol Econ 64:269-285

Barzman M, Dachbrodt-Saaydeh S (2011) Comparative analysis of pesticide action plans in five European countries. Pest Manag Sci 67:1481-1485

Becker GS (1965) A theory of the allocation of time. Econ J 75:493-517

Beketov MA, Kefford BJ, Schäfer RB, Liess M (2013) Pesticides reduce regional biodiversity of stream invertebrates. Proc Natl Acad Sci U S A 110:11039-11043 
Berny P, Caloni F, Croubels S, Sachana M, Vandenbroucke V, Davanzo F, Guitart R (2010) Animal poisoning in Europe. Part 2: companion animals. Vet J 183:255-259

Blouin M, Hodson ME, Delgado EA, Baker G, Brussaard L, Butt KR, Dai J, Dendooven L, Peres G, Tondoh JE, Cluzeau D, Brun J-J (2013) A review of earthworm impact on soil function and ecosystem services. Eur J Soil Sci 64:161-182

Bommarco R, Miranda F, Bylund H, Björkman C (2011) Insecticides suppress natural enemies and increase pest damage in cabbage. J Econ Entomol 104:782-791

Bonfante P, Anca IA (2009) Plants, mycorrhizal fungi, and bacteria: a network of interactions. Annu Rev Microbiol 63:363-383

Bonti-Ankomah S, Yiridoe E (2006) Organic and conventional food: a literature review of the economics of consumer perceptions and preferences. Organic Agriculture Centre of Canada, Canada

Boutin C, Strandberg B, Carpenter D, Mathiassen SK, Thomas PJ (2014) Herbicide impact on non-target plant reproduction: what are the toxicological and ecological implications? Environ Pollut 185:295-306

Bowles RG, Webster JPG (1995) Some problems associated with the analysis of the costs and benefits of pesticides. Crop Prot 14:593-600

Brenna E (2001) I costi sanitari per le intossicazioni acute da antiparassitari: un'analisi empirica. Ann Ist Super Sanita 37:153-158

Cahill JF Jr, Elle E, Smith GR, Shore BH (2008) Disruption of a belowground mutualism alters interactions between plants and their floral visitors. Ecology 89:1791-1801

Calvert GM, Karnik J, Mehler L, Beckman J, Morrissey B, Sievert J, Barrett R, Lackovic M, Mabee L, Schwartz A, Mitchell Y, Moraga-McHaley S (2008) Acute pesticide poisoning among agricultural workers in the United States, 1998-2005. Am J Ind Med 51:883-898

Cantin NE, Negri AP, Willis BL (2007) Photoinhibition from chronic herbicide exposure reduces reproductive output of reef-building corals. Mar Ecol Prog Ser 344:81-93

Cedergreen N, Streibig JC (2005) The toxicity of herbicides to non-target aquatic plants and algae: assessment of predictive factors and hazard. Pest Manag Sci 61:1152-1160

Choi Y, Kim Y, Ko Y, Cha ES, Kim J, Lee WJ (2012) Economic burden of acute pesticide poisoning in South Korea. Trop Med Int Health 17:1534-1543

Chopra AK, Sharma MK, Chamoli S (2011) Bioaccumulation of organochlorine pesticides in aquatic system - an overview. Environ Monit Assess 173:905-916

Christensen TK, Lassen P, Elmeros M (2012) High exposure rates of anticoagulant rodenticides in predatory bird species in intensively managed landscapes in Denmark. Arch Environ Contam Toxicol 63:437-444

Cohn BA, Wolff MS, Cirillo PM, Sholtz RI (2007) DDT and breast cancer in young women: new data on the significance of age at exposure. Environ Health Perspect 115:1406-1414

Cohn BA, La Merrill M, Krigbaum NY, Yeh G, Park JS, Zimmermann L, Cirillo PM (2015) DDT exposure in utero and breast cancer. J Clin Endocrinol Metabol. doi:10.1210/jc.2015-1841

Cole DC, Mera-Orcés V (2003) Intoxicaciones por plaguicidas: incidencia e impacto economico. In: Yanggen D, Crissman CC, Espinosa P (eds) Impactos del uso de plaguicidas en la produccion, salud y medioambiente en Carchi: un compendio de investigaciones y respuestas multidisciplinarias. Ediciones Abya-Yala, Quito, pp 95-113

Cole DC, Carpio F, León N (2000) Economic burden of illness from pesticide poisonings in highland Ecuador. Pan Am J Public Health 8:196-201

Consonni D, Pesatori AC, Zocchetti C, Sindaco R, D’ Oro LC, Rubagotti M, Bertazzi PA (2008) Mortality in a population exposed to dioxin after the Seveso, Italy, accident in 1976: 25 years of follow-up. Am J Epidemiol 167:847-858

Cooper J, Dobson H (2007) The benefits of pesticides to mankind and the environment. Crop Prot 26:1337-1348

Corriols M, Marin J, Berroteran J, Lozano LM, Lundberg I, Thörn Å (2008) The Nicaraguan pesticide poisoning register: constant underreporting. Int J Health Serv 38:773-787

Crissman CC, Cole DC, Carpio F (1994) Pesticide use and farm worker health in Ecuadorian potato production. Am J Agr Econ 76:593-597 
Croft BA, Brown AWA (1975) Responses of arthropod natural enemies to insecticides. Annu Rev Entomol 20:285-335

Damalas CA, Eleftherohorinos IG (2011) Pesticide exposure, safety issues, and risk assessment indicators. Int J Environ Res Public Health 8:1402-1419

De A, Bose R, Kumar A, Mozumdar S (2014) Worldwide pesticide use. In: De A, Bose R, Kumar A, Mozumdar S (eds) Targeted delivery of pesticides using biodegradable polymeric nanoparticles. Springer, New Delhi, pp 5-6

Desneux N, Decourtye A, Delpuech JM (2007) The sublethal effects of pesticides on beneficial arthropods. Annu Rev Entomol 52:81-106

Devi PI (2007) Pesticide use in the rice bowl of Kerala: health costs and policy options. Working paper No 20-07. South Asian Network for Development and Environmental Economics (SANDEE), Kathmandu

Dich J, Zahm SH, Hanberg A, Adami HO (1997) Pesticides and cancer. Cancer Causes Control 8:420-443

Dickie M (2003) Defensive behavior and damage cost methods. In: Champ PA, Boyle KJ, Brown TC (eds) A primer on nonmarket valuation. Springer, Dordrecht, pp 395-444

Ding W, Reddy KN, Krutz LJ, Thomson SJ, Huang Y, Zablotowicz RM (2011) Biological response of soybean and cotton to aerial glyphosate drift. J Crop Improv 25:291-302

Doria MF (2006) Bottled water versus tap water: understanding consumers' preferences. J Water Health 4:271-276

Doria MF (2010) Factors influencing public perception of drinking water quality. Water Policy 12:1-19

Doria MF, Pidgeon N, Hunter PR (2009) Perceptions of drinking water quality and risk and its effect on behaviour: a cross-national study. Sci Tot Environ 407:5455-5464

Dung NH (2007) Economic and environmental consequence of agrochemical use in intensive rice cultivation in the Mekong Delta, Vietnam. Dissertation, Institute of Social Studies, The Hague

Dung NH, Dung TT (1999) Economic and health consequences of pesticide use in paddy production in the Mekong Delta, Vietnam. Economic and Environmental Program for Southeast Asia (EEPSEA). IDRC, Singapore

Dunier M, Siwicki AK (1993) Effects of pesticides and other organic pollutants in the aquatic environment on immunity of fish: a review. Fish Shellfish Immunol 3:423-438

Dupont DP, Jahan N (2012) Defensive spending on tap water substitutes: the value of reducing perceived health risks. J Water Health 10:56-68

Dupont DP, Adamowicz W, Krupnick A (2010) Differences in water consumption choices in Canada: the role of socio-demographics, experiences and perceptions of risks. J Water Health 8:671-686

Dvorská A, Sír M, Honzajková Z, Komprda J, Cupr P, Petrlík J, Anakhasyan E, Simonyan L, Kubal M (2012) Obsolete pesticide storage sites and their POP release into the environment an Armenian case study. Environ Sci Pollut Res Int 19:1944-1952

Ecobichon DJ (1999) Our changing perspectives on benefits and risks of pesticides: a historical overview. NeuroToxicol 21:211-218

Egan JF, Bohnenblust E, Goslee S, Mortensen D, Tooker J (2014) Herbicide drift can affect plant and arthropod communities. Agric Ecosyst Environ 185:77-87

Egea-Serrano A, Relyea RA, Tejedo M, Torralva M (2012) Understanding of the impact of chemicals on amphibians: a meta-analytic review. Ecol Evol 2:1382-1397

Elfvendahl S, Mihale M, Kishimba MA, Kylin H (2004) Pesticide pollution remains severe after cleanup of a stockpile of obsolete pesticides at Vikuge, Tanzania. AMBIO 33:503-508

Elliott JE, Hindmarch S, Albert CA, Emery J, Mineau P, Maisonneuve F (2014) Exposure pathways of anticoagulant rodenticides to nontarget wildlife. Environ Monit Assess 186:895-906

Epp DJ, Tellefsen FR, Shute GA, Bear RM, Wilkinson KP (1977) Identification and specification of inputs for benefit-cost modeling of pesticide use. A report to the Office of Research and Development, US EPA, Washington, DC, EPA-600/5-77-012. National Technical Information Service, Springfield 
Eveleens KG, Van Den Bosch R, Ehler LE (1973) Secondary outbreak induction of beet armyworm by experimental insecticide applications in cotton in California. Environ Entomol 2:497-503

Evenson RE, Gollin D (2003) Assessing the impact of the Green Revolution, 1960 to 2000. Science 300:758-762

Fabricius KE (2005) Effects of terrestrial runoff on the ecology of corals and coral reefs: review and synthesis. Mar Pollut Bull 50:125-146

FAO (2011a) Prevention and disposal of obsolete pesticides. http://www.fao.org/agriculture/crops/ obsolete-pesticides/prevention-and-disposal-of-obsolete-pesticides/en/. Accessed 24 Sept 2014

FAO (2011b) Joining forces to protect vulnerable groups from pesticides exposure. FAO and ILO, Geneva. http://www.fao.org/agriculture/crops/news-events-bulletins/detail/en/item/88900/ icode/?no_cache=1. Accessed 1 Sept 2014

Felix J, Doohan DJ, Bruins D (2007) Differential vegetable crop responses to mesotrione soil residues a year after application. Crop Prot 26:1395-1403

Felsot AS (2011) Pesticides and health: myths vs. realities. American Council on Science, Health. http://www.croplife.ca/wp-content/uploads/2012/02/Pesticides-and-Health-Myth-vs-Realities. pdf. Accessed 1 Sept 2014

Fernandez-Cornejo J, Jans S, Smith M (1998) Issues in the economics of pesticide use in agriculture: a review of the empirical evidence. Rev Agric Econ 20:462-488

Fitch Haumann B (2014) Another milestone year for the US organic industry. In: Willer H, Lernoud J (eds) The world of organic agriculture. Statistics and emerging trends 2014. FiBL/ IFOAM, Frick/Bonn, pp 241-246

Fleischer G (1999) Social costs and benefits of chemical pesticide use - case study of German agriculture. In: Waibel H, Fleischer G, Kenmore PE, Feder G (eds) Evaluation of IPM programs - concepts and methodologies. Pesticide Policy Project publication series No 8. Institute for Economics in Horticulture, Hannover, pp 38-41

Florax RJ, Travisi CM, Nijkamp P (2005) A meta-analysis of the willingness to pay for reductions in pesticide risk exposure. Eur Rev Agric Econ 32:441-467

Flores F, Collier CJ, Mercurio P, Negri AP (2013) Phytotoxicity of four photosystem II herbicides to tropical seagrasses. PLoS One 8, e75798

Fotopoulos C, Krystallis A (2002) Purchasing motives and profile of the Greek organic consumer: a countrywide survey. Br Food J 104:730-765

Fournier-Chambrillon C, Berny PJ, Coiffier O, Barbedienne P, Dassé B, Delas G, Galineau H, Mazet A, Pouzenc P, Rosoux R, Fournier P (2004) Evidence of secondary poisoning of free-ranging riparian mustelids by anticoagulant rodenticides in France: implications for conservation of European mink (Mustela lutreola). J Wildl Dis 40:688-695

Freemark K, Boutin C (1995) Impacts of agricultural herbicide use on terrestrial wildlife in temperate landscapes: a review with special reference to North America. Agr Ecosyst Environ 52:67-91

Friberg N, Lindstrøm M, Kronvang B, Larsen SE (2003) Macroinvertebrate/sediment relationships along a pesticide gradient in Danish streams. Hydrobiologia 494:103-110

García JE (1998) Intoxicaciones agudas con plaguicidas: costos humanos y económicos. Pan Am J Public Health 4:383-387

Geiger F, de Snoo GR, Berendse F, Guerrero I, Morales MB, Onate JJ, Eggers S, Pärt T, Bommarco R, Bengtsson L, Clement LW, Weisser WW, Olszewski A, Ceryngier P, Hawro V, Inchausti P, Fischer C, Flohre A, Thies C, Tscharntke T (2010) Persistent negative effects of pesticides on biodiversity and biological control potential on European farmland. Basic Appl Ecol 11:97-105

Gianessi LP (2009) The value of insecticides in US crop production. Croplife Foundation, Crop Protection Research Institute (CPRI). http://croplifefoundation.files.wordpress.com/2012/07/ insecticide-benefits-execsum.pdf. Accessed 1 Sept 2014 
Gianessi LP, Reigner NP (2005) The value of fungicides in US crop production. Croplife Foundation, Crop Protection Research Institute (CPRI). http://croplifefoundation.files.wordpress.com/2012/07/completed-fungicide-report.pdf. Accessed 1 Sept 2014

Gianessi LP, Reigner NP (2007) The value of herbicides in US crop production. Weed Technol 21:559-566

Gibbons D, Morrissey C, Mineau P (2014) A review of the direct and indirect effects of neonicotinoids and fipronil on vertebrate wildlife. Environ Sci Pollut Res 22:103-118

Gil Y, Sinfort C (2005) Emission of pesticides to the air during sprayer application: a bibliographic review. Atmos Environ 39:5183-5193

Gil JM, Gracia A, Sanchez M (2000) Market segmentation and willingness to pay for organic products in Spain. Int Food Agribus Man 3:207-226

Gleick PH, Cooley HS (2009) Energy implications of bottled water. Environ Res Lett 4:014009

Gomiero T, Pimentel D, Paoletti MG (2011) Environmental impact of different agricultural management practices: conventional vs. organic agriculture. Crit Rev Plant Sci 30:95-124

Goss MJ, Barry DAJ, Rudolph DL (1998) Contamination in Ontario farmstead domestic wells and its association with agriculture: 1. Results from drinking water wells. J Contam Hydrol 32:267-293

Gove B, Power SA, Buckley GP, Ghazoul J (2007) Effects of herbicide spray drift and fertilizer overspread on selected species of woodland ground flora: comparison between short-term and long-term impact assessments and field surveys. J Appl Ecol 44:374-384

Griffith R, Nesheim L (2008) Household willingness to pay for organic products. The Institute for Fiscal Studies, Department of Economics, UCL, (Cemmap working paper No CWP18/08). http://www.cemmap.ac.uk/wps/cwp1808.pdf. Accessed 1 Sept 2014

Guitart R, Sachana M, Caloni F, Croubels S, Vandenbroucke V, Berny P (2010) Animal poisoning in Europe. Part 3: wildlife. Vet J 183:260-265

Gunnell D, Eddleston M, Phillips MR, Konradsen F (2007) The global distribution of fatal pesticide self-poisoning: systematic review. BMC Public Health 7:357

Guyton KZ, Loomis D, Grosse Y et al (2015) Carcinogenicity of tetrachlorvinphos, parathion, malathion, diazinon, and glyphosate. Lancet Oncol 16:490-491

Hagood ES Jr, Williams JL Jr, Bauman TT (1980) Influence of herbicide injury on the yield potential of soybeans (Glycine max). Weed Sci 28:40-45

Hallberg GR (1989) Pesticides pollution of groundwater in the humid United States. Agric Ecosyst Environ 26:299-367

Hallmann CA, Foppen RP, van Turnhout CA, de Kroon H, Jongejans E (2014) Declines in insectivorous birds are associated with high neonicotinoid concentrations. Nature 511:341-343

Hardin MR, Benrey B, Coll M, Lamp WO, Roderick GK, Barbosa P (1995) Arthropod pest resurgence: an overview of potential mechanisms. Crop Prot 14:3-18

Hartwell SI (2011) Chesapeake Bay watershed pesticide use declines but toxicity increases. Environ Toxicol Chem 30:1223-1231

Hayes TB, Case P, Chui S, Chung D, Haeffele C, Haston K, Lee M, Mai VP, Marjuoa Y, Parker J, Tsui M (2006) Pesticide mixtures, endocrine disruption, and amphibian declines: are we underestimating the impact? Environ Health Perspect 114:40-50

Haynes D, Müller J, Carter S (2000) Pesticide and herbicide residues in sediments and seagrasses from the Great Barrier Reef World heritage area and Queensland coast. Mar Pollut Bull 41:279-287

Headley JC (1968) Estimating the production of agricultural pesticides. Am J Agric Econ 50:13-23

Heier A (1991) Pesticide carbofuran phased out under settlement agreement. Environmental News, 14 May 1991. US Environmental Protection Agency, Washington, DC

Helweg A, Bay H, Hansen HPB, Rabølle M, Sonnenborg A, Stenvang L (2002) Pollution at and below sites used for mixing and loading of pesticides. Int J Environ Anal Chem 82:583-590

Henry M, Béguin M, Requier F, Rollin O, Odoux JF, Aupinel P, Aptel J, Tchamitchian S, Decourtye A (2012) A common pesticide decreases foraging success and survival in honey bees. Science $336: 348-350$ 
Holmstrup M, Bindesbøl AM, Oostingh GJ, Duschl A, Scheil V, Köhler HR, Loureiro S, Soares AMVM, Ferreira ALG, Kienle C, Gerhardt A, Laskowski R, Kramarz PE, Bayley M, Svendsen C, Spurgeon DJ (2010) Interactions between effects of environmental chemicals and natural stressors: a review. Sci Total Environ 408:3746-3762

Houndekon VA, De Groote H (1998) Health costs and externalities of pesticide use in locust and grasshopper control in the Sahel. In: Proceeding of the annual conference of the American Agricultural Economics Association (New Name 2008: Agricultural and Applied Economics Association), Salt Lake City

Houndekon VA, De Groote H, Lomer C (2006) Health costs and externalities of pesticide use in the Sahel. Outlook Agric 35:25-31

Huang CL (1996) Consumer preferences and attitudes towards organically grown produce. Eur Rev Agric Econ 23:331-342

Huang J, Qiao F, Zhang L, Rozelle S (2000) Farm pesticide, rice production, and human health. Economic and Environmental Program for Southeast Asia (EEPSEA). IDRC, Singapore

Hudson NL, Kasner EJ, Beckman J, Mehler L, Schwartz A, Higgins S, Bonnar-Prado J, Lackovic M, Mulay P, Mitchell Y, Larios L, Walker R, Waltz J, Moraga-McHaley S, Roisman R, Calvert GM (2014) Characteristics and magnitude of acute pesticide-related illnesses and injuries associated with pyrethrin and pyrethroid exposures - 11 states, 2000-2008. Am J Ind Med 57:15-30

Huggett RJ, Bender ME (1980) Kepone in the James River. Environ Sci Technol 14:918-923

Hughner RS, McDonagh P, Prothero A, Shultz CJ, Stanton J (2007) Who are organic food consumers? A compilation and review of why people purchase organic food. J Consum Behav 6:94-110

Imfeld G, Vuilleumier S (2012) Measuring the effects of pesticides on bacterial communities in soil: a critical review. Eur J Soil Biol 49:22-30

Jacquet F, Butault JP, Guichard L (2011) An economic analysis of the possibility of reducing pesticides in French field crops. Ecol Econ 70:1638-1648

Jakus PM, Shaw WD, Nguyen TN, Walker M (2009) Risk perceptions of arsenic in tap water and consumption of bottled water. Water Resour Res 45, W05405

James PC (1995) Internalizing externalities: granular carbofuran use on rapeseed in Canada. Ecol Econ 13:181-184

Jansen H, Uytewaal E, Stoorvogel JJ (1998) Health costs and pesticide use in the Atlantic zone of Costa Rica. In: Book of abstracts of the international conference on pesticide use in developing countries: impact on health and environment, San José, p 166

Jeyaratnam J (1990) Acute pesticide poisoning: a major global health problem. World Health Stat Q 43:139-144

Jit S, Dadhwal M, Kumari H, Jindal S, Kaur J, Lata P, Niharika N, Lal D, Garg N, Kumar Gupta S, Sharma P, Bala K, Singh A, Vijgen J, Weber R, Lal R (2010) Evaluation of hexachlorocyclohexane contamination from the last lindane production plant operating in India. Env Sci Pollut Res 18:586-597

Jones RJ, Mueller JF, Haynes D, Schreiber U (2003) Effects of herbicides diuron and atrazine on corals of the Great Barrier Reef, Australia. Mar Ecol Prog Ser 251:153-167

Jungbluth F (1996) Crop protection policy in Thailand: economic and political factors influencing pesticide use. Pesticide Policy Project, special issue publication series No 5. University of Hannover

Jungbluth N (2005) Comparison the environmental impact of drinking water vs. bottled mineral water. Swiss Gas and Water Association. http://www.esu-services.ch/download/jungbluth2006-LCA-water.pdf. Accessed 1 Sept 2014

Karabelas AJ, Plakas KV, Solomou ES, Drossou V, Sarigiannis DA (2009) Impact of European legislation on marketed pesticides: a view from the standpoint of health impact assessment studies. Environ Int 35:1096-1107

Kaya HK, Gaugler R (1993) Entomopathogenic nematodes. Annu Rev Entomol 38:181-206

Khan MA, Iqbal M, Ahmad I, Soomro MH, Chaudhary MA (2002) Economic evaluation of pesticide use externalities in the cotton zones of Punjab, Pakistan. Pak Dev Rev 41:683-698 
Kiesecker JM (2002) Synergism between trematode infection and pesticide exposure: a link to amphibian limb deformities in nature? Proc Natl Acad Sci U S A 99:9900-9904

Kishi M, Hirschhorn N, Djajadisastra M, Satterlee LN, Strowman S, Dilts R (1995) Relationship of pesticide spraying to signs and symptoms in Indonesian farmers. Scand J Work Environ Health 21:124-133

Klingen I, Haukeland S (2006) The soil as a reservoir for natural enemies of pest insects and mites with emphasis on fungi and nematodes. In: Eilenberg J, Hokkanen HMT (eds) An ecological and societal approach to biological control. Springer, Dordrecht, pp 145-211

Kniesner TK, Viscusi WK, Woock C, Ziliak JP (2012) The value of statistical life: evidence from panel data. Rev Econ Stat 94:74-87

Köhler HR, Triebskorn R (2013) Wildlife ecotoxicology of pesticides: can we track effects to the population level and beyond? Science 341:759-765

Kroon FJ, Kuhnert PM, Henderson BL, Wilkinson SN, Kinsey-Henderson A, Abbott B, Brodie JE, Turner RDR (2012) River loads of suspended solids, nitrogen, phosphorus and herbicides delivered to the Great Barrier Reef lagoon. Mar Pollut Bull 65:167-181

Langford KH, Reid M, Thomas KV (2013) The occurrence of second generation anticoagulant rodenticides in non-target raptor species in Norway. Sci Total Environ 450:205-208

Lee SJ, Mehler L, Beckman J, Diebolt-Brown B, Prado J, Lackovic M, Waltz J, Mulay P, Schwartz A, Mitchell Y, Moraga-McHaley S, Gergely R, Calvert GM (2011) Acute pesticide illnesses associated with off-target pesticide drift from agricultural applications: 11 States, 1998-2006. Environ Health Perspect 119:1162-1169

Lee WJ, Cha ES, Park J, Ko Y, Kim HJ, Kim J (2012) Incidence of acute occupational pesticide poisoning among male farmers in South Korea. Am J Ind Med 55:799-807

Lekei EE, Ngowi AV, London L (2014) Farmers' knowledge, practices and injuries associated with pesticide exposure in rural farming villages in Tanzania. BMC Public Health 14:389

Lewis SE, Brodie JE, Bainbridge ZT, Rohde KW, Davis AM, Masters BL, Maughan M, Devlin MJ, Mueller JF, Schaffelke B (2009) Herbicides: a new threat to the Great Barrier Reef. Environ Pollut 157:2470-2484

Lewis SE, Schaffelke B, Shaw M, Bainbridge ZT, Rohde KW, Kennedy K, Davis AM, Masters BL, Devlin MJ, Mueller JF, Brodie JE (2012) Assessing the additive risks of PSII herbicide exposure to the Great Barrier Reef. Mar Pollut Bull 65:280-295

Liess M, von der Ohe PC (2005) Analyzing effects of pesticides on invertebrate communities in streams. Environ Toxicol Chem 24:954-965

Lindhjem H, Navrud S, Braathen NA, Biausque V (2011) Valuing mortality risk reductions from environmental, transport, and health policies: a global meta-analysis of stated preference studies. Risk Anal 31:1381-1407

Lo CC (2010) Effect of pesticides on soil microbial community. J Environ Sci Health B 45:348-359

Löfstedt RE (2003) Swedish chemical regulation: an overview and analysis. Risk Anal 23:411-421

Losey JE, Vaughan M (2006) The economic value of ecological services provided by insects. BioScience 56:311-323

Mackenzie-Ross S, McManus IC, Harrison V, Mason O (2013) Neurobehavioral problems following low-level exposure to organophosphate pesticides: a systematic and meta-analytic review. Crit Rev Toxicol 43:21-44

Mäder P, Fliessbach A, Dubois D, Gunst L, Fried P, Niggli U (2002) Soil fertility and biodiversity in organic farming. Science 296:1694-1697

Magnusson MK, Arvola A, Hursti UKK, Åberg L, Sjödén PO (2003) Choice of organic foods is related to perceived consequences for human health and to environmentally friendly behaviour. Appetite 40:109-117

Magnusson M, Heimann K, Negri AP (2008) Comparative effects of herbicides on photosynthesis and growth of tropical estuarine microalgae. Mar Pollut Bull 56:1545-1552

Magnusson M, Heimann K, Quayle P, Negri AP (2010) Additive toxicity of herbicide mixtures and comparative sensitivity of tropical benthic microalgae. Mar Pollut Bull 60:1978-1987 
Magnusson M, Heimann K, Ridd M, Negri AP (2012) Chronic herbicide exposures affect the sensitivity and community structure of tropical benthic microalgae. Mar Pollut Bull 65:363-372

Mahmoudi M, Rahnemaie R, Soufizadeh S, Malakouti MJ, Eshaghi A (2011) Residual effect of thiobencarb and oxadiargyl on spinach and lettuce in rotation with rice. J Agric Sci Tech 13:785-794

Malek AM, Barchowsky A, Bowser R, Youk A, Talbott EO (2012) Pesticide exposure as a risk factor for amyotrophic lateral sclerosis: a meta-analysis of epidemiological studies: pesticide exposure as a risk factor for ALS. Environ Res 117:112-119

Mann RM, Hyne RV, Choung CB, Wilson SP (2009) Amphibians and agricultural chemicals: review of the risks in a complex environment. Environ Pollut 157:2903-2927

Martenies SE, Perry MJ (2013) Environmental and occupational pesticide exposure and human sperm parameters: a systematic review. Toxicology 307:66-73

Maumbe BM, Swinton SM (2003) Hidden health costs of pesticide use in Zimbabwe's smallholder cotton growers. Soc Sci Med 57:1559-1571

McLeod L, Bharadwaj L, Waldner C (2014) Risk factors associated with the choice to drink bottled water and tap water in rural Saskatchewan. Int J Environ Res Public Health $11: 1626-1646$

Mehrpour O, Karrari P, Zamani N, Tsatsakis AM, Abdollahi M (2014) Occupational exposure to pesticides and consequences on male semen and fertility: a review. Toxicol Lett 230:146-156

Mineau P (2002) Estimating the probability of bird mortality from pesticide sprays on the basis of the field study record. Environ Toxicol Chem 24:1497-1506

Mineau P (2005) Direct losses of birds to pesticides - beginnings of a quantification. In: Ralph CJ, Rich TD (eds) Bird conservation implementation and integration in the Americas: proceedings of the third international partners in flight conference 2002, U.S.D.A. Forest Service, GTRPSW-191, Albany; Vol 2, pp 1065-1070

Mineau P, Collins BT (1988) Avian mortality in agroecosystems. 2. Methods of detection. In: Greaves MP, Smith BD, Greig-Smith PW (eds) Field methods for the study of environmental effects of pesticides. British Crop Protection Council, Croydon, pp 13-27

Mineau P, Whiteside M (2006) Lethal risk to birds from insecticide use in the United States: a spatial and temporal analysis. Environ Toxicol Chem 25:1214-1222

Mineau P, Whiteside M (2013) Pesticide acute toxicity is a better correlate of US grassland bird declines than agricultural intensification. PLoS One 8, e57457

Mineau P, Downes CM, Kirk DA, Bayne E, Csizy M (2005) Patterns of bird species abundance in relation to granular insecticide use in the Canadian prairies. Ecoscience 12:267-278

Mineau P, Porter S, Meteyer CU (2012) Carbofuran: toxicity, diagnosing poisoning and rehabilitation of poisoned birds. In: Richards NL (ed) Carbofuran and wildlife poisoning: global perspectives and forensic approaches. Wiley, Chichester, Chapter 2, pp 19-30

Mishra P, Samarth R, Pathak N, Jain S, Banerjee S, Maudar K (2009) Bhopal gas tragedy: review of clinical and experimental findings after 25 years. Int $\mathrm{J}$ Occup Med Environ Health 22:193-202

Misra SK, Huang CL, Ott SL (1991) Consumer willingness to pay for pesticide-free fresh produce. West J Agric Econ 16:218-227

Mitra A, Chatterjee C, Mandal FB (2011) Synthetic chemical pesticides and their effects on birds. Res J Environ Toxicol 5:81-96

Morjan WE, Pedigo LP, Lewis LC (2002) Fungicidal effects of glyphosate and glyphosate formulations on four species of entomopathogenic fungi. Environ Entomol 31:1206-1212

Mukherjee A, Sengupta MK, Hossain MA, Ahamed S, Das B, Nayak B, Lodh D, Rahman MM, Chakraborti D (2006) Arsenic contamination in groundwater: a global perspective with emphasis on the Asian scenario. J Health Popul Nutr 24:142-163

Negri AP, Flores F, Röthig T, Uthicke S (2011) Herbicides increase the vulnerability of corals to rising sea surface temperature. Limnol Oceanogr 56:471-485

Ngowi AVF, Mbise TJ, Ijani ASM, London L, Ajayi OC (2007) Smallholder vegetable farmers in Northern Tanzania: pesticides use practices, perceptions, cost and health effects. Crop Prot 26:1617-1624 
Nickson R, McArthur J, Burgess W, Ahmed KM, Ravenscroft P, Rahmanñ M (1998) Arsenic poisoning of Bangladesh groundwater. Nature 395:338

Nordstrom DK (2002) Worldwide occurrences of arsenic in ground water. Science 296:2143-2145

Norris RF, Kogan M (2000) Interactions between weeds, arthropod pests and their natural enemies in managed ecosystems. Weed Sci 48:94-158

Norris RF, Kogan M (2005) Ecology of interactions between weeds and arthropods. Annu Rev Entomol 50:479-503

Oerke EC (2006) Crop losses to pests. J Agric Sci 144:31-43

Onozaka Y, Bunch D, Larson D (2006) What exactly are they paying for? Explaining the price premium for organic fresh produce. Agric Resour Econ Update 9:1-4

Osteen CD, Fernandez-Cornejo J (2013) Economic and policy issues of US agricultural pesticide use trends. Pest Manag Sci 69:1001-1025

Packett R, Dougall C, Rohde K, Noble R (2009) Agricultural lands are hot-spots for annual runoff polluting the southern Great Barrier Reef lagoon. Mar Pollut Bull 58:976-986

Pearce D, Tinch R (1998) The true price of pesticides. In: Vorley W, Keeney D (eds) Bugs in the system. Earthscan Publications, London, pp 50-93

Pearson D, Henryks J, Jones H (2011) Organic food: what we know (and do not know) about consumers. Renewable Agric Food Syst 26:171-177

Petit AN, Fontaine F, Vatsa P, Clément C, Vaillant-Gaveau N (2012) Fungicide impacts on photosynthesis in crop plants. Photosynth Res 111:315-326

Pimentel D (1995) Amounts of pesticides reaching target pests: environmental impacts and ethics. J Agric Environ Ethics 8:17-29

Pimentel D (2005) Environmental and economic costs of the application of pesticides primarily in the United States. Environ Dev Sustain 7:229-252

Pimentel D (2009) Environmental and economic costs of the application of pesticides primarily in the United States. In: Peshin R, Dhawan AK (eds) Integrated pest management: innovationdevelopment process. Springer, Dordrecht, pp 89-111

Pimentel D, Burgess M (2014) Environmental and economic costs of the application of pesticides primarily in the United States. In: Pimentel D, Peshin R (eds) Integrated pest management. Springer, Dordrecht, pp 47-71

Pimentel D, Greiner A (1997) Environmental and socio-economic costs of pesticide use. In: Pimentel D (ed) Techniques for reducing pesticide use: environmental and economic benefits. Wiley, Chichester, pp 51-78

Pimentel D, Hart K (2001) Pesticide use: ethical, environmental, and public health implications. In: Galston W, Shurr E (eds) New dimensions in bioethics: science, ethics and the formulation of public policy. Kluwer, Boston, pp 79-108

Pimentel D, Krummel J, Gallahan D, Hough J, Merrill A, Schreiner I, Vittum P, Koziol F, Back E, Yen D, Fiance S (1978) Benefits and costs of pesticide use in the U.S. food production. BioScience 28:772, 778-784

Pimentel D, Krummel J, Gallahan D, Hough J, Merrill A, Schreiner I, Vittum P, Koziol F, Back E, Yen D, Fiance S (1979) A cost-benefit analysis of pesticide use in US food production. In: Sheets TJ, Pimentel D (eds) Pesticides: their contemporary roles in agriculture, health, and the environment. The Humana Press, Clifton, pp 97-149

Pimentel D, Andow D, Dyson-Hudson R, Gallahan D, Jacobson S, Irish M, Kroop S, Moss A, Schreiner I, Shepard M, Thompson T, Vinzant B (1980a) Environmental and social costs of pesticides: a preliminary assessment. Oikos 34:126-140

Pimentel D, Andow D, Gallahan D, Schreiner I, Thompson T, Dyson-Hudson R, Jacobson S, Moss A, Shepard M, Vinzant B (1980b) Pesticides: environmental and social costs. In: Pimentel D, Perkins JH (eds) Pest control: cultural and environmental aspects. Westview Press, Boulder, pp 99-158

Pimentel D, McLaughlin L, Zepp A, Lakitan B, Kraus T, Kleinman P, Vancini F, Roach WJ, Graap E, Keeton WS, Selig G (1991a) Environmental and economic impacts of reducing US agricultural pesticide use. In: Pimentel D (ed) Handbook of pest management in agriculture, vol 1, 2nd edn. CRC Press, Boca Raton, pp 679-718 
Pimentel D, McLaughlin L, Zepp A, Lakitan B, Kraus T, Kleinman P, Vancini F, Roach WJ, Graap E, Keeton WS, Selig G (1991b) Environmental and economic effects of reducing pesticide use. BioScience 41:402-409

Pimentel D, Acquay H, Biltonen M, Rice P, Silva M, Nelson J, Lipner V, Giordano S, Horowitz A, D'Amore M (1992) Environmental and economic costs of pesticide use. BioScience 42:750-760

Pimentel D, Acquay H, Biltonen M, Rice P, Silva M, Nelson J, Lipner V, Giordano S, Horowitz A, D'Amore M (1993a) Assessment of environmental and economic impacts of pesticide use. In: Pimentel D, Lehman H (eds) The pesticide question: environment, economics, and ethics. Chapman and Hall, New York, pp 47-83

Pimentel D, McLaughlin L, Zepp A, Lakitan B, Kraus T, Kleinman P, Vancini F, Roach WJ, Graap E, Keeton WS, Selig G (1993b) Environmental and economic effects of reducing pesticide use in agriculture. Agric Ecosyst Environ 46:273-288

Pingali PL, Marquez CB, Palis FG (1994) Pesticides and Philippine rice farmer health: a medical and economic analysis. Am J Agric Econ 76:587-592

Pingali PL, Marquez CB, Palis FG, Rola AC (1995) The impact of pesticides on farmer health: a medical and economic analysis in the Philippines. In: Pingali PL, Roger PA (eds) Impact of pesticides on farmer health and the rice environment. Kluwer, Norwell, pp 343-360

Popp J (2011) Cost-benefit analysis of crop protection measures. J Verbr Lebensm 6:105-112

Popp J, Pető K, Nagy J (2013) Pesticide productivity and food security. A review. Agron Sustain Dev 33:243-255

Praneetvatakul S, Schreinemachers P, Pananurak P, Tipraqsa P (2013) Pesticides, external costs and policy options for Thai agriculture. Environ Sci Policy 27:103-113

Pretty JN, Brett C, Gee D, Hine RE, Mason CF, Morison JIL, Raven H, Rayment M, van der Bijl G (2000) An assessment of the external costs of UK agriculture. Agric Syst 65:113-136

Pretty JN, Brett C, Gee D, Hine R, Mason C, Morison J, Rayment M, van der Bijl G, Dobbs T (2001) Policy challenges and priorities for internalizing the externalities of modern agriculture. J Environ Plann Man 44:263-283

Prosser P, Nattrass C, Prosser C (2008) Rate of removal of bird carcasses in arable farmland by predators and scavengers. Ecotoxicol Environ Saf 71:601-608

Rasmussen JJ, Wiberg-Larsen P, Kristensen EA, Cedergreen N, Friberg N (2013) Pyrethroid effects on freshwater invertebrates: a meta-analysis of pulse exposures. Environ Pollut 182:479-485

Reddy VR, Baker DN, Whisler FD, McKinion JM (1990) Analysis of the effects of herbicides on cotton yield trends. Agric Syst 33:347-359

Reddy KN, Ding W, Zablotowicz RM, Thomson SJ, Huang Y, Krutz LJ (2010) Biological responses to glyphosate drift from aerial application in non-glyphosate-resistant corn. Pest Manag Sci 66:1148-1154

Relyea RA (2005) The lethal impact of roundup on aquatic and terrestrial amphibians. Ecol Appl 15:1118-1124

REX Consortium (2013) Heterogeneity of selection and the evolution of resistance. Trends Ecol Evol 28:110-118

Ritter WF (1990) Pesticide contamination of ground water in the United States - a review. J Environ Sci Health B 25:1-29

Ritter WF (2001) Pesticides and water quality impacts. In: Ritter WF, Shirmohammadi A (eds) Agricultural nonpoint source pollution: watershed management and hydrology. Lewis Publishers, Boca Raton, pp 111-133

Robinson DE (2008) Atrazine accentuates carryover injury from mesotrione in vegetable crops. Weed Technol 22:641-645

Rodríguez E, Lacaze V, Lupín, B (2008) Contingent valuation of consumers' willingness-to-pay for organic food in Argentina. 12th congress of the European Association of Agricultural Economists, Ghent

Rohr JR, McCoy KA (2010) A qualitative meta-analysis reveals consistent effects of atrazine on freshwater fish and amphibians. Environ Health Perspect 118:20-32 
Rohr JR, Schotthoefer AM, Raffel TR, Carrick HJ, Halstead N, Hoverman JT, Johnson CM, Johnson LB, Lieske C, Piwoni MD, Schoff PK, Beasley VR (2008) Agrochemicals increase trematode infection in a declining amphibian species. Nature 455:1235-1239

Rola AC, Pingali PL (1993) Pesticides, rice productivity, and farmers' health: an economic assessment. International Rice Research Institute (IRRI)/Philippines and World Resources Institute (WRI), Manila/Washington, DC

Saba A, Messina F (2003) Attitudes towards organic foods and risk/benefit perception associated with pesticides. Food Qual Prefer 14:637-645

Sahota A (2014) The global market for organic food and drink. In: Willer H, Lernoud J (eds) The world of organic agriculture. Statistics and emerging trends 2014. FiBL/IFOAM, Frick/Bonn, pp 125-132

Sánchez-Bayo F (2011) Impacts of agricultural pesticides on terrestrial ecosystems. In: SánchezBayo F, van den Brink PJ, Mann R (eds) Ecological impacts of toxic chemicals. Bentham Science Publishers, Saif Zone, pp 63-87

Santana VS, Moura MCP, Nogueira FF (2013) Occupational pesticide poisoning mortality, 20002009, Brazil. Rev Saude Publica 47:598-606

Sargent-Michaud J, Boyle KJ, Smith AE (2006) Cost effective arsenic reductions in private well water in Maine. J Am Water Resour Assoc 42:1237-1245

Schaack D, Lernoud J, Schlatter B, Willer H (2014) The organic market in Europe 2012. In: Willer H, Lernoud J (eds) The world of organic agriculture. Statistics and emerging trends 2014. FiBL/IFOAM, Frick/Bonn, pp 207-214

Schäfer RB, Caquet T, Siimes K, Mueller R, Lagadic L, Liess M (2007) Effects of pesticides on community structure and ecosystem functions in agricultural streams of three biogeographical regions in Europe. Sci Total Environ 382:272-285

Schäfer RB, Pettigrove V, Rose G, Allinson G, Wightwick A, von der Ohe PC, Shimeta J, Kühne R, Kefford BJ (2011) Effects of pesticides monitored with three sampling methods in 24 sites on macroinvertebrates and microorganisms. Environ Sci Technol 45:1665-1672

Schäfer RB, von der Ohe PC, Rasmussen J, Kefford BJ, Beketov MA, Schulz R, Liess M (2012) Thresholds for the effects of pesticides on invertebrate communities and leaf breakdown in stream ecosystems. Environ Sci Technol 46:5134-5142

Schifferstein HN, Oude Ophuis PA (1998) Health-related determinants of organic food consumption in the Netherlands. Food Qual Prefer 9:119-133

Schinasi L, Leon ME (2014) Non-Hodgkin lymphoma and occupational exposure to agricultural pesticide chemical groups and active ingredients: a systematic review and meta-analysis. Int J Environ Res Public Health 11:4449-4527

Schipper PN, Wissers MJ, van der Linden AM (2008) Pesticides in groundwater and drinking water wells: overview of the situation in the Netherlands. Water Sci Technol 57:1277-1286

Schlegelmilch BB, Bohlen GM, Diamantopoulos A (1996) The link between green purchasing decisions and measures of environmental consciousness. Eur J Mark 30:35-55

Schmitz J, Schäfer K, Brühl CA (2014a) Agrochemicals in field margins: field evaluation of plant reproduction effects. Agric Ecosyst Environ 189:82-91

Schmitz J, Hahn M, Brühl CA (2014b) Agrochemicals in field margins: an experimental field study to assess the impacts of pesticides and fertilizers on a natural plant community. Agric Ecosyst Environ 193:60-69

Schneider CW, Tautz J, Grünewald B, Fuchs S (2012) RFID tracking of sublethal effects of two neonicotinoid insecticides on the foraging behavior of Apis mellifera. PLoS One 7, e30023

Schreinemachers P, Tipraqsa P (2012) Agricultural pesticides and land use intensification in high, middle and low income countries. Food Policy 37:616-626

Shetty PK, Hiremath MB, Murugan M, Nerli RB (2011) Farmer's health externalities in pesticide use predominant regions in India. World J Sci Technol 1:1-11

Siegel R, Ma J, Zou Z, Jemal A (2014) Cancer statistics, 2014. CA Cancer J Clin 64:9-29

Sivayoganathan C, Gnanachandran S, Lewis J, Fernando M (1995) Protective measure use and symptoms among agropesticide applicators in Sri Lanka. Soc Sci Med 40:431-436

Slaninova A, Smutna M, Modra H, Svobodova Z (2009) A review: oxidative stress in fish induced by pesticides. Neuroendocrinol Lett 30(Suppl. 1):2-12 
Smedley PL, Kinniburgh DG (2002) A review of the source, behaviour and distribution of arsenic in natural waters. Appl Geochem 17:517-568

Soares WL, Porto MFDS (2009) Estimating the social cost of pesticide use: an assessment from acute poisoning in Brazil. Ecol Econ 68:2721-2728

Soares WL, Porto MFDS (2012) Pesticide use and economic impacts on health. Rev Saude Publica 46:209-217

Soares WL, Moro S, Almeida RMVR (2002) Rural workers' health and productivity: an economic assessment of pesticide use in Minas Gerais, Brazil. Appl Health Econ Health Policy $1: 157-164$

Squires L, Juric B, Cornwell TB (2001) Level of market development and intensity of organic food consumption: cross-cultural study of Danish and New Zealand consumers. J Consum Market 18:392-409

Statistics Canada (2009) Households and the environment survey (HES) 11-526-X. February 2009. http://www.statcan.gc.ca/pub/11-526-x/11-526-x2011001-eng.pdf. Accessed 29 Sept 2014

Steenland K, Armstrong B (2006) An overview of methods for calculating the burden of disease due to specific risk factors. Epidemiology 17:512-519

Steiner R, McLaughlin L, Faeth P, Janke R (1995) Incorporating externality costs in productivity measures: a case study using US agriculture. In: Barbett V, Payne R, Steiner R (eds) Agricultural sustainability: environmental and statistical considerations. Wiley, New York, pp 209-230

Tegtmeier EM, Duffy MD (2004) External costs of agricultural production in the United States. Int J Agric Sustain 2:1-20

Thomas PH, Mineau P, Shore RF, Champoux L, Martin PA, Wilson LK, Fitzgerald G, Elliott JE (2011) Second generation anticoagulant rodenticides in predatory birds: probabilistic characterization of toxic liver concentrations and implications for predatory bird populations in Canada. Environ Int 37:914-920

Tierney KB, Baldwin DH, Hara TJ, Ross PS, Scholz NL, Kennedy CJ (2010) Olfactory toxicity in fishes. Aquat Toxicol 96:2-26

Toccalino PL, Gilliom RJ, Lindsey BD, Rupert MG (2014) Pesticides in groundwater of the United States: decadal-scale changes, 1993-2011. Groundwater 52:112-125

Toscano NC, Sances FV, Johnson MW, LaPre LF (1982) Effect of various pesticides on lettuce physiology and yield. J Econ Entomol 75:738-741

Travisi CM, Nijkamp P, Vindigni G (2006) Pesticide risk valuation in empirical economics: a comparative approach. Ecol Econ 56:455-474

Tregear A, Dent JB, McGregor MJ (1994) The demand for organically grown produce. Br Food J 96:21-25

Tsakiridou E, Boutsouki C, Zotos Y, Mattas K (2008) Attitudes and behaviour towards organic products: an exploratory study. Int J Retail Distrib Manag 36:158-175

Türe C, Böcük H (2008) Investigation of threatened arable weeds and their conservation status in Turkey. Weed Res 48:289-296

United Nations Environment Programme (2001) Final act of the conference of plenipotentiaries on the Stockholm convention on persistent organic pollutants, Stockholm, Sweden, 22 to 23 May 2001. UNEP, Geneva

United States Environmental Protection Agency (2002) Drinking water from household wells. US Environmental Protection Agency, Washington, DC. http://www.epa.gov/privatewells/pdfs/ household_wells.pdf. Accessed 1 Sept 2014

United States Environmental Protection Agency (2007) What is a pesticide? US Environmental Protection Agency, Washington, DC. http://www.epa.gov/pesticides/about/index.htm\#what_ pesticide. Accessed 1 Sept 2014

United States Environmental Protection Agency (2008) About pesticides. http://www.epa.gov/pesticides/about/. Accessed 12 Sept 2014

United States Environmental Protection Agency (2011) Pesticide industry sales and usage. US Environmental Protection Agency, Washington, DC. http://www.epa.gov/opp00001/pestsales/. Accessed 1 Sept 2014 
van Dam JW, Negri AP, Mueller JF, Uthicke S (2012) Symbiont-specific responses in foraminifera to the herbicide diuron. Mar Pollut Bull 65:373-383

van den Berg H, Zaim M, Yadav RS, Soares A, Ameneshewa B, Mnzava A, Hiij J, Dash AP, Ejov M (2012) Global trends in the use of insecticides to control vector-borne diseases. Environ Health Perspect 120:577-582

Van Maele-Fabry G, Lantin AC, Hoet P, Lison D (2010) Childhood leukaemia and parental occupational exposure to pesticides: a systematic review and meta-analysis. Cancer Causes Control 21:787-809

Van Maele-Fabry G, Hoet P, Vilain F, Lison D (2012) Occupational exposure to pesticides and Parkinson's disease: a systematic review and meta-analysis of cohort studies. Environ Int 46:30-43

Van Maele-Fabry G, Hoet P, Lison D (2013) Parental occupational exposure to pesticides as risk factor for brain tumors in children and young adults: a systematic review and meta-analysis. Environ Int 56:19-31

Venkatachalam L (2004) The contingent valuation method: a review. Environ Impact Assess Rev 24:89-124

Vinson F, Merhi M, Baldi I, Raynal H, Gamet-Payrastre L (2011) Exposure to pesticides and risk of childhood cancer: a meta-analysis of recent epidemiological studies. Occup Environ Med 68:694-702

Viscusi WK, Aldy JE (2003) The value of a statistical life: a critical review of market estimates throughout the world. J Risk Uncertain 27:5-76

Viscusi WK, Huber J, Bell J (2014) Assessing whether there is a cancer premium for the value of a statistical life. Health Econ 23:384-396

Waibel H, Fleischer G (1998) Kosten und Nutzen des chemischen Pflanzenschutzes in der deutschen Landwirtschaft aus gesamtwirtschaftlicher Sicht (Social costs and benefits of chemical plant protection in German agriculture). Vauk Verlag, Kiel

Waibel H, Fleischer G, Becker H (1999) The economic benefits of pesticides: a case study from Germany. Agrarwirtschaft 48:219-229

Walker CH (1983) Pesticides and birds-mechanisms of selective toxicity. Agr Ecosyst Environ 9:211-226

Wang S, Mulligan CN (2006) Occurrence of arsenic contamination in Canada: sources, behavior and distribution. Sci Total Environ 366:701-721

Wang Y, Kruzik P, Helsberg A, Helsberg I, Rausch WD (2007) Pesticide poisoning in domestic animals and livestock in Austria: a 6 years retrospective study. Forensic Sci Int 169:157-160

Whelan CJ, Wenny DG, Marquis RJ (2008) Ecosystem services provided by birds. Ann N Y Acad Sci 1134:25-60

Whitehorn PR, O'Connor S, Wackers FL, Goulson D (2012) Neonicotinoid pesticide reduces bumble bee colony growth and queen production. Science 336:351-352

Wier M, O'Doherty Jensen K, Andersen LM, Millock K (2008) The character of demand in mature organic food markets: Great Britain and Denmark compared. Food Policy 33:406-421

Williams PR, Hammitt JK (2001) Perceived risks of conventional and organic produce: pesticides, pathogens, and natural toxins. Risk Anal 21:319-330

Wilson C (1999a) Cost and policy implications of agricultural pollution with special reference to pesticides. Dissertation, Department of Economics, University of St. Andrews

Wilson C (1999b) Pesticide avoidance: results from a Sri Lankan study with health and environmental policy implications. Discussion paper No 264. Department of Economics, The University of Queensland. http://espace.library.uq.edu.au/eserv/UQ:11075/DP264Oct99.pdf. Accessed 1 Sept 2014

Wilson C (2000a) Environmental and human costs of commercial agricultural production in South Asia. Int J Soc Econ 27:816-846

Wilson C (2000b) The private costs of exposure to pesticides in Sri Lanka: estimates from three valuation techniques. Discussion paper No 277. Department of Economics, The University of Queensland. http://espace.library.uq.edu.au/eserv/UQ:10427/econ_dp_277_00.pdf. Accessed 1 Sept 2014 
Wilson C (2002a) Private costs and the relation between pesticide exposure and ill health: evidence from Sri Lanka. Environ Econ Policy Stud 5:213-227

Wilson C (2002b) Pesticide avoidance: results from a Sri Lankan study with health policy implications. Adv Econ Environ Resour 4:231-258

Wilson C (2003) Empirical evidence showing the relationships between three approaches for pollution control. Environ Resour Econ 24:97-101

Wilson C (2005) Exposure to pesticides, ill-health and averting behaviour: costs and determining the relationships. Int J Soc Econ 32:1020-1034

Wilson LJ, Bauer LR, Lally DA (1998) Effect of early season insecticide use on predators and outbreaks of spider mites (Acari: Tetranychidae) in cotton. Bull Entomol Res 88:477-488

Wilson JD, Morris AJ, Arroyo BE, Clark SC, Bradbury RB (1999) A review of the abundance and diversity of invertebrate and plant foods of granivorous birds in northern Europe in relation to agricultural change. Agric Ecosyst Environ 75:13-30

World Health Organization (WHO) (1990) Public health impact of pesticides used in agriculture. http://apps.who.int/iris/bitstream/10665/39772/1/9241561394.pdf. Accessed 1 Oct 2014

Yamamuro M (2012) Herbicide-induced macrophyte-to-phytoplankton shifts in Japanese lagoons during the last 50 years: consequences for ecosystem services and fisheries. Hydrobiologia 699:5-19

Yancy CH Jr (2005) Study touts herbicide benefits. Southeast Farm Press 32:16

Yanggen D, Cole D, Crissman CC, Sherwood S (2003) Human health, environmental and economic effects of pesticide use in potato production in Ecuador. Research Brief (May). International Potato Center (CIP)

Yasmin S, D'Souza D (2010) Effects of pesticides on the growth and reproduction of earthworm: a review. Appl Environ Soil Sci Article ID 678360

Youngman RR, Leigh TF, Kerby TA, Toscano NC, Jackson CE (1990) Pesticides and cotton: effect on photosynthesis, growth, and fruiting. J Econ Entomol 83:1549-1557

Zaki MH, Moran D, Harris D (1982) Pesticides in groundwater: the aldicarb story in Suffolk County, NY. Am J Public Health 72:1391-1395

Zehnder G, Hope C, Hill H, Hoyle L, Blake JH (2003) An assessment of consumer preferences for IPM-and organically grown produce. Age 18:26-35

Zhao J, Neher DA, Fu S, Li ZA, Wang K (2013) Nontarget effects of herbicides on soil nematode assemblages. Pest Manag Sci 69:679-684

Zilberman D, Schmitz A, Casterline G, Lichtenberg E, Siebert JB (1991) The economics of pesticide use and regulation. Science 253:518-522

Zivin JG, Neidell M, Schlenker W (2011) Water quality violations and avoidance behaviour: evidence from bottled water consumption. Am Econ Rev Papers Proc 101:448-453 